\title{
How Much Human-Caused Global Warming Should We Expect with Business-As-Usual (BAU) Climate Policies? A Semi-Empirical Assessment
}

\author{
Ronan Connolly ${ }^{1,2, * \mathbb{C}}$, Michael Connolly ${ }^{1}$, Robert M. Carter ${ }^{3,+}$ and Willie Soon ${ }^{2}$ \\ 1 Independent Scientist, Dublin D11, Ireland; michael@ceres-science.com \\ 2 Center for Environmental Research and Earth Sciences (CERES), Salem, MA 01970, USA; \\ willie@ceres-science.com \\ 3 Independent Scientist, Townsville, QLD 4000, Australia; info@ceres-science.com \\ * Correspondence: ronan@ceres-science.com \\ $+\quad$ Robert M. Carter was a retired professor and independent scientist, but passed away on 19 January 2016.
}

Received: 17 February 2020; Accepted: 11 March 2020; Published: 15 March 2020

\begin{abstract}
In order to assess the merits of national climate change mitigation policies, it is important to have a reasonable benchmark for how much human-caused global warming would occur over the coming century with "Business-As-Usual" (BAU) conditions. However, currently, policymakers are limited to making assessments by comparing the Global Climate Model (GCM) projections of future climate change under various different "scenarios", none of which are explicitly defined as BAU. Moreover, all of these estimates are ab initio computer model projections, and policymakers do not currently have equivalent empirically derived estimates for comparison. Therefore, estimates of the total future human-caused global warming from the three main greenhouse gases of concern $\left(\mathrm{CO}_{2}\right.$, $\mathrm{CH}_{4}$, and $\mathrm{N}_{2} \mathrm{O}$ ) up to 2100 are here derived for BAU conditions. A semi-empirical approach is used that allows direct comparisons between GCM-based estimates and empirically derived estimates. If the climate sensitivity to greenhouse gases implies a Transient Climate Response (TCR) of $\geq 2.5^{\circ} \mathrm{C}$ or an Equilibrium Climate Sensitivity (ECS) of $\geq 5.0^{\circ} \mathrm{C}$ then the 2015 Paris Agreement's target of keeping human-caused global warming below $2.0^{\circ} \mathrm{C}$ will have been broken by the middle of the century under BAU. However, for a TCR $<1.5^{\circ} \mathrm{C}$ or ECS $<2.0^{\circ} \mathrm{C}$, the target would not be broken under BAU until the 22nd century or later. Therefore, the current Intergovernmental Panel on Climate Change (IPCC) "likely" range estimates for TCR of 1.0 to $2.5^{\circ} \mathrm{C}$ and ECS of 1.5 to $4.5^{\circ} \mathrm{C}$ have not yet established if human-caused global warming is a 21 st century problem.
\end{abstract}

Keywords: climate change mitigation; climate sensitivity; airborne fraction; Paris Agreement; climate policies; business-as-usual

\section{Introduction}

Since the late-1960s and early-1970s, computer model simulations of the Earth's climate have been predicting that increasing concentrations of "greenhouse gases" (chiefly, carbon dioxide or $\mathrm{CO}_{2}$ ) in the atmosphere from human activity should be causing substantial global warming at the Earth's surface and in the lower atmosphere [1,2]. In the 1960s [3] and 1970s [4], estimates of global surface temperature trends (which mostly were confined to the Northern Hemisphere since there is less long-term data for the Southern Hemisphere) suggested, if anything, a global cooling trend. However, during the 1980s, the cooling trend reversed and, by the late-1980s, the long-term linear trend since the (relatively cold) late-19th century was warming [5-7]. This prompted several researchers to argue that the long-term warming trend was in fact the "enhanced greenhouse warming" originally predicted by the computer models, e.g., [8-10]. To distinguish this predicted "enhanced greenhouse warming" due to increasing 
greenhouse gas concentrations from a naturally occurring global warming trend which might have occurred anyway, the term "Anthropogenic Global Warming" (AGW) is often used. These claims garnered a lot of media attention and public concern, e.g., [11].

Ultimately, this led the United Nations to set up the United Nations Framework Convention on Climate Change (UNFCCC) with the goal of facilitating international negotiations to achieve the “(... ) stabilization of greenhouse gas concentrations in the atmosphere at a level that would prevent dangerous anthropogenic interference with the climate system" [12]. To work in parallel with the political work of the UNFCCC, the United Nations also co-founded, with the World Meteorological Organization, a separate body called the Intergovernmental Panel on Climate Change (IPCC) to provide amongst other things "a comprehensive review (... on) the state of knowledge of the science of climate and climatic change" [13].

In the ensuing years, the computer models have continued to predict that increasing greenhouse gas concentrations should be causing substantial global warming. Indeed, based on the results of simulations with one of the NASA Goddard Institute of Space Studies (GISS)' computer models, Lacis et al. (2010) concluded that "atmospheric $\mathrm{CO}_{2}$ ( . . is the) principal control knob governing Earth's temperature" [14]. Largely on the basis of comparing the results of such computer models to global temperature trends, the IPCC's most recent complete Assessment Report (2013) concluded that, "It is extremely likely that human influence has been the dominant cause of the observed warming since the mid-20th century" [15] (Emphasis in original). Although a competing series of reports has been published by the Nongovernmental International Panel on Climate Change (NIPCC), which contradicts many of the IPCC's findings, e.g., NIPCC (2013) [16] and (2019) [17], the IPCC reports are widely cited and have been highly influential among both the scientific community and policymakers.

Meanwhile, the efforts of the UNFCCC have led to a series of major international treaties and agreements to try to reduce greenhouse gas emissions, from the Kyoto Protocol (1996) [18] to the Paris Agreement (2015) [19]. In particular, the Paris Agreement specifically aims to encourage national and international policies to reduce greenhouse gas emissions with the view to, "Holding the increase in the global average temperature to well below $2{ }^{\circ} \mathrm{C}$ above pre-industrial levels and pursuing efforts to limit the temperature increase to $1.5^{\circ} \mathrm{C}$ above pre-industrial levels" [19]. Although the United States has decided to withdraw from the Paris Agreement [20], most nations are currently signed up to the voluntary Paris Agreement.

The selection of a specific "global average temperature" in ${ }^{\circ} \mathrm{C}$ as an international "goal" is a remarkably arbitrary and subjective process, e.g., see Mahoney (2015) [21]. Hence, there has been some debate over whether a target of 1.5 or $2{ }^{\circ} \mathrm{C}$ is better, e.g., [22-25], and whether or not such targets in terms of global temperature are helpful, e.g., [26-30]. However, there is a more fundamental question -what specifically should an individual nation do differently in order to "(keep) the global average temperature to well below $2{ }^{\circ} \mathrm{C}$ above pre-industrial levels (or even) $1.5^{\circ} \mathrm{C}^{\prime \prime}$ ? If the motivation of the Paris Agreement was to encourage individual nations to significantly alter their national policies relative to "Business-As-Usual", then it is important to know how much Anthropogenic Global Warming to expect under "Business-As-Usual" conditions.

In other words, what is the "human-caused global warming baseline" against which efforts to meet the Paris Agreement are to be assessed? This is the question we will attempt to answer in this paper. However, while the question might initially seem fairly reasonable and straightforward, as we will discuss, it is remarkably challenging to answer satisfactorily. In essence, it depends on the answers to four separate questions:

- Question 1. What would future greenhouse gas emissions be over the coming century under "Business-As-Usual" conditions?

- Question 2. For each of the greenhouse gases, what is the relationship between emissions and actual changes in atmospheric concentrations? 
- Question 3. How different would global average temperatures be at present if greenhouse gases were still at "pre-industrial concentrations"? In other words, how do we define the "pre-industrial levels" of global average temperatures to which the Paris Agreement refers?

- Question 4. How "sensitive" are global average temperatures to increases in the atmospheric concentrations of greenhouse gases?

With each of these questions, there is considerable debate in the scientific literature. However, the relevant literature for each subject comes from quite different academic disciplines. The first question is typically addressed by economists, political scientists, environmental governance researchers, etc. The second question is mostly the realm of biologists, ecologists, geochemists, oceanographers, etc. The third and fourth questions are both climate science problems, but even within these topics, there are separate bodies of literature from, e.g., computer modelling research groups, groups evaluating climate records, statisticians evaluating results from a meta-analysis perspective, etc.

In other words, many researchers who might be familiar with the debates in one relevant branch of the literature are often completely unaware of the debates in other relevant branches. In our personal experience in dealing with these four questions, we have found that researchers with expertise on one aspect are frequently delighted to have a robust scientific discussion on the controversies within that specific aspect. However, as soon as the discussion shifts to one of the other aspects, the researcher will typically tell us that they are "getting outside of their comfort zone" or that they are "not very familiar with that subject", and that they "would have to spend more time reading the literature before continuing this discussion".

We totally appreciate the discomfort felt by those researchers and recognize that many readers might share this discomfort. However, we suggest that unless the scientific debate over all four of these questions are simultaneously considered, it is unlikely that truly satisfactory answers will be achieved to the over-arching question, "How much human-caused global warming should we expect with Business-As-Usual (BAU) climate policies?" With that in mind, we will discuss all four of these sub-questions in turn, including a brief review of the key relevant literature, before attempting to answer the main question. Specifically, we will consider Question 1 in Section 2; Question 2 in Section 3; Question 3 in Section 4 and Question 4 in Section 5. In Section 6, we will combine the answers to all four questions to develop a set of Business-As-Usual projections.

\section{What Would Future Greenhouse Gas Emissions Be Under “Business-As-Usual” Conditions?}

As can be seen from Table 1, the Earth's atmosphere is largely composed of nitrogen $(\sim 78 \%)$, oxygen $(\sim 21 \%)$, argon $(\sim 1 \%)$ and some water vapor ( $\sim 0.33 \%$ by mass, $\sim 0.53 \%$ by volume). However, when Tyndall (1861) [31] studied the infrared activity of the atmospheric gases, he noted that nitrogen and oxygen were largely inactive with respect to infrared activity (argon was not discovered until 1894, but also is infrared-inactive). On the other hand, he noted that water vapor, and also some of the trace gases (e.g., $\mathrm{CO}_{2}$ and $\mathrm{CH}_{4}$ ) were strongly infrared-active, i.e., they are what we now call "greenhouse gases". On this basis, he argued that if the dramatic climatic changes between glacial and interglacial periods were due to changes in atmospheric composition (a theory that was popular at the time), then changes in water (rather than $\mathrm{CO}_{2}$ ) would be a plausible candidate [31]. 
Table 1. Key statistics on the Earth's atmospheric composition. The fraction by volume and total mass figures are adapted from Table 1 of Hartmann (1994) [32]. Calculated “Global Warming Potential (GWP)" values are taken from Table 8.7 of the Intergovernmental Panel on Climate Change (IPCC) Working Group 1's 5th Assessment Report (2013 [33]). One ppmv is one part per million (by volume), i.e., $0.0001 \%$ and one ppbv is one part per billion (by volume), i.e., $0.0000001 \%$.

\begin{tabular}{|c|c|c|c|c|c|c|}
\hline Constituent & $\begin{array}{l}\text { Chemical } \\
\text { Formula }\end{array}$ & Infrared-Active & $\begin{array}{l}\text { Calculated } \\
\text { "GWP" }\end{array}$ & $\begin{array}{c}\text { Molecular Weight } \\
\text { (g/mole) }\end{array}$ & $\begin{array}{c}\text { Fraction by Volume } \\
\text { of Dry Air in } 1990\end{array}$ & $\begin{array}{l}\text { Total Mass } \\
\text { (g) in } 1990\end{array}$ \\
\hline Total Atmosphere & & & & 28.97 & & $5.136 \times 10^{21}$ \\
\hline Dry Air & & & & 28.964 & $100.0 \%$ & $5.119 \times 10^{21}$ \\
\hline Nitrogen & $\mathrm{N}_{2}$ & No & & 28.013 & $78.08 \%$ & $3.876 \times 10^{21}$ \\
\hline Oxygen & $\mathrm{O}_{2}$ & No & & 31.999 & $20.95 \%$ & $1.185 \times 10^{21}$ \\
\hline Argon & $\mathrm{Ar}$ & No & & 39.948 & $0.934 \%$ & $6.59 \times 10^{19}$ \\
\hline Water Vapor & $\mathrm{H}_{2} \mathrm{O}$ & Yes & N/A & 18.015 & - & $1.7 \times 10^{19}$ \\
\hline Carbon Dioxide & $\mathrm{CO}_{2}$ & Yes & 1 & 44.01 & 353 ppmv & $\sim 2.76 \times 10^{18}$ \\
\hline Neon & $\mathrm{Ne}$ & No & & 20.183 & $18.2 \mathrm{ppmv}$ & $6.48 \times 10^{16}$ \\
\hline Krypton & $\mathrm{Kr}$ & No & & 83.80 & $1.14 \mathrm{ppmv}$ & $1.69 \times 10^{16}$ \\
\hline Helium & $\mathrm{He}$ & No & & 4.003 & $5.24 \mathrm{ppmv}$ & $3.71 \times 10^{15}$ \\
\hline Methane & $\mathrm{CH}_{4}$ & Yes & 28 & 16.043 & $1720 \mathrm{ppbv}$ & $\sim 4.9 \times 10^{15}$ \\
\hline Xenon & $\mathrm{Xe}$ & No & & 131.30 & 87 ppmv & $2.02 \times 10^{15}$ \\
\hline Ozone & $\mathrm{O}_{3}$ & Yes & & 47.998 & Variable & $\sim 3.3 \times 10^{15}$ \\
\hline Nitrous Oxide & $\mathrm{N}_{2} \mathrm{O}$ & Yes & 265 & 44.013 & $310 \mathrm{ppbv}$ & $\sim 2.3 \times 10^{15}$ \\
\hline "F-compounds" & Various & Yes & $>1000$ & Various & $\sim 1 \mathrm{ppbv}$ & $<<1 \times 10^{15}$ \\
\hline
\end{tabular}

Several decades later, Arrhenius (1896) argued that because atmospheric water vapor concentrations were more immediately responsive to air temperatures (e.g., warmer temperatures lead to more evaporation from water-enriched surfaces and oceans), carbon dioxide was a better candidate - even though by volume the average concentration of water vapor is more than 10 times that of carbon dioxide [34]. Although Arrhenius' arguments were disputed by, e.g., Ångstrom (1901) [35] and Simpson (1929) [36], the theory has remained popular. Moreover, Callendar (1938) [37] argued that human activities since the Industrial Revolution (chiefly the use of fossil fuels) were probably increasing the atmospheric concentration of $\mathrm{CO}_{2}$ and thereby leading to human-caused global warming. We will briefly discuss the debate which this provoked in later sections. However, for here it is sufficient to note that this theory was incorporated into the early computer climate models, e.g., refs. [1,2], and as described in Section 1, this ultimately led the UN to argue that the international community needed to dramatically reduce emissions of greenhouse gases in order to minimize any future (human-caused) global warming that would occur if the world continued business-as-usual.

In this paper, we are trying to quantify what the expected (human-caused) global warming from "business-as-usual" would be. In this section, we deal with the first step of this process, which is to quantify what future greenhouse gas emissions would be under business-as-usual. As can be seen from Table 1, the most common of the greenhouse gases in the Earth's atmosphere (by an order of magnitude) is water vapor. However, like Arrhenius (1896) [34], the current computer climate models assume that water vapor concentrations respond to changes in climate rather than drive climate change, e.g., Lacis et al. (2010) [14]. Moreover, the emissions of water vapor from human activity are a relatively minor contributor to the hydrological cycle.

Therefore, in terms of the expected (human-caused) global warming, the chief "anthropogenic greenhouse gas" of concern is $\mathrm{CO}_{2}$. However, various human activities can also lead to emissions of other infrared active gases, and so the UNFCCC's Kyoto Protocol (1996) [18] also included several other greenhouse gases as being of potential concern: methane $\left(\mathrm{CH}_{4}\right)$, nitrous oxide $\left(\mathrm{N}_{2} \mathrm{O}\right.$, also known as "laughing gas") and three halogenated gases that are collectively known as the "F-gases" (as they all are fluorine-containing compounds).

There are many other trace gases which could also be regarded as "greenhouse gases". However, according to the latest IPCC assessment reports [15] and computer models (e.g., Ref. [14]), three greenhouse gases- $\mathrm{CO}_{2}, \mathrm{CH}_{4}$ and $\mathrm{N}_{2} \mathrm{O}$ - together account for more than $90 \%$ of the expected anthropogenic global warming under business-as-usual [38]. With that in mind, we will confine our analysis to just these three gases. 
As we will discuss in Section 3, all three of these gases are naturally occurring gases that are essential for life as we know it on this planet. Therefore, there are many natural sources and sinks of these gases, e.g., photosynthesis requires $\mathrm{CO}_{2}$ and aerobic respiration releases $\mathrm{CO}_{2}$, while anaerobic respiration releases $\mathrm{CH}_{4}$. However, various human activities are known to contribute to additional emissions of these gases. In this section, we will look in turn at various estimates and projections of the magnitude of the annual "anthropogenic emissions" of the three gases, and extrapolate from these estimates how these annual emissions would be expected to change if things continued business-as-usual. The estimates and projections used are listed in Table 2.

Table 2. Sources used in this study for emissions data.

\begin{tabular}{|c|c|c|}
\hline Emissions Type & Dataset & Ref. \\
\hline $\begin{array}{l}\text { Historical } \mathrm{CO}_{2} \text { Emissions (fossil } \\
\text { fuels/industry) }\end{array}$ & Global Carbon Budget (2019), https://www.globalcarbonproject.org/ & [39] \\
\hline (Alternative Source) & CDIAC, https://doi.org/10.3334/CDIAC/00001_V2017 & [40] \\
\hline $\mathrm{CO}_{2}$ Emissions (Land use/Land Cover) & Global Carbon Budget (2019), https://www.globalcarbonproject.org/ & [39] \\
\hline (Alternative Source) & Smith and Rothwell (2013), CDIAC, https://cdiac.ess-dive.lbl.gov/land_use.html & [41] \\
\hline Historical $\mathrm{CH}_{4}$ and $\mathrm{N}_{2} \mathrm{O}$ Emissions & $\begin{array}{l}\text { Gütschow et al. (2019): The PRIMAP-hist national historical emissions time } \\
\text { series (1850-2017). v2.1. GFZ Data Services. https://doi.org/10.5880/pik.2019.018 }\end{array}$ & {$[42,43]$} \\
\hline IPCC AR1 Projections & $\begin{array}{l}\text { IPCC Working Group 3, 1st Assessment Report (1990). There are } 5 \text { scenarios: A, } \\
\text { B, C, D and D* }\end{array}$ & [44] \\
\hline IPCC AR2 Projections & $\begin{array}{l}\text { IS92 Emissions Scenarios. The scenarios are A, B, C, D, E and F. Source: } \\
\text { https://sedac.ciesin.columbia.edu/data/set/ipcc-is92-emissions-scenarios-v1-1 }\end{array}$ & [45] \\
\hline IPCC AR3 and AR4 Projections & $\begin{array}{l}\text { Special Report on Emissions Scenarios (“SRES”). This comprises more than } 40 \\
\text { different scenarios, but six are recommended as "representative scenarios”, i.e., } \\
\text { A1, A1G, A1T, A2, B1 and B2. Source: https://sedac.ciesin.columbia.edu/ddc/sres/ }\end{array}$ & [46] \\
\hline IPCC AR5 Projections & $\begin{array}{c}\text { Representative Concentrations Projections ("RCP") Database (Version } 2.0 .5 \text { ). This } \\
\text { comprises four scenarios each of which is named in terms of the expected } \\
\text { increase in radiative forcing in } \mathrm{W} / \mathrm{m}^{2} \text { by } 2100 \text {, i.e., } 2.6,4.5,6.0 \text {, and } 8.5 \text {. Source: } \\
\text { http://www.iiasa.ac.at/web-apps/tnt/RcpDb }\end{array}$ & [47] \\
\hline IPCC AR6 Projections & $\begin{array}{l}\text { The Shared Socioeconomic Pathways ("SSP") scenarios are paired with a slightly } \\
\text { extended range of the RCP projections (increases in radiative forcing of } 1.9,3.4 \\
\text { and } 7.0 \mathrm{~W} / \mathrm{m}^{2} \text { are also considered). Hence, they are sometimes referred to as } \\
\text { "SSP/RCP". Nine scenarios have been recommended for use by the CMIP6 } \\
\text { climate modelling groups, i.e., SSP1-19, SSP1-26, SSP2-45, SSP3-70 (Baseline), } \\
\text { SSP3-70 (LowNTCF), SSP4-34, SSP4-60, SSP5-34-OS, and SSP5-85 (Baseline). The } \\
\text { naming format is SSP } n-x x \text {, where } n \text { is the pathway and } x x \text { is the projected increase } \\
\text { in radiative forcing by } 2100(\times 10) \text {. Source: https://ntcat.iiasa.ac.at/SspDb/dsd }\end{array}$ & [48] \\
\hline
\end{tabular}

\subsection{Some Notes on Units and Acronyms}

In order to minimize the use of large and cumbersome numbers, emissions are usually reported in units of, e.g., gigatons of carbon dioxide $\left(\mathrm{Gt} \mathrm{CO}_{2}\right)$, teragrams of methane $\left(\mathrm{Tg} \mathrm{CH}_{4}\right)$, etc. Moreover, since much of the focus is on carbon dioxide emissions, for brevity, carbon dioxide emissions are frequently reported in terms of the carbon component of carbon dioxide, i.e., gigatons of "carbon" (Gt C) instead of $\mathrm{Gt} \mathrm{CO}_{2}$. This is a simple arithmetic calculation of dividing the mass of $\mathrm{CO}_{2}$ by 3.6675 (i.e., the molecular weight of $\mathrm{CO}_{2} /$ molecular weight of $\left.\mathrm{C}=44.01 / 12=3.6675\right)$. For convenience, here is a summary of the main relevant relationships for the three main anthropogenic greenhouse gases:

- $1 \mathrm{GtC}=1 \mathrm{PgC}=1000 \mathrm{Tg} \mathrm{C}=3.6675 \mathrm{Gt} \mathrm{CO}_{2}=3.6675 \times 10^{12} \mathrm{~kg}$ of $\mathrm{CO}_{2}=3.6675 \times 10^{15} \mathrm{~g}$ of $\mathrm{CO}_{2}$

- $1 \mathrm{Mt} \mathrm{CH}_{4}=1 \mathrm{TgCH} 4=1 \times 10^{9} \mathrm{~kg}$ of $\mathrm{CH}_{4}=1 \times 10^{12} \mathrm{~g}_{4}$ of $\mathrm{CH}_{4}$

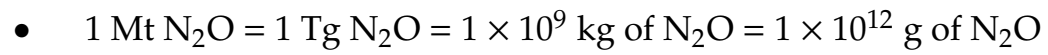

Although emissions are usually described in terms of the mass of the gas, measurements of the atmospheric concentrations are usually reported in fractions by volume. Therefore, in order to consider the relationship between the emissions of a particular gas and the actual changes in atmospheric concentrations of that gas (as we will do in Section 3), it is useful to convert the emissions into an equivalent atmospheric concentration or vice versa. This can be approximated by using the values of the atmospheric composition in 1990 listed in Table 1. For instance, given that the atmospheric concentration of carbon dioxide of 353 ppmv ( $0.0353 \%$ by volume) in c. 1990 represents a total mass of 
$\sim 2.76 \times 10^{18} \mathrm{~g} \mathrm{CO}_{2}=\sim 2760 \mathrm{Gt} \mathrm{CO}{ }_{2}=\sim 752.6 \mathrm{Gt} \mathrm{C}, 1 \mathrm{ppmv}$ of $\mathrm{CO}_{2}$ is equivalent to $\sim 7.8 \mathrm{Gt}_{2}$ or 2.13 Gt C. We can approximate the relationships for both $\mathrm{CH}_{4}$ and $\mathrm{N}_{2} \mathrm{O}$ similarly:

- 1 ppmv of $\mathrm{CO}_{2} \cong 7.8 \mathrm{Gt} \mathrm{CO}_{2}$ or $2.13 \mathrm{GtC}$

- 1 ppbv of $\mathrm{CH}_{4} \cong 2.85 \mathrm{Tg} \mathrm{CH}_{4}$

- 1 ppbv of $\mathrm{N}_{2} \mathrm{O} \cong 7.42 \mathrm{Tg} \mathrm{N}_{2} \mathrm{O}$

We appreciate that there are many different acronyms, abbreviations, and shorthands repeatedly used in this article. Therefore, we have listed them in Table 3 for quick reference.

Table 3. List of acronyms, abbreviations, and shorthands used in this article.

\begin{tabular}{|c|c|}
\hline Acronym & Meaning \\
\hline AGW & Anthropogenic, i.e., human-caused Global Warming \\
\hline BAU & Business-As-Usual \\
\hline $\mathrm{CH}_{4}$ & Methane \\
\hline CMIPn & Coupled Model Intercomparison Project, phase $n$, where $n=3,5$ or 6 \\
\hline $\mathrm{CO}_{2}$ & Carbon dioxide \\
\hline ECS & Equilibrium Climate Sensitivity \\
\hline GCM & $\begin{array}{c}\text { Global Climate Model. Note that historically this acronym originally referred to General Circulation Models, i.e., early climate } \\
\text { models }\end{array}$ \\
\hline Gt & Gigatonne, i.e., $10^{15} \mathrm{~g}$ \\
\hline GWP & Global Warming Potential \\
\hline IPCC & Intergovernmental Panel on Climate Change \\
\hline IPCC AR $n$ & The $n$th IPCC Assessment Report (where $n=1-6$ ) \\
\hline IS-92 & Projections used for IPCC AR2 (1995) \\
\hline$n \times \mathrm{CO}_{2}$ & A climate model simulation that is run assuming atmospheric $\mathrm{CO}_{2}$ is $n$ times that of present (where $n$ is typically 1,2 or 4 ) \\
\hline $\mathrm{N}_{2} \mathrm{O}$ & Nitrous oxide, "laughing gas" \\
\hline NASA GISS & NASA Goddard Institute of Space Studies, based in New York, USA \\
\hline $\operatorname{Pg}$ & Petagram, identical to gigatonne, i.e., $10^{15} \mathrm{~g}$ \\
\hline ppbv & parts per billion by volume \\
\hline ppmv & parts per million by volume \\
\hline $\mathrm{RCP}$ & Representative Concentrations Projections, projections used for IPCC AR5 (2013) \\
\hline RF & Radiative Forcing \\
\hline SRES & Special Report on Emissions Scenarios, projections used for IPCC AR3 (2001) and AR4 (2007) \\
\hline SSP or SSP/RCP & $\begin{array}{c}\text { Shared Socioeconomic Pathways. (Often described with an accompanying Representative Concentrations Projection), } \\
\text { projections to be used for the upcoming IPCC AR6 report }\end{array}$ \\
\hline TCR & Transient Climate Response, a type of climate sensitivity estimate \\
\hline $\operatorname{Tg}$ & Teragram, i.e., $10^{12} \mathrm{~g}$ \\
\hline UNFCCC & United Nations Framework Convention on Climate Change \\
\hline
\end{tabular}

\subsection{Carbon Dioxide $\left(\mathrm{CO}_{2}\right)$ Emissions}

The largest source of human-caused $\mathrm{CO}_{2}$ emissions comes from fossil fuel use and industrial processes (e.g., cement production). Boden et al. (2017) have compiled estimates of the national and global emissions from these processes from 1751 to the near present [40], and this is the main dataset used by most researchers-either directly or indirectly (through using a dataset which is based on the Boden et al. dataset). For convenience we use Friedlingstein et al. (2019)'s updated version of this dataset, which was compiled as part of the "Global Carbon Budget" project [39].

The annual emissions since 1850 to the near present (2018) are plotted in Figure 1a. We can see that since the end of World War 2, i.e., post-1945, there has been a substantial and almost continuous growth in annual emissions. The solid black line represents a linear extrapolation of the data from 1946-2018 up to 2100, and therefore represents one estimate of "business-as-usual" growth in emissions. However, as discussed in the Introduction, since the late-1980s, there has been international interest in reducing $\mathrm{CO}_{2}$ emissions due to the concerns raised by the UNFCCC and IPCC. Therefore, arguably the linear extrapolation for the period post-1990 (dashed line) is a better period for estimating "business-as-usual" growth. Ironically, the extrapolation from 1990-2018 implies a slightly higher rate of growth. At any rate, we will use the linear extrapolations from both periods as an upper and lower bound for business-as-usual growth in $\mathrm{CO}_{2}$ emissions from fossil fuels and industrial usage. 
(a) $\mathrm{CO}_{2}$ emissions from fossil fuel usage and industry

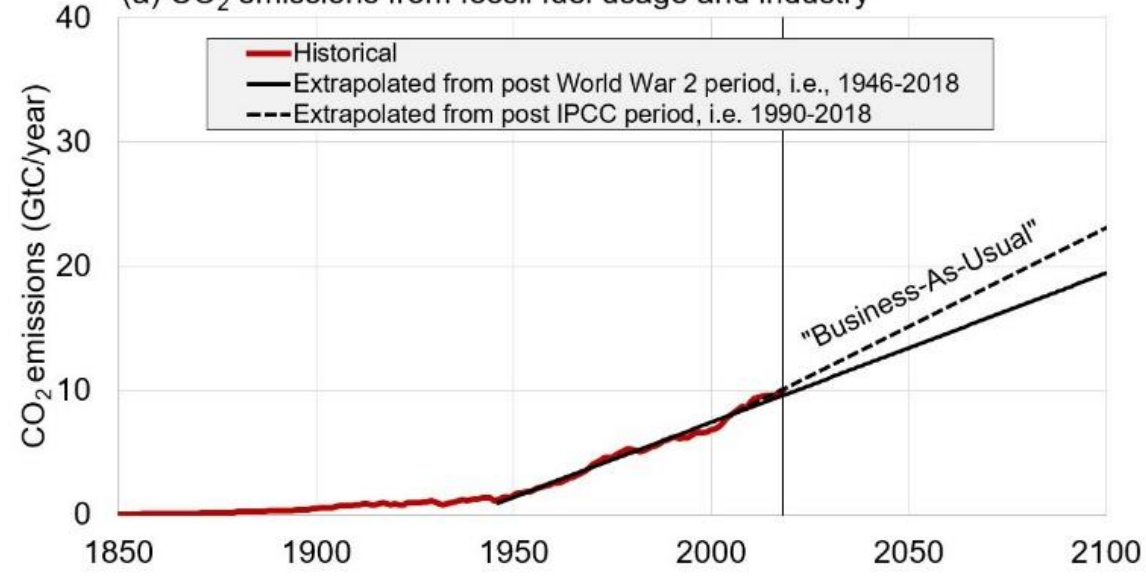

(b) $\mathrm{CO}_{2}$ emissions from changes in land use/land cover

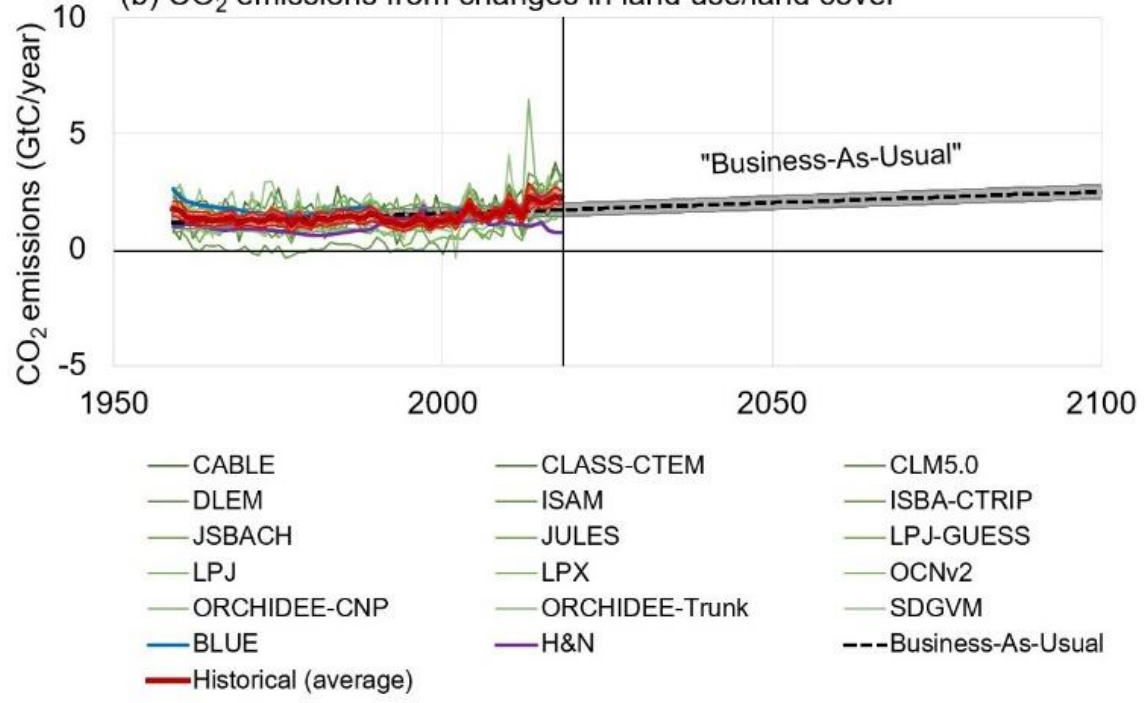

(c) Total $\mathrm{CO}_{2}$ emissions

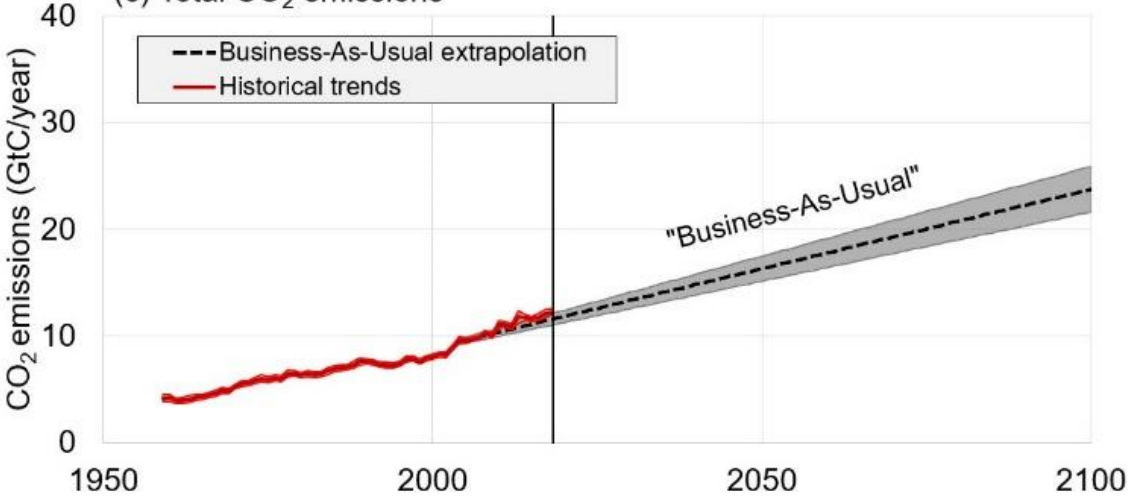

Figure 1. Historical and projected "Business-As-Usual" $\mathrm{CO}_{2}$ emissions for: (a) fossil fuel and industry usage; (b) changes in land use/land cover; (c) the sum of both components. The horizontal axes correspond to years. Each of the plots for the historical period in (b) represents a different estimate of the $\mathrm{CO}_{2}$ emissions since 1959, as compiled by the Global Carbon Budget project. The acronyms of these estimates are provided in the legend below (b), but for further details on each of these estimates, we refer the reader to Friedlingstein et al. (2019) and references therein. However, for the analysis in this paper we will use the mean \pm twice the Standard Error of all these estimates, which is shown with a thick solid red line (with light red envelope). 
There is a second source of indirect $\mathrm{CO}_{2}$ emissions that is human-caused, however. These are emissions which occur from changes in land use or land cover, e.g., deforestation. Unfortunately, these indirect emissions are rather hard to quantify, and there are multiple different estimates, e.g., refs. [41,49-52]. We had initially considered just using one of the more widely cited of these estimates for extrapolating future emissions from changes in land use/land cover under BAU. However, often these estimates imply opposing trends, e.g., the Houghton and Nassikas (2017) [52] estimate implies that there has been a slight decreasing trend in annual emissions since 1997, while Hansis et al. (2015)'s "BLUE" estimate implies a slight increasing trend over the same period [50]. However, we note that Friedlingstein et al. (2019) have compiled both these estimates and 15 different model-based estimates for the post-1958 period as part of the "Global Carbon Budget" project [39]. Therefore, for our analysis in this paper, we have calculated the mean and standard errors of all 17 of these estimates. We then use a linear extrapolation of the upper and lower bounds of the error bars as our projection of BAU emissions from changes in land use/land cover up to 2100 - see Figure $1 \mathrm{~b}$.

In Figure 1c, we have summed the two separate components together to develop a BAU projection of the total annual human-caused $\mathrm{CO}_{2}$ emissions up to 2100. In Figure 2, we then compare this projection to the various emission scenarios that have been considered by each of the IPCC reports. Figure 3 shows the equivalent comparisons for the two separate components from the IPCC's 2nd Assessment Report (1995), but such a breakdown was not available for the 1st Assessment Report (1990)'s emissions scenarios.

Comparing our BAU projection to the various IPCC scenarios, we see from Figure 2a, that Scenario A from the 1st Assessment Report (1990) [53] was actually a fairly good match for BAU. However, all the other scenarios implied a continual decrease in emissions post-1990 which did not occur. For the 2nd Assessment Report (1995) [54], our BAU projection is intermediate between scenarios IS92-F and IS92-A/IS92-B-see Figure 2b-but they also considered a much higher-growth scenario as IS92-E and two scenarios with a more modest emissions rate from 1995 up to present than has been observed and which imply a steady decrease in emissions from about 2025 until the end of the century.

The "SRES" projections that were developed in a special IPCC (2000) [46] report were used for both the 3rd (2001) [55] and 4th (2007) [56] Assessment Reports. These included more than 40 different scenarios, but six of these ("A1", "A1G", "A1T", "A2", "B1", and "B2") were chosen as being representative of the full range of available scenarios. We compare them to our BAU projection in Figure 2c. None of these six "SRES" scenarios match well with our BAU projection. "A1G" and "A2" both imply a growth in emissions that is considerably higher than BAU. This is broadly consistent with the findings of McKitrick et al. (2013) [57] as well as the earlier critique by Castles and Henderson (2003) [58], which led to considerable debate, e.g., [59-62]. Meanwhile, the rest of the scenarios imply changes that are considerably less than BAU. "A1" and "A2" match our BAU projection reasonably well up to 2050, but then they diverge in opposite directions ("A1" increasing faster than BAU and "A2" decreasing).

Figure 2d compares our BAU projections to the four Representative Concentrations Projections (RCP) scenarios [47] considered by the most recent 5th Assessment Report (2013) [33]. As for the SRES projections, none of them match well. The RCP 8.5 scenario implies a growth in emissions much greater than BAU. This agrees with several recent articles pointing out that RCP 8.5 substantially overestimates $\mathrm{CO}_{2}$ emissions relative to BAU, e.g., [63-66]. Meanwhile, all of the other scenarios imply that emissions are substantially decreasing relative to BAU over the 21st century.

In preparation for the upcoming 6th Assessment Report, the RCP scenarios have been updated and elaborated on with a series of "Shared Socioeconomic Pathways" (SSP) $[48,67,68]$. Nine of these combined SSP/RCP scenarios have been recommended to the CMIP6 modelling groups, and we compare these to our BAU projection in Figure 2e. Two of these recommended scenarios actually match quite well to BAU, i.e., the two "SSP3-70" scenarios. However, the "SSP5-85 (Baseline)" scenario implies much higher growth in emissions over the 21st century than BAU, while the other scenarios imply much lower emissions than BAU. 
Total $\mathrm{CO}_{2}$ emissions

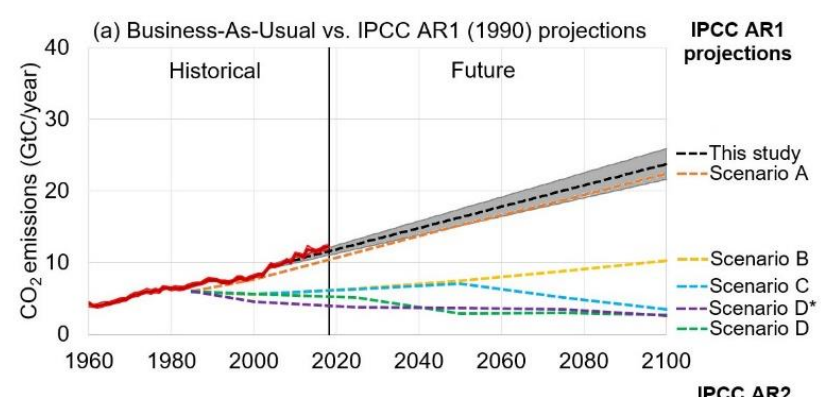

(b) Business-As-Usual vs. IPCC AR2 (1995) projections projections
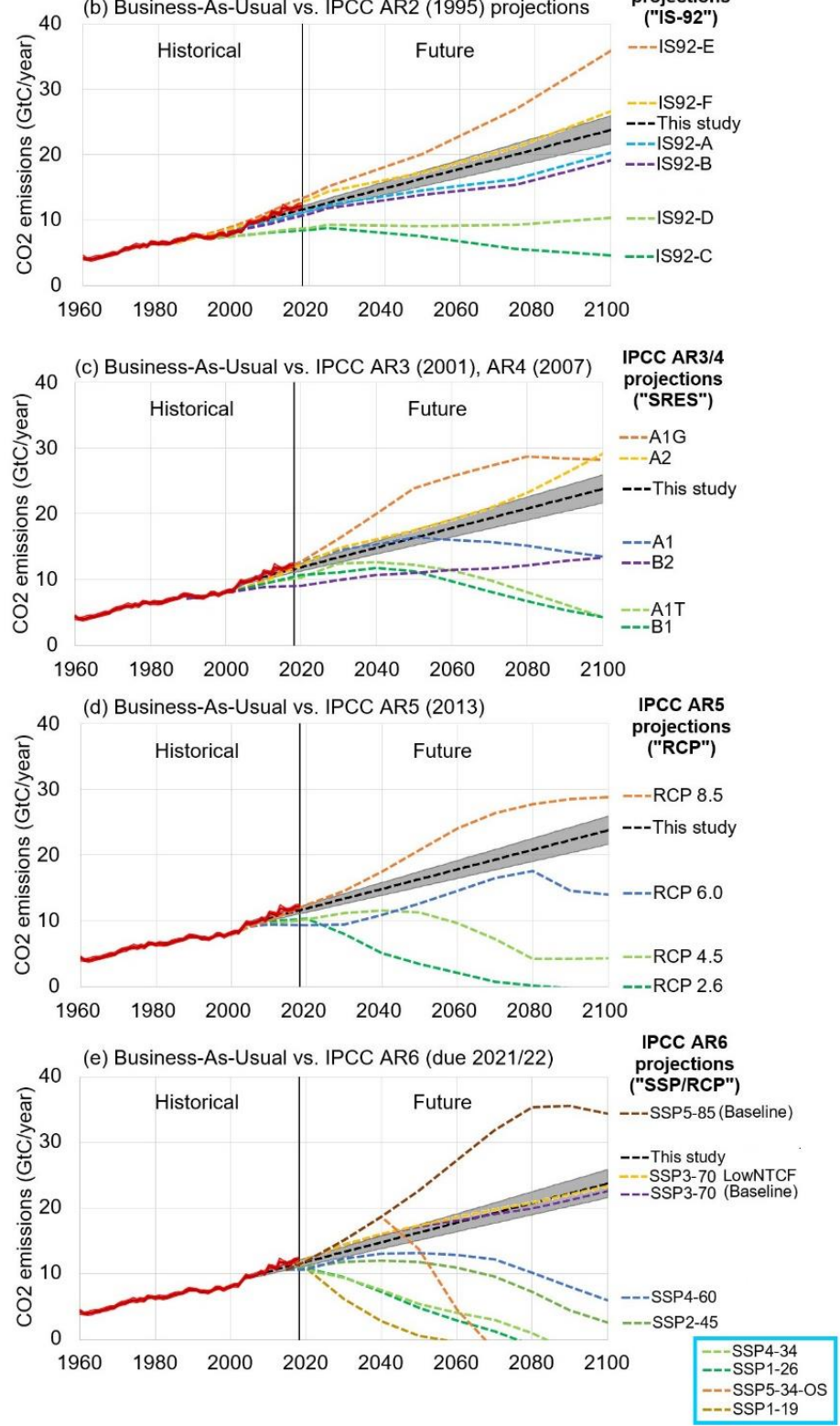

Figure 2. Comparison of the new "Business-As-Usual" projections of future total $\mathrm{CO}_{2}$ emissions with the various projections considered by the IPCC's (a) 1st Assessment Report (AR1, 1990); (b) the 2nd Assessment Report (AR2, 1995); (c) the 3rd Assessment Report (AR3, 2001); the 4th Assessment Report (AR4, 2007); (d) the 5th Assessment Report (AR5, 2013); and (e) the upcoming 6th Assessment Report (AR6, due c. 2021/2022). The horizontal axes correspond to years. Details on the projections are provided in Table 2. 

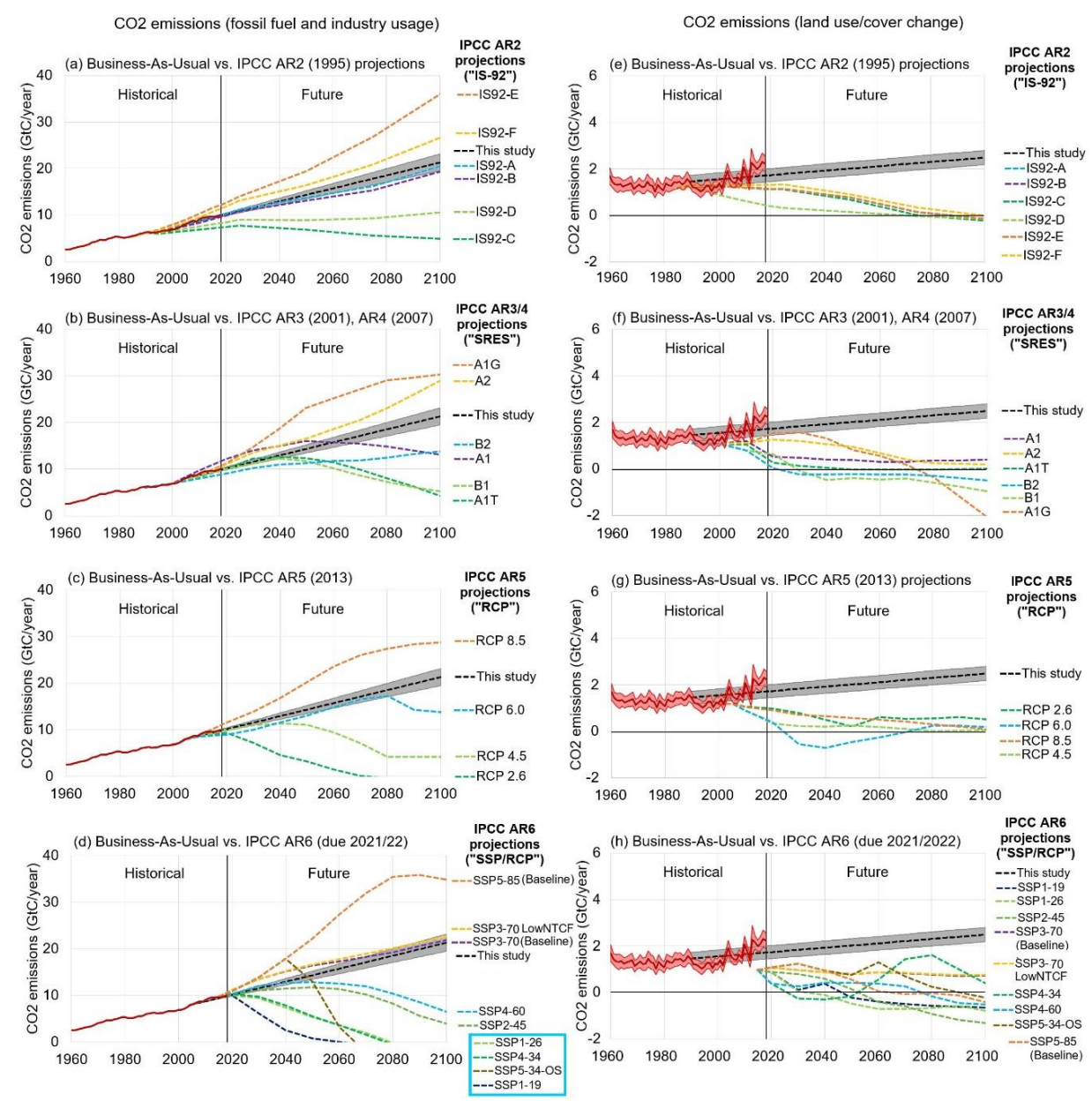

Figure 3. Comparison of the new "Business-As-Usual" projections of future $\mathrm{CO}_{2}$ emissions for (a-d) fossil fuel and industry usage and $(\mathbf{e}-\mathbf{h})$ changes in land use/land cover with the various projections considered by the IPCC's Assessment Reports. Note that the vertical axes for (e-h) have a different scale than for $(\mathbf{a}-\mathbf{d})$. The horizontal axes correspond to years. Details on the projections are provided in Table 2.

\subsection{Methane $\left(\mathrm{CH}_{4}\right)$ Emissions}

Historical estimates of past $\mathrm{CH}_{4}$ and $\mathrm{N}_{2} \mathrm{O}$ appear to have been much less studied so far. However, recently, Gütschow et al. (2016) [42] have published version 2 of the "PRIMAP-hist national historical emissions time series". We have used their 2019 update (version 2.1) [43] to extrapolate $\mathrm{CH}_{4}$ annual emissions up to 2100 in this section and the equivalent extrapolations for $\mathrm{N}_{2} \mathrm{O}$ in Section 2.4.

Version 2.1 of the dataset estimates emissions up to 2017, and also provides an upper and lower bound. Therefore, we applied our 1946-2017 and 1990-2017 linear extrapolations to both the upper and lower bound. The results are shown in Figure 4a. We use the lowest and highest extrapolations from these four extrapolations as the upper and lower bound for BAU annual emissions up to 2100 .

In Figure $4 b-f$, we again compare our BAU projections to the scenarios used by each of the IPCC reports. We note that all the scenarios for the 1st Assessment Report start at a much higher annual emission rate than observed-see Figure $4 \mathrm{~b}$. This thereby implies much greater emissions over the 21st century than our BAU projection. However, this seems to be because they apparently mistakenly included several natural sources of $\mathrm{CH}_{4}$ emissions in their total annual human-caused emissions.

For subsequent reports, these naturally occurring emissions appear to have been separated out. As a result, the starting point for the later IPCC report scenarios matches quite well with the historical human-caused emission estimates (and therefore also with our BAU projection). However, for the 2nd Assessment Report, scenarios and the SRES projections used in the 3rd and 4th Assessment Reports, 
$\mathrm{CH}_{4}$ emissions were projected to increase at a much higher rate than was observed up to present and continue to increase at a rate much higher than BAU for much of the 21st century-see Figure 2c,d. Some of the projections imply lower annual emissions than BAU by 2100, but this appears to be because it is assumed that there will be active policy-driven reductions in $\mathrm{CH}_{4}$ emissions in the second half of the 21st century.

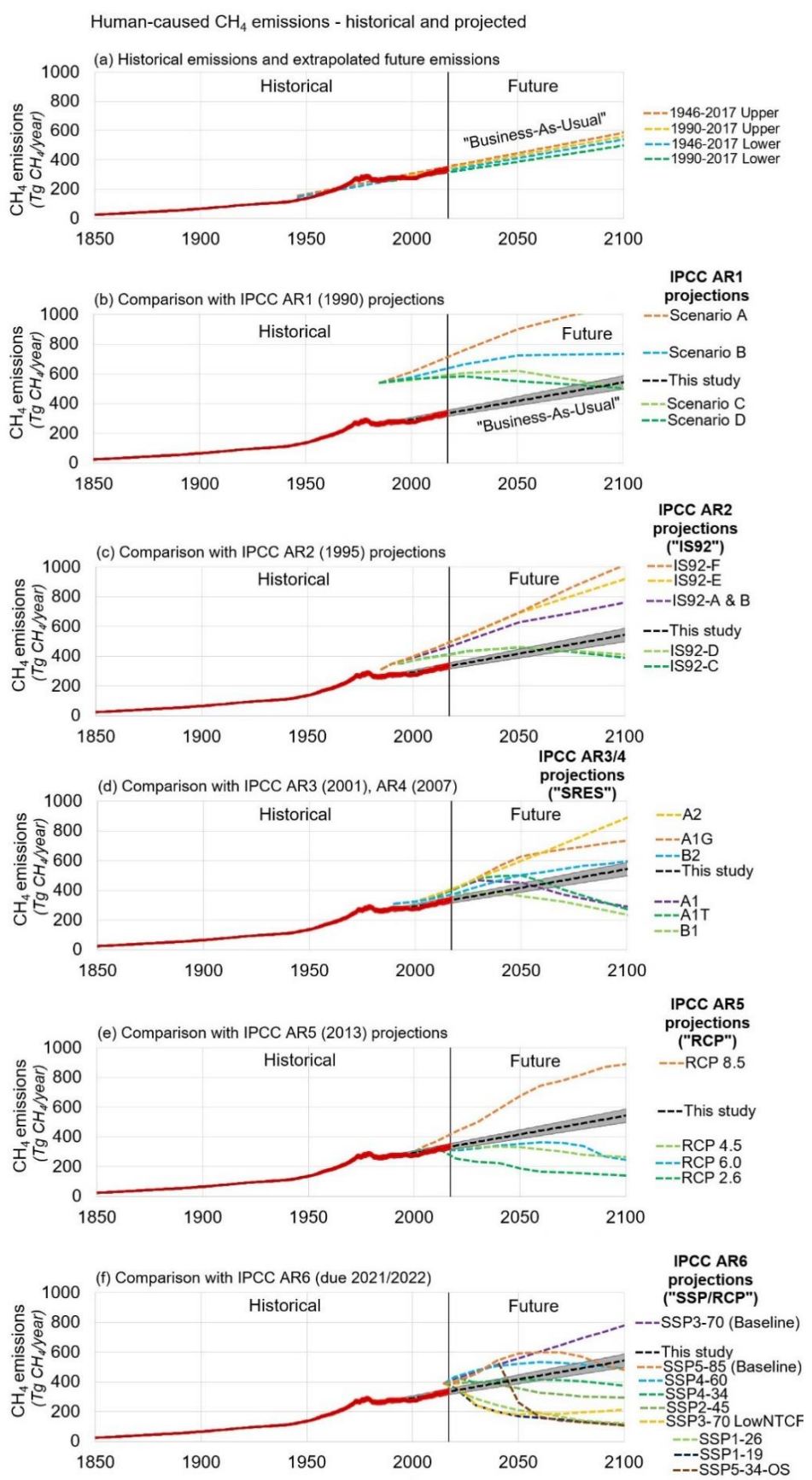

Figure 4. (a) Historical and projected "Business-As-Usual" $\mathrm{CH}_{4}$ emissions. (b-f) A comparison of said Business-As-Usual projections to the projections considered by the various IPCC reports. The horizontal axes correspond to years. Details on the projections are provided in Table 2.

On the other hand, several of the scenarios in both the RCP scenarios-Figure 4e-and the new SSP/RCP scenarios-Figure $4 \mathrm{f}$-imply that $\mathrm{CH}_{4}$ emissions will be much less than our BAU projection. Although, again, the RCP 8.5 scenario overestimates $\mathrm{BAU} \mathrm{CH}_{4}$ emissions, as do several of the SSP/RCP scenarios over most of the century, i.e., "SSP3-70 (Baseline)"; "SSP5-85 (Baseline)" and "SSP4-60". 


\subsection{Nitrous Oxide $\left(\mathrm{N}_{2} \mathrm{O}\right)$ Emissions}

Figure 5 presents the equivalent analysis for annual $\mathrm{N}_{2} \mathrm{O}$ emissions. For brevity, we will not comment in too much detail on the comparisons, but we will note a key point difference. As for $\mathrm{CH}_{4}$, the starting point for annual $\mathrm{N}_{2} \mathrm{O}$ emissions seems to have been higher than the current estimates of historical emissions. However, there appears to have been much more inconsistency in the estimates of current emissions between reports. The scenarios used by both the 1st and 5th Assessment Reports imply higher annual emissions at the start of their projections than the current estimates, while those used by the 2nd, 3rd, and 4th Assessment Reports imply lower annual emissions. On the other hand, the starting annual emissions implied by the latest SSP/RCP scenarios match well with the current estimates of historical emissions.
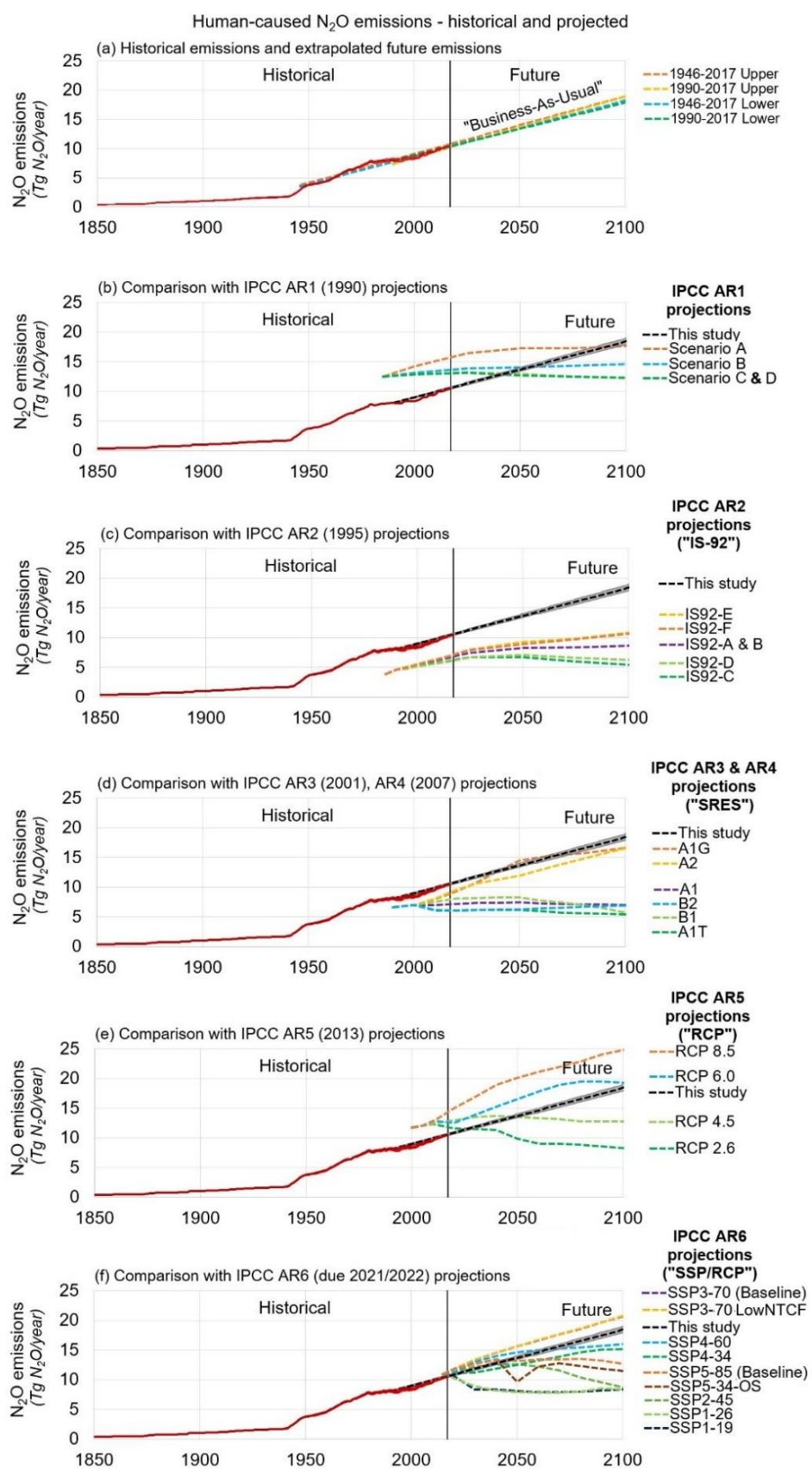

Figure 5. (a) Historical and projected "Business-As-Usual" $\mathrm{N}_{2} \mathrm{O}$ emissions. (b-f) A comparison of said Business-As-Usual projections to the projections considered by the various IPCC reports. The horizontal axes correspond to years. Details on the projections are provided in Table 2. 


\section{What Is the Relationship between Greenhouse Gas Emissions and Actual Changes in Atmospheric Concentrations?}

It is the atmospheric concentrations of these gases that the computer model simulations predict should be influencing global temperatures [1,2,8-10], rather than the rates of anthropogenic emissions. However, $\mathrm{CO}_{2}, \mathrm{CH}_{4}$, and $\mathrm{N}_{2} \mathrm{O}$ are all naturally occurring gases. They also each play important roles in many biological processes. In particular, $\mathrm{CO}_{2}$ is consumed by photosynthesis and released by (aerobic) respiration, and therefore is a key component for all life on this planet. Hence, there are many natural fluxes into and out of the atmosphere for these gases. For convenience, a flux out of the atmosphere is usually referred to as a "sink" and a flux into the atmosphere as a "source".

Therefore, in order to estimate how much human-caused global warming the projected BAU emissions in Section 2 could potentially cause, we need to estimate what fraction of the emitted gases will remain in the atmosphere, i.e., what will the "airborne fraction" of the emitted gases be? Given the many uncertainties associated with the natural sources and sinks for each of the three gases, we argue that currently the best way to estimate this is to consider how the airborne fractions have behaved since continuous records of atmospheric concentrations began (in 1958/59 for $\mathrm{CO}_{2} ; 1978 / 79$ for $\mathrm{CH}_{4}$ and $\mathrm{N}_{2} \mathrm{O}$ ). In this section, we will calculate the airborne fractions by comparing the anthropogenic emissions described in the previous section to the observed changes in atmospheric concentrations using the datasets listed in Table 4.

Table 4. Sources for atmospheric greenhouse gas concentration data used in this study.

\begin{tabular}{ccc}
\hline Emissions Type & Dataset & Reference \\
\hline $\mathrm{CO}_{2}, \mathrm{CH}_{4}$ and $\mathrm{N}_{2} \mathrm{O}$ Atmospheric & NOAA ESRL Global Monitoring Division, & - \\
Concentrations & https:/www.esrl.noaa.gov/gmd/ccgg/ & - \\
(Alternative Source) & $\begin{array}{r}\text { The NOAA Annual Greenhouse Gas Index (AGGI) } \\
\text { https://www.esrl.noaa.gov/gmd/aggi/aggi.html }\end{array}$ & {$[69]$} \\
$\mathrm{N}_{2} \mathrm{O}$ (Alternative Source) & Combined Nitrous Oxide data from NOAA ESRL & {$[70]$} \\
Law Dome, Antarctic Ice Core & ftp://ftp.cmdl.noaa.gov/hats/n2o/combined/ & NOAA NCEI Paleoclimatology Data, https: \\
Estimates & //www.ncdc.noaa.gov/paleo-search/study/25830 & {$[38,71]$} \\
IPCC AR5 Projections & RCP Database (Version 2.0.5), & {$[47]$} \\
\hline
\end{tabular}

\subsection{The Airborne Fraction of Carbon Dioxide $\left(\mathrm{CO}_{2}\right)$ Emissions}

Figure 6a shows the observed annual atmospheric $\mathrm{CO}_{2}$ concentrations as recorded at Mauna Loa observatory in Hawai'i (solid green line) since systematic measurements began in early-1958 and also globally averaged estimates from multiple observatories around the world since 1979 (dashed blue line). Although the globally averaged curve is slightly below the Mauna Loa curve, they both almost overlap each other. Therefore, since the Mauna Loa record is longer, for the rest of this paper, we will treat it as being representative of "global atmospheric $\mathrm{CO}_{2}$ concentrations". It can be easily seen that-as discussed earlier-atmospheric $\mathrm{CO}_{2}$ concentrations have been steadily rising at a rate of roughly $\sim 1.5$ ppmv per year since at least 1959, i.e., the start of the record. Antarctic ice core estimates of pre-historic atmospheric $\mathrm{CO}_{2}$ concentrations suggest that up until the 19th/20th centuries, concentrations had remained fairly constant since the end of the last glacial period more than 10,000 years ago [72], only fluctuating within the range 271-285 ppmv [38]. This small range of "pre-industrial variability" is shown by the grey band in Figure 6a, with the dashed black line corresponding to the mean value of 280 ppmv.

We will discuss below some of the scientific debate over exactly how reliable the Antarctic ice core estimates are. Nonetheless, if we assume for now that the Antarctic ice core estimates are reliable, we can see why it is widely believed that the rise in atmospheric $\mathrm{CO}_{2}$ from $\sim 280 \mathrm{ppmv}$ to $\sim 410 \mathrm{ppmv}$ today (a $46 \%$ increase) is largely human-caused and due to human-driven $\mathrm{CO}_{2}$ emissions. However, as can be seen from Figure $6 b$, there is a challenging complication. The lower green curve represents 
the annual change in atmospheric $\mathrm{CO}_{2}$, i.e., the increase in atmospheric $\mathrm{CO}_{2}$ from each year to the next. As discussed in Section 2.1, we can convert the anthropogenic (i.e., human-caused) annual $\mathrm{CO}_{2}$ emissions determined in Section 2.2 from Gt C/year into the equivalent annual change in atmospheric concentrations. This is the upper curve (solid red line with a surrounding envelope) of Figure $6 \mathrm{~b}$. The two vertical axes are scaled so that they are directly interchangeable, i.e., an annual change of 1 ppmv on the left-hand vertical axis is equivalent to $2.13 \mathrm{Gt} \mathrm{C/yr}$ on the right-hand axis.
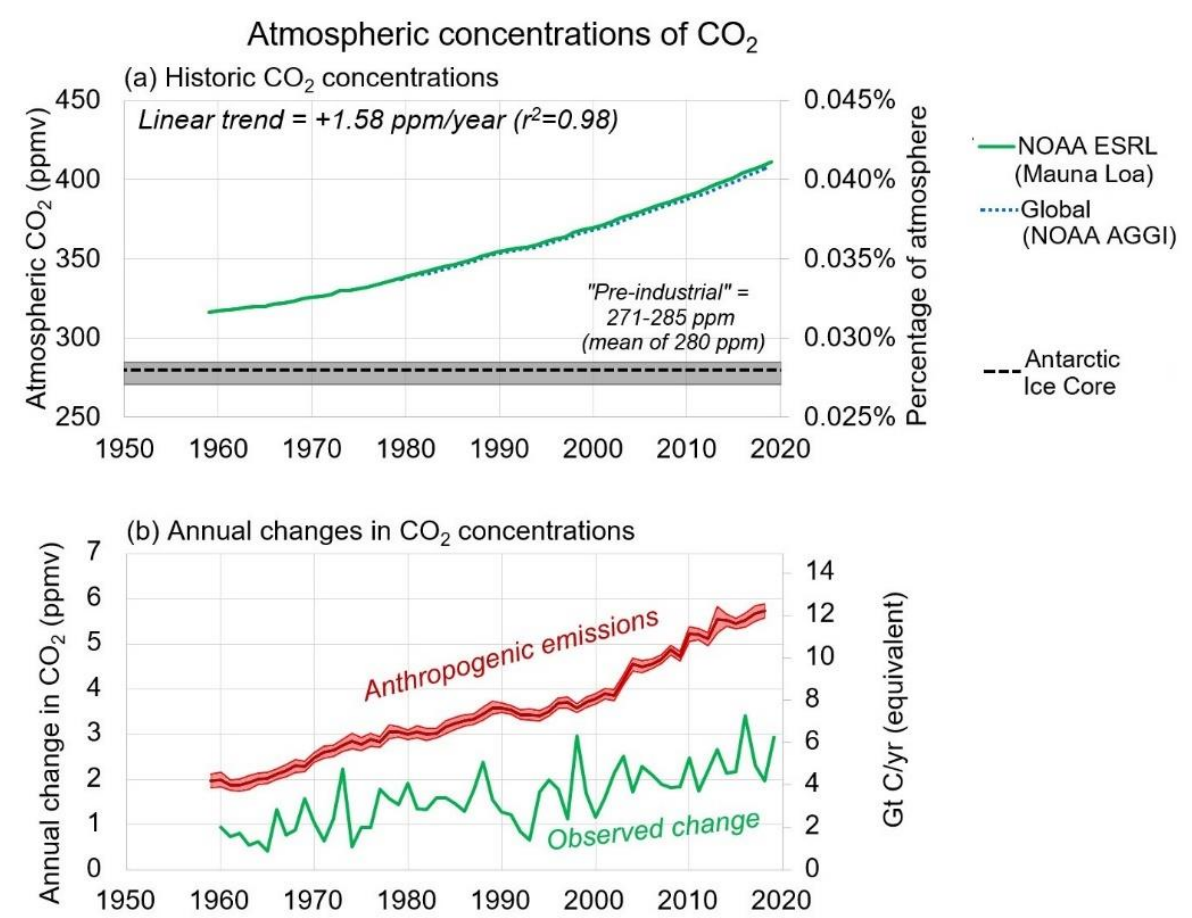

(c) Airborne fraction of anthropogenic $\mathrm{CO}_{2}$ emissions

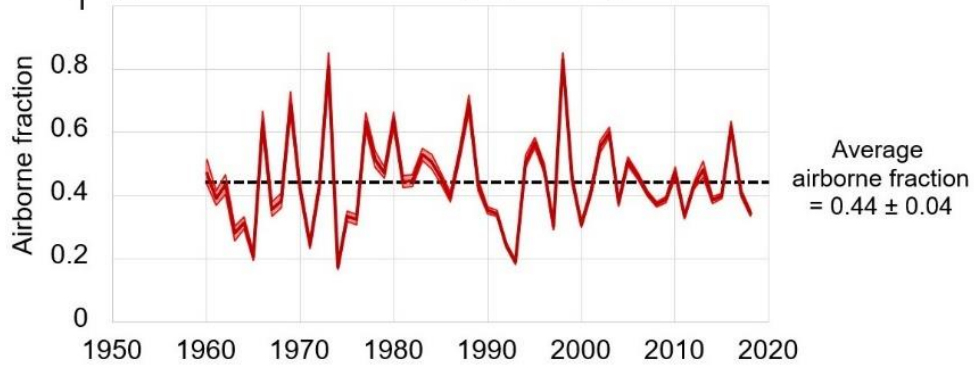

Figure 6. (a) Changes in annually averaged atmospheric $\mathrm{CO}_{2}$ concentrations since direct and (almost) continuous measurements began in 1959. Estimates of pre-industrial concentrations derived from the Antarctic Law Dome ice core are shown with a grey band for comparison. (b) A comparison of the annual anthropogenic $\mathrm{CO}_{2}$ emissions (red band) with the observed annual changes in atmospheric $\mathrm{CO}_{2}$ (green line). (c) The "airborne fraction" for $\mathrm{CO}_{2}$, i.e., the fraction of anthropogenic $\mathrm{CO}_{2}$ emissions that remained in the atmosphere for each year since 1960. The horizontal axes correspond to years.

Although both curves have generally increased over time, the lower curve corresponding to the observed atmospheric changes has been consistently below the curve corresponding to anthropogenic emissions. In other words, only a fraction of the anthropogenic $\mathrm{CO}_{2}$ emissions remains in the atmosphere from year-to-year. The so-called "airborne fraction", i.e., the ratio of atmospheric change to anthropogenic emissions is plotted in Figure 6c.

The reason that there is not an exact 1:1 relationship between anthropogenic $\mathrm{CO}_{2}$ emissions and atmospheric $\mathrm{CO}_{2}$ concentrations is that $\mathrm{CO}_{2}$ is a naturally occurring gas. Moreover, it is one of the most important gases biologically speaking. Life as we know it on Earth is carbon-based, and this 
carbon in living organisms largely comes from the photosynthesis of atmospheric $\mathrm{CO}_{2}$ by plants and other photosynthetic organisms. As a result, as well as the anthropogenic sources for $\mathrm{CO}_{2}$, there are also natural sinks and sources for $\mathrm{CO}_{2}$. In fact, current estimates for the annual anthropogenic $\mathrm{CO}_{2}$ emissions are $\sim 12 \mathrm{Gt}$ gC/year, but the current estimates for the emissions from natural sources are $\sim 200 \mathrm{Gt}$ C/year, and it is also estimated that natural sinks absorb $200 \mathrm{Gt}$ C/year of $\mathrm{CO}_{2}$ from the atmosphere [73]. Therefore, the exact relationship between anthropogenic $\mathrm{CO}_{2}$ emissions and actual atmospheric $\mathrm{CO}_{2}$ concentrations depends on the many complex interactions between the various natural and anthropogenic $\mathrm{CO}_{2}$ sources and sinks, known collectively as "the carbon cycle".

The annual changes in atmospheric concentrations show quite a lot of variability from year-to-year, which is not apparent from the annual anthropogenic emissions, and the airborne fraction actually varies quite a bit from year-to-year, as has been noted by others (e.g., refs. [74-82]). This suggests that natural variability actually plays quite a substantial role in atmospheric $\mathrm{CO}_{2}$ concentration trends. On the other hand, if the Antarctic ice core estimates are reliable, then it implies that atmospheric $\mathrm{CO}_{2}$ has been almost constant for more than 10,000 years, making it very difficult to see why the steady increase since at least 1959 is not a recent and human-caused phenomenon. Moreover, if it were to transpire that all (or even most) of the recent increase in atmospheric $\mathrm{CO}_{2}$ were a natural phenomenon, then this would completely undermine the entire basis for claiming that society's $\mathrm{CO}_{2}$ emissions are causing "human-caused global warming". Therefore, whenever a researcher publishes an analysis suggesting that some or all of the recent increase could be natural in origin, such as the references cited above [76,78-82] and also refs. [74,75,77,83-89], their arguments are attacked with a particular vehemence, e.g., [90-99].

In Kuhn's 1962 book, "The structure of scientific revolutions" [100], he argued that for the vast majority of what he called "normal science", i.e., the day-to-day work of most researchers, scientists carry out their research implicitly relying on one or more paradigms that are assumed to be indisputable. Although the specific paradigms within one discipline might be different from a separate discipline, and that they change over time, he argued that "normal science" implicitly relied upon these paradigms being correct. As a result, Kuhn proposed that whenever a researcher questions a key paradigm within a discipline, they are immediately attacked or ridiculed by their peers. On the other hand, he noted that over time an increasing number of "anomalies" that are difficult to explain may arise within that paradigm, and during "revolutionary science", the community may undergo a shift to a replacement paradigm. Ultimately, Kuhn argued that science progresses over time through both processes.

We refer to this Kuhnian approach to viewing science here because in our opinion, a lot of the (often acrimonious) debate between researchers on this particular topic, as well as several of the topics we will discuss later (Sections 4.1, 4.2 and 5) can be best understood in terms of competing paradigms. With regards to the debate over the relationships between natural and human-caused sinks and sources of $\mathrm{CO}_{2}$, we have identified four distinct paradigms:

- Paradigm 1-the "anthropocentric" approach. It is assumed that any natural sinks and sources of $\mathrm{CO}_{2}$ are effectively balanced, and that all human-caused $\mathrm{CO}_{2}$ emissions will contribute to human-caused global warming. This was originally proposed by studies before the Mauna Loa observations had begun or had only recently begun, e.g., refs. [37,101-103]. It also seems to be implicit among researchers who consider carbon dioxide $\left(\mathrm{CO}_{2}\right)$ to be a "pollutant", even though it is a naturally-occurring gas, e.g., the US EPA's 2009 so-called "Endangerment finding" [104].

- Paradigm 2-the "airborne fraction" approach. Like Paradigm 1, it is assumed that any natural sinks and sources are roughly balanced from year-to-year. However, given the fact that the airborne fraction is $<1$, it is acknowledged that the natural sinks and sources are not exactly balancing each other. Instead, it is assumed that some of the natural sinks (chiefly, the oceans and terrestrial vegetation) are absorbing some of the anthropogenic emissions. Within this paradigm, there is ongoing debate over whether these sinks will continue to take up a fraction of this anthropogenic $\mathrm{CO}_{2}$ at the same rate they have been since 1959, e.g., refs. [105-107], or whether the airborne fraction is going to start increasing towards 1 in the near future, e.g., refs. [39,108,109]. 
- Paradigm 3-the "sinks and sources" approach. Within this paradigm, it is recognized that anthropogenic emissions are a new source of $\mathrm{CO}_{2}$, but that there is also significant variability in the magnitudes of the natural sinks and sources. In particular, it is widely acknowledged that increasing temperatures should increase the natural $\mathrm{CO}_{2}$ emissions from soil respiration $[110,111]$ as well as reducing the solubility of $\mathrm{CO}_{2}$ in the upper oceans [112] (which could potentially lead to net outgassing of $\mathrm{CO}_{2}$ into the atmosphere). For this reason, several researchers have argued that some component of the observed increase in atmospheric $\mathrm{CO}_{2}$ since 1959 could be a result of a natural global warming trend (i.e., the opposite of the human-caused global warming theory), e.g., refs. $[16,17,74,75,77,79-81,85,113]$. Importantly, this paradigm does not rule out a contribution from anthropogenic emissions in the recent increase-rather, anthropogenic emissions are treated as an additional source that needs to be taken into account.

- Paradigm 4-the "resilient Earth" approach. This is similar to Paradigm 3, except that it is disputed whether there is anything unusual about the increase since 1959. Within this paradigm, it is argued that the Antarctic ice core estimates are unreliable and that similar $\mathrm{CO}_{2}$ concentrations to present may well have occurred in the decades and centuries before the Mauna Loa record began. Instead, it is argued that most (if not all) of the rise in $\mathrm{CO}_{2}$ over the Mauna Loa record was natural in origin (due to natural global warming), e.g., refs. [82-84,87-89,114].

Notice that the four paradigms cannot all be correct. As a result, proponents of one paradigm may consider proponents of competing paradigms to be not just wrong, but scientifically incompetent. However, once the existence of different paradigms is appreciated and respected, it may be possible for fruitful discussions to take place between competing paradigms. Indeed, it is worth noting that the Mauna Loa observations were largely initiated in order to resolve the debate [115] between proponents of Paradigm 1 (e.g., refs. [37,101-103]) and Paradigm 4 (e.g., Revelle and Suess (1957) [116]). Yet, ironically, as explained below, the "airborne fraction" results implied by the Mauna Loa record, i.e., Figure $6 c$, actually point towards either Paradigm 2 or 3.

Let us consider the evidence for and against each of these paradigms. First, if Paradigm 1 were correct, then we would expect the airborne fraction to be 1 (or at least nearly 1 ). That is, we would be expecting most of the emitted anthropogenic $\mathrm{CO}_{2}$ to remain in the atmosphere. On the other hand, if Paradigm 4 were correct, then we would expect the airborne fraction to be near-zero on average, i.e., we would be expecting the changes in atmospheric $\mathrm{CO}_{2}$ to be largely independent of anthropogenic emissions. However, as can be seen from Figure $6 c$, the airborne fraction has been fairly constant with a mean of $0.44 \pm 0.04$ over the entire record. This appears to rule out Paradigms 1 and 4 , leaving either Paradigm 2 or 3.

Now, let us consider the reliability of the Antarctic ice core estimates. If these estimates are correct and atmospheric $\mathrm{CO}_{2}$ was almost constant for nearly 10,000 years up to the 19th century [38,72], then that seems to rule out much room for naturally occurring trends of more than a dozen ppmv. In other words, it appears to rule out Paradigms 3 and 4 . However, in this context it is worth noting that several estimates of past $\mathrm{CO}_{2}$ concentrations derived from the stomata of fossilised leaves imply considerably more variability during the pre-industrial era than that implied by the Antarctic ice cores, see refs. [117-127]. Moreover, Greenland ice cores imply increases of 20-30 ppmv more than the Antarctic ice cores during relatively warm periods in the pre-industrial era, although it has been argued that the Antarctic ice cores are more reliable, e.g., refs. [128-130].

If the greater variability implied by the stomatal-based estimates (or even the Greenland ice cores) are accurate, then this could provide support for Paradigm 3. For instance, Kouwenberg et al. (2005) suggest that atmospheric $\mathrm{CO}_{2}$ could have dropped as low as $260 \mathrm{ppmv}$ and risen as high as $320 \mathrm{ppmv}$ several times over the last millennium [123], while the Antarctic ice cores suggest that $\mathrm{CO}_{2}$ remained within the range 271-285 ppmv [38]. However, it should be stressed that the current concentrations of $\sim 410$ ppmv are still higher than those stomata-based estimates, which suggests that anthropogenic emissions have significantly increased concentrations above natural variability, i.e., disagreeing with 
Paradigm 4. Moreover, the stomata-based estimates have been disputed by supporters of the Antarctic ice core estimates $[129,131]$.

Others have also suggested that the Antarctic ice core estimates are problematic and unreliable, e.g., refs. [83,84,87-89], and Beck has suggested that early measurements of atmospheric $\mathrm{CO}_{2}$ before the Mauna Loa observations began implied atmospheric concentrations above $400 \mathrm{ppmv}$ in the 1940s as well as in the early 19th century [87-89]. This would be very consistent with Paradigm 4, but, again, all of these studies have been vehemently disputed by advocates for Paradigm $2[98,99]$.

What does this tell us about the relationship between anthropogenic $\mathrm{CO}_{2}$ emissions and changes in atmospheric $\mathrm{CO}_{2}$ up to 2100? Well, if Paradigm 4 were correct, then there should be no relationship (or at best a weak one). In that case, arguably the rest of the analysis in this paper would be largely redundant, and we could say that there should be no (or very little) human-caused global warming up to 2100 [82-84,87-89,114], although it would not preclude the possibility of natural global warming. However, as explained above, this would also imply an average airborne fraction of 0 or close to 0 . Similarly, we can rule out Paradigm 1, as this would imply an average airborne fraction close to 1.

If Paradigm 3 is correct, then at least some of the observed increase in atmospheric $\mathrm{CO}_{2}$ over the Mauna Loa record is anthropogenic in origin, and therefore we argue that "business-as-usual" conditions imply that the airborne fraction will remain fairly constant. Within Paradigm 2, there is some debate over whether some of the sinks that are currently reducing the airborne fraction might become "saturated", e.g., refs. [39,105-109]. However, given that the annual airborne fraction has remained fairly constant since the Mauna Loa record began in 1959, we will define "business-as-usual" conditions to mean this will remain constant with a mean of $0.44 \pm 0.04$. In Section 3.4, we will compare this assumption to the airborne fractions implicit in the IPCC RCP scenarios. But, first, let us consider the other two relevant gases.

\subsection{The Airborne Fraction of Methane $\left(\mathrm{CH}_{4}\right)$ Emissions}

Figure 7 shows the equivalent results for $\mathrm{CH}_{4}$. Although the $\mathrm{CH}_{4}$ observational records are not as long as for $\mathrm{CO}_{2}$, there are more than 40 years of measurements (compilations of various flask measurements beginning in 1978, and more systematic measurements beginning in 1984 [132]). Unlike for $\mathrm{CO}_{2}$, the airborne fraction of anthropogenic emissions has been almost zero $(0.07 \pm 0.02)$ over the entire record, and for a few years even went slightly below zero, i.e., atmospheric concentrations decreased even though anthropogenic emissions continued.

Antarctic ice core estimates of atmospheric $\mathrm{CH}_{4}$ before the instrumental record [38] suggest pre-industrial concentrations of less than half the current concentrations, i.e., 624-737 ppbv (0.624-0.737 ppmv) compared to $1850 \mathrm{ppbv}$ today [133]. Furthermore, during the 1980s, atmospheric concentrations were still rising. This led many researchers to suggest that anthropogenic $\mathrm{CH}_{4}$ emissions were significantly altering atmospheric concentrations of $\mathrm{CH}_{4}$ as well as $\mathrm{CO}_{2}$. Therefore, $\mathrm{CH}_{4}$ was included as one of the six greenhouse gases considered under the 1996 Kyoto protocol [18]. Indeed, as Ganesan et al. (2019) [134] note, attempting to reduce anthropogenic $\mathrm{CH}_{4}$ emissions is one of the main goals of the 2015 Paris Agreement [19]. However, during the 1990s and early 2000s, the rise in $\mathrm{CH}_{4}$ concentrations began to slow down and even plateaued for several years. It is only after 2006 that concentrations began to rise again. Over this entire period, anthropogenic emissions have continued and even increased-see Figure $7 b$.

This has been a puzzle for researchers who had been assuming something like the Paradigm 2 we described in the previous section applied to $\mathrm{CH}_{4}$ emissions, e.g., refs. [133,135]. As a result, researchers working on the "Global Methane Budget" are recognizing that there is significant variability in many of the natural sinks and sources of methane, and that this natural variability may be a major factor for the unexpected trends in atmospheric $\mathrm{CH}_{4}$ - see Saunois et al. (2016) [136], which builds on the work of Kirschke et al. (2013) [133].

Unlike $\mathrm{CO}_{2}$, where most of the anthropogenic emissions have tended to come from developed nations with relatively high GDPs $[137,138]$, most of the anthropogenic $\mathrm{CH}_{4}$ and $\mathrm{N}_{2} \mathrm{O}$ emissions 
apparently come from agricultural processes (e.g., rice paddies and cattle production) in developing nations-especially in Asia and South America, e.g., Tian et al. (2015) [139]. However, Zhang et al. (2020) have recently shown that the contribution of rice paddies in monsoon Asia has declined since 2007 [140], suggesting that other changes in sources and sinks are probably involved in the post-2006 increase.
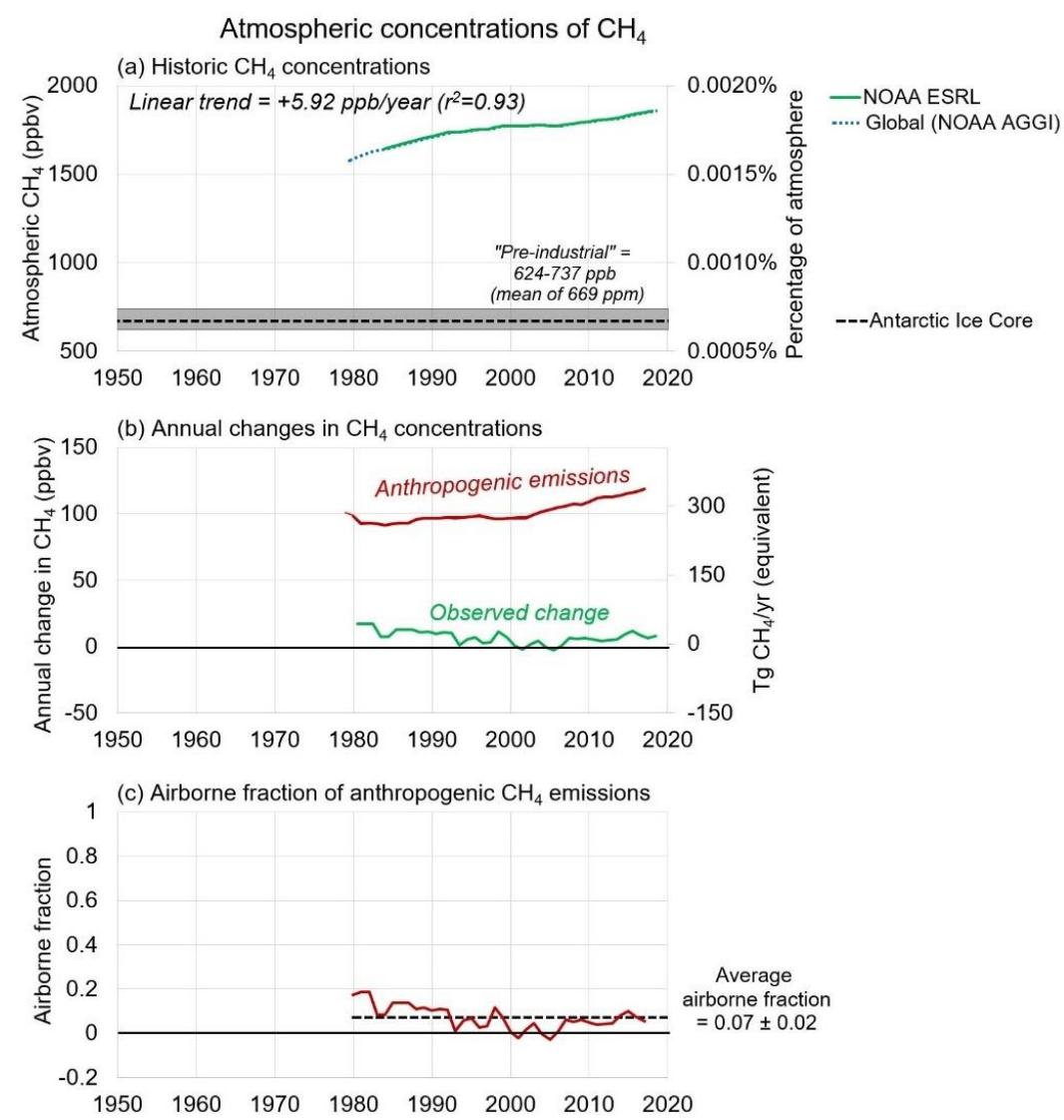

Figure 7. (a) Changes in annually averaged atmospheric $\mathrm{CH}_{4}$ concentrations since direct and (almost) continuous measurements began in 1979. The estimates of pre-industrial concentrations derived from the Antarctic Law Dome ice core are shown with a grey band for comparison. (b) A comparison of the annual anthropogenic $\mathrm{CH}_{4}$ emissions (red line) with the observed annual changes in atmospheric $\mathrm{CH}_{4}$ (green line). (c) The "airborne fraction" for $\mathrm{CH}_{4}$, i.e., the fraction of anthropogenic $\mathrm{CH}_{4}$ emissions that remained in the atmosphere for each year since 1980. Note that the airborne fraction was below 0 on three years (2001, 2004 and 2005). The horizontal axes correspond to years.

Although Saunois et al. estimate that anthropogenic emissions (approximately 540-568 $\mathrm{Tg}$ $\mathrm{CH}_{4} /$ year) comprise about $60 \%$ of the total annual $\mathrm{CH}_{4}$ emissions, they caution that the uncertainties over the natural sources appear to be much larger than for anthropogenic sources [136]. The variability in the natural sources and sinks remains poorly understood, e.g., Bastviken et al. (2011) estimated that freshwater lakes, reservoirs, streams, and rivers could be contributing at least $103 \mathrm{Tg} \mathrm{CH}_{4}$ /year [141].

If the Antarctic ice core estimates of past atmospheric $\mathrm{CH}_{4}$ are inaccurate, then on the basis of the very low airborne fraction of $0.07 \pm 0.02$ over the instrumental record, it is quite plausible that most of the apparent trends in atmospheric $\mathrm{CH}_{4}$ are due to variability in the natural sinks and sources. In that case, it would suggest that anthropogenic $\mathrm{CH}_{4}$ emissions might not be influencing atmospheric concentrations, in which case they probably could be removed as a potential source of human-caused global warming. We suggest that this possibility should be considered and we encourage more research into identifying and quantifying the variability in the various natural sources and sinks, perhaps building on the work of Saunois et al. (2016) [136], but explicitly considering Paradigms 3 or even 
4 as relevant for $\mathrm{CH}_{4}$. However, for the purposes of this analysis, we will define BAU to imply that anthropogenic emissions are increasing the atmospheric concentration, but with an airborne fraction of only $0.07 \pm 0.02$ up to at least 2100 . As we will discuss in Section 3.4, this is actually assuming a higher airborne fraction for $\mathrm{CH}_{4}$ than most of the IPCC RCP scenarios.

\subsection{The Airborne Fraction of Nitrous Oxide $\left(\mathrm{N}_{2} \mathrm{O}\right)$ Emissions}

Figure 8 shows the equivalent results for $\mathrm{N}_{2} \mathrm{O}$. The $\mathrm{N}_{2} \mathrm{O}$ observational record is of a similar length to that of $\mathrm{CH}_{4}$. However, unlike $\mathrm{CH}_{4}$, the airborne fraction has been quite high, although there seems to have been quite a bit of interannual variability with three years being above 1 (implying atmospheric concentrations increased more than was emitted anthropogenically) and one year being below 0 (i.e., the atmospheric concentration slightly decreased in spite of anthropogenic emissions). Averaged over the entire record, the airborne fraction has remained fairly constant at $0.65 \pm 0.09$. This suggests that anthropogenic $\mathrm{N}_{2} \mathrm{O}$ emissions are responsible for much (if not all) of the fairly steady increase in atmospheric concentration (with a rate of $+0.75 \mathrm{ppbv} /$ year).
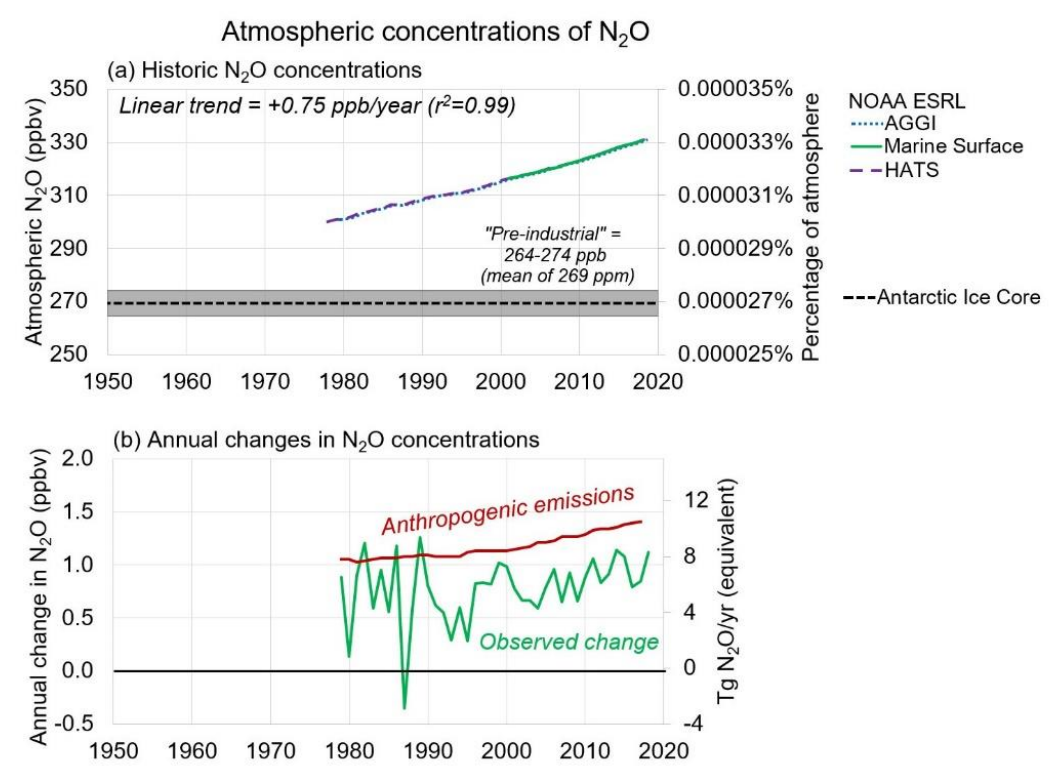

(c) Airborne fraction of anthropogenic $\mathrm{N}_{2} \mathrm{O}$ emissions

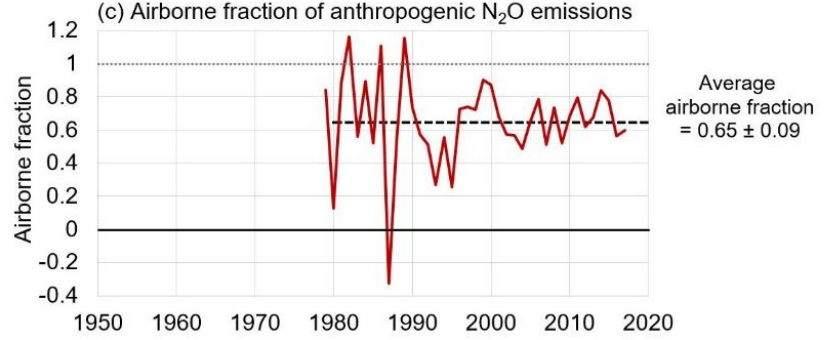

Figure 8. (a) Changes in annually averaged atmospheric $\mathrm{N}_{2} \mathrm{O}$ concentrations since direct and (almost) continuous measurements began in 1979. The estimates of pre-industrial concentrations derived from the Antarctic Law Dome ice core are shown with a grey band for comparison. (b) A comparison of the annual anthropogenic $\mathrm{N}_{2} \mathrm{O}$ emissions (red line) with the observed annual changes in atmospheric $\mathrm{N}_{2} \mathrm{O}$ (green line). (c) The "airborne fraction" for $\mathrm{N}_{2} \mathrm{O}$, i.e., the fraction of anthropogenic $\mathrm{N}_{2} \mathrm{O}$ emissions that remained in the atmosphere for each year since 1980. Note that the airborne fraction was below 0 in one year (1987) and above 1 in three years (1982, 1986 and 1989). The horizontal axes correspond to years.

Having said that, the airborne fraction has been quite variable, and well below 1 . Therefore, there does seem to have been quite a bit of variability in the natural sinks and sources. Davidson and Kanter (2014) [142] estimate that $65 \%-69 \%$ of the annual $\mathrm{N}_{2} \mathrm{O}$ emissions are natural in origin. However, 
there is still a lot of ongoing research into quantifying different natural sources, e.g., refs. [143,144]. We suggest that a similar attempt to quantify the natural sinks and sources for $\mathrm{N}_{2} \mathrm{O}$ to what Saunois et al. (2016) [136] have been doing for the Global Methane Budget project would be helpful (perhaps building on studies such as Davidson and Kanter (2014) [142]. We would recommend following the lead of Saunois et al. (2016) who seem to have been approaching the Global Methane Budget from Paradigm 3, rather than the Paradigm 2 approach used by Friedlingstein et al. (2019) [39] for the Global Carbon Budget. In the meantime, as for the other two gases, we will define BAU to imply that the experimentally observed airborne fraction for $\mathrm{N}_{2} \mathrm{O}$ of $0.65 \pm 0.09$ will continue up to at least 2100 .

\subsection{Comparison of "Business-As-Usual" Airborneffractions with the RCP Scenarios}

In Figure 9, we compare the historical airborne fractions up to present and our projected constant airborne fractions up to 2100 with the equivalent airborne fractions used in the IPCC's four RCP scenarios for (a) $\mathrm{CO}_{2}$, (b) $\mathrm{CH}_{4}$, and (c) $\mathrm{N}_{2} \mathrm{O}$.

Future airborne fractions

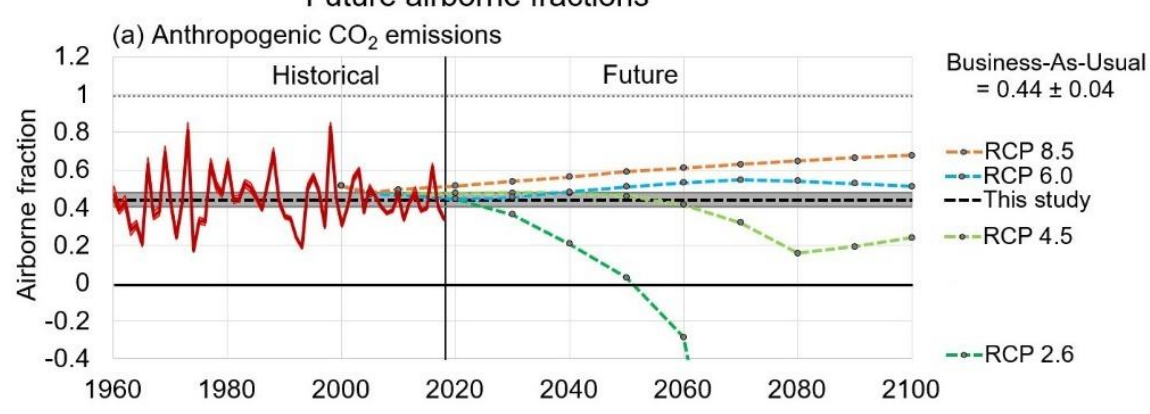

(b) Anthropogenic $\mathrm{CH}_{4}$ emissions
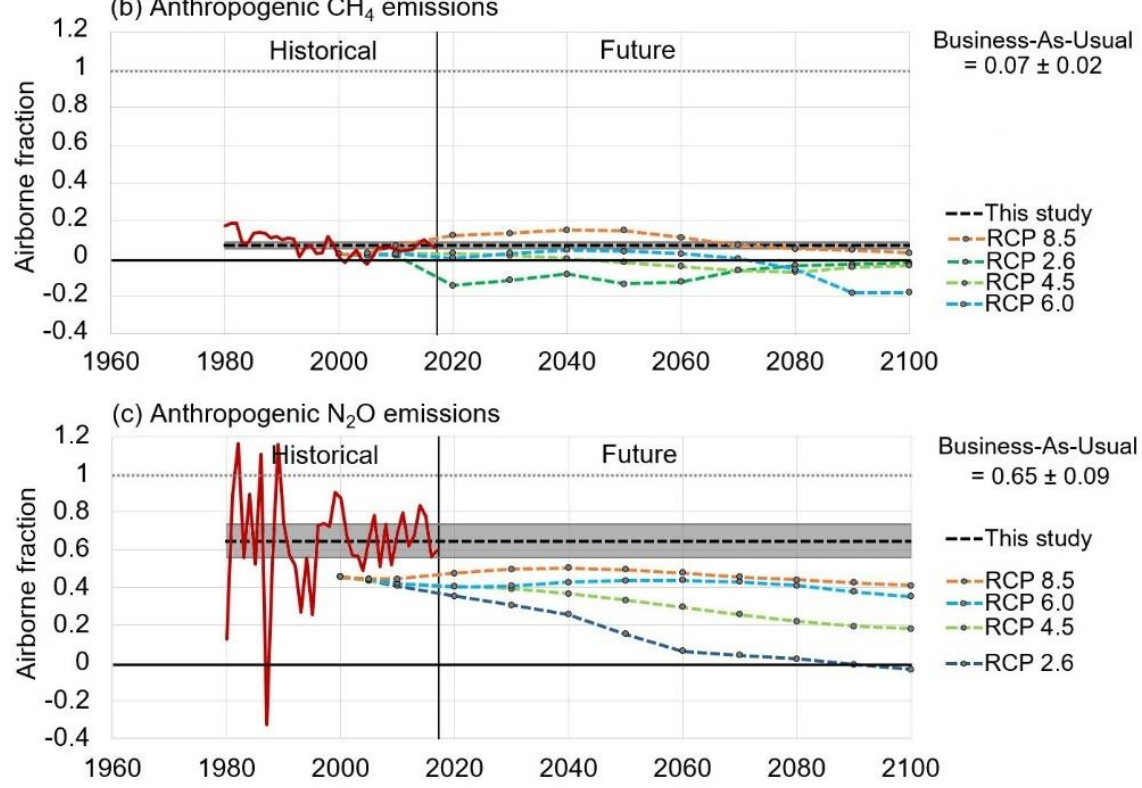

Figure 9. Comparison of the future airborne fractions implied by each of the IPCC AR5's RCP scenarios to our projected "Business-As-Usual" ranges for: (a) carbon dioxide $\left(\mathrm{CO}_{2}\right)$; (b) methane $\left(\mathrm{CH}_{4}\right)$; and (c) nitrous oxide $\left(\mathrm{N}_{2} \mathrm{O}\right)$. The horizontal axes correspond to years. Details on the projections are provided in Table 2.

For $\mathrm{CO}_{2}$, one of the scenarios ( $\mathrm{RCP}$ 2.6) predicts a rapid decline in the airborne fraction becoming negative after 2050. This scenario predicts that society will develop and implement technologies to allow substantial carbon sequestration, leading to "negative $\mathrm{CO}_{2}$ emissions", such as those considered by Fuss et al. (2018) [145]. On the other hand, for RCP 8.5, it is predicted that the airborne fraction 
will gradually increase over the century (which would thereby increase the rate at which atmospheric $\mathrm{CO}_{2}$ concentrations would increase). The other two scenarios imply a fairly constant airborne fraction up to the middle of the century, but RCP 6.0 predicts a slight increase from 2040-2070, followed by a slight decrease to 2100, while RCP 4.5 predicts a rather sharp drop in airborne fraction (associated with "negative $\mathrm{CO}_{2}$ emissions") from 2060 to 2080 followed by an increase to 2100. In comparison, our BAU projection lies in between the two intermediate scenarios (RCP 4.5 and 6.0) for the entire 21st century.

For $\mathrm{CH}_{4}$, all of the $\mathrm{RCP}$ scenarios except 8.5 predict that the airborne fraction will be lower than our BAU projection. Even with RCP 8.5, the airborne fraction is predicted to decrease towards 0 from 2050 onwards. As a result, by 2100 , our BAU projection, which is already very modest (as discussed in Section 3.2) is higher than all four RCP scenarios. In other words, our BAU projection predicts a slightly greater fraction of anthropogenic $\mathrm{CH}_{4}$ emissions will remain in the atmosphere than the RCP scenarios.

As for $\mathrm{N}_{2} \mathrm{O}$, all four of the RCP scenarios assume a starting airborne fraction of 0.45 in 2000, which is lower than the historical airborne fraction of $0.65 \pm 0.09$. As a result, even though RCP 8.5 predicts a relative increase from 2010 to 2040 and RCP 6.0 predicts a slight increase from 2030 to 2050, all four scenarios predict a lower airborne fraction than our BAU projection for the entire 21st century.

\subsection{Projected Greenhouse Gas Concentrations up to 2100 under "Business-As-Usual" Airborne Fractions}

Let us now combine the results of the previous sections in order to estimate future greenhouse gas concentrations up to 2100 for our three gases assuming (a) that anthropogenic emissions continue to grow "business-as-usual" and (b) that the observed airborne fractions for the gases remain constant "business-as-usual". In that case, the increase in atmospheric concentration for each of our gases for each year is equal to the projected emissions for that year multiplied by the airborne fraction. The results are plotted with black dashed lines in Figure 10, along with the equivalent projections for the four RCP scenarios (in colored dashed lines) [47], the historical values (in red solid line), and the range of "pre-industrial" variability implied by the Antarctic ice cores (in black dotted line) [38]. Since both our projected emissions and the average airborne fractions have uncertainty ranges associated with them (see previous sections), the resulting concentration projections have a combined uncertainty range shown with a gray bounding envelope.

Although the concentrations of both $\mathrm{CH}_{4}$ and $\mathrm{N}_{2} \mathrm{O}$ are still projected to be several orders of magnitude lower than that of $\mathrm{CO}_{2}$ by 2100 (e.g., $\mathrm{CH}_{4}$ and $\mathrm{N}_{2} \mathrm{O}$ being reported in units of parts per billion by volume and $\mathrm{CO}_{2}$ in parts per million by volume), according to the current computer models (e.g., [14]) and the IPCC assessment reports (e.g., [33]), they are both expected to cause much more global warming on a molecule-by-molecule basis than $\mathrm{CO}_{2}$. Specifically, it is argued that these gases have a much greater "Global Warming Potential" (GWP) than $\mathrm{CO}_{2}$. The exact values of these GWP calculations have changed between IPCC reports and depending on the timescale used (e.g., 20 years, 100 years or 500 years). However, if we use the 100-year GWP values from the more recent IPCC Assessment Reports, i.e., Table 8.7 of the IPCC Working Group 1's 5th Assessment Report (2013 [33]), $\mathrm{CH}_{4}$ apparently has a "Global Warming Potential (GWP)" 28 times that of $\mathrm{CO}_{2}$ and $\mathrm{N}_{2} \mathrm{O}$ has a GWP 265 times that of $\mathrm{CO}_{2}$ (see Table 1). This means that $100 \mathrm{ppbv}$ of $\mathrm{CH}_{4}$ is "equivalent to" $1.02 \mathrm{ppmv}$ of $\mathrm{CO}_{2}$ in terms of GWP and that $100 \mathrm{ppbv}$ of $\mathrm{N}_{2} \mathrm{O}$ is equivalent to $25.21 \mathrm{ppmv}$ of $\mathrm{CO}_{2}$. We have shown these " $\mathrm{CO}_{2}$ equivalent" scales on the right-hand vertical axes of Figure 10b,c. For interested readers, in the Supplementary Materials, we compare the total projected greenhouse gas concentrations under $\mathrm{BAU}$ (in $\mathrm{CO}_{2}$ equivalent concentrations) to alternative projections that used the projected airborne fractions implied by the RCP scenarios.

Comparing our projected $\mathrm{CO}_{2}$ concentrations to those of the RCP scenarios, it is actually quite similar to the RCP 6.0 scenario, and indeed the RCP 6.0 scenario curve just about fits within the gray bounding envelope of our projection up to 2100. This suggests that the $\mathrm{CO}_{2}$ concentrations of the RCP 6.0 scenario are actually a reasonable estimate of "Business-As-Usual" for the 21st century. This is consistent with several recent articles that argue that RCP 8.5 implies a dramatic increase in $\mathrm{CO}_{2}$ emissions relative to "Business-As-Usual", e.g., [63-66]. Readers might wonder why the RCP $6.0 \mathrm{CO}_{2}$ 
concentrations match so well with our BAU projection when the RCP 6.0 emissions projections curve in Figure $2 \mathrm{~d}$ was lower than our BAU projection. This seems to be a consequence of the slight temporary increase in airborne fraction of the RCP 6.0 scenario from 2040-2070 that can be seen in Figure 9a.
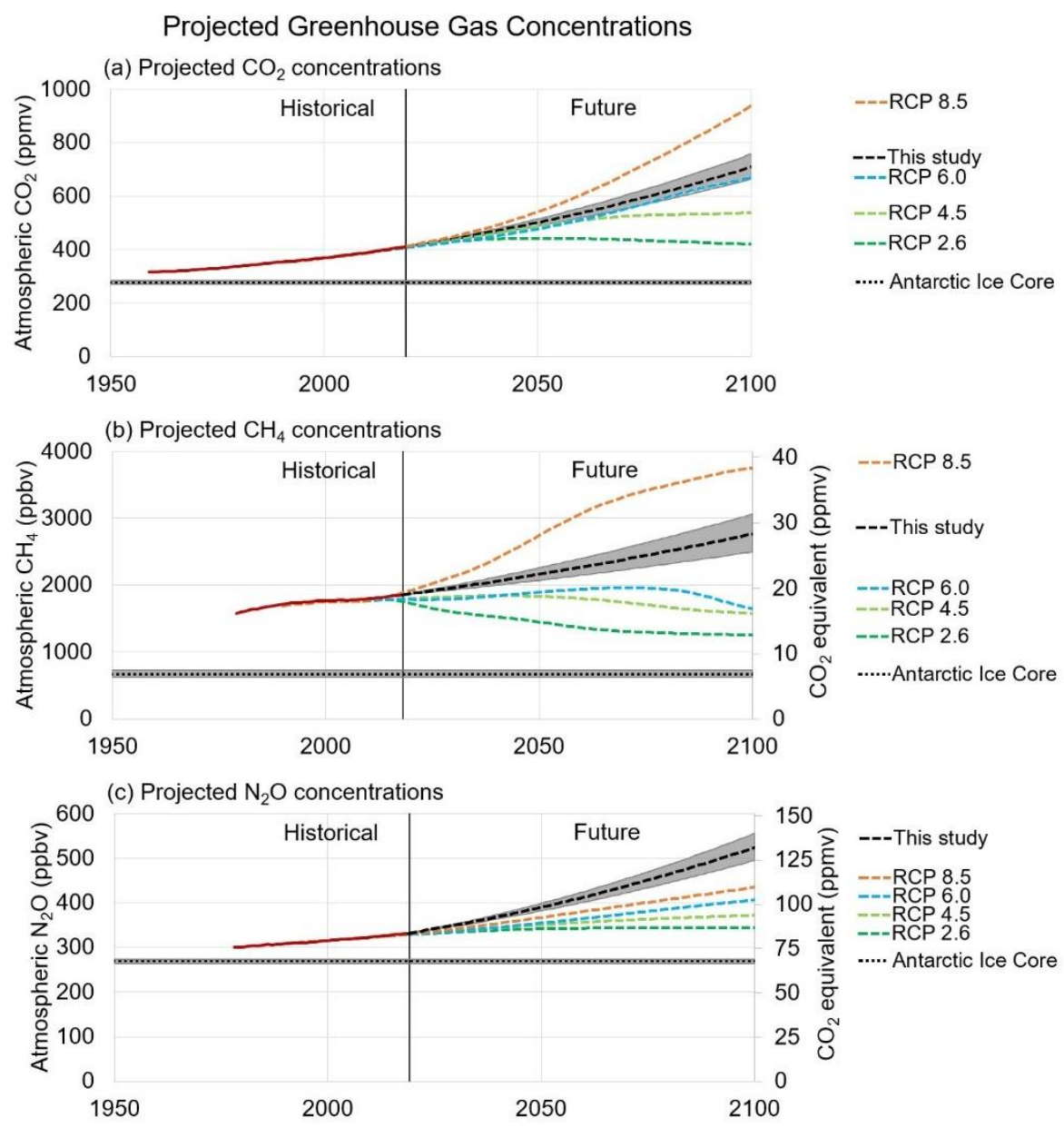

Figure 10. Future greenhouse gas concentrations up to 2100 under "Business-As-Usual" conditions, compared to the RCP scenarios, for (a) $\mathrm{CO}_{2} ;$ (b) $\mathrm{CH}_{4}$; and (c) $\mathrm{N}_{2} \mathrm{O}$. Concentrations for $\mathrm{CH}_{4}$ and $\mathrm{N}_{2} \mathrm{O}$ in " $\mathrm{CO}_{2}$ equivalents" are shown on the right-hand side vertical axes for comparison. The horizontal axes correspond to years.

With regards to $\mathrm{CH}_{4}$, our projected $\mathrm{CH}_{4}$ concentrations are higher than all of the $\mathrm{RCP}$ scenarios except RCP 8.5-see Figure 9b. RCP 8.5 projects a rapid acceleration in atmospheric $\mathrm{CH}_{4}$ beginning over the coming decades, which is not predicted under BAU growth.

Meanwhile, our BAU projections for $\mathrm{N}_{2} \mathrm{O}$ imply a growth rate that is higher than all of the RCP scenarios, even though our projected emissions in Figure $5 \mathrm{~d}$ implied a projection intermediate between the two middle RCP scenarios (RCP 4.5 and 6.0). This is due to the relatively low airborne fraction for $\mathrm{N}_{2} \mathrm{O}$ projected by the $\mathrm{RCP}$ scenarios for the 21st century.

\section{How Do We Define “Pre-Industrial" Global Temperatures?}

\subsection{How Much of the Recent Global Warming is Human-Caused vs. Natural?}

Several widely cited papers have argued that $90 \%-95 \%$ (or more) of scientists agree on global warming and climate change, e.g., Doran and Zimmerman (2009) [146]; Cook et al. (2013) [147]; Stenhouse et al. (2013) [148]; Verheggen et al. (2014) [149]. Separately, the IPCC 5th Assessment Report has stated that, "warming of the climate system is unequivocal", and that, "it is extremely likely that human 
influence has been the dominant cause of the observed warming since the mid-20th century." [15]. For this reason, many readers may be wondering at the title of this subsection. With that in mind, let us briefly dissect what exactly was found by the studies just mentioned.

There have indeed been many surveys of the scientific community that have confirmed that $90 \%-95 \%$ (or more) of scientists agree that it is probably warmer today than during the late-19th century and/or that the climate is changing. However, as we have written elsewhere, the climate is always changing, and global temperatures have changed on timescales varying from decades and centuries, e.g., Soon et al. (2003) [150,151]; Soon et al. (2015) [152], to millennia, e.g., Carter and Gammon (2004) [153], to millions of years, e.g., Carter (2010) [113]. Therefore, agreeing that the climate has changed and/or that there has been long-term global warming since the late-19th century does not in itself say anything about whether this is natural, human-caused, or a mixture of both. That said, it is often implied that these surveys have also shown that 90\%-95\% (or more) of scientists agree that this climate change and global warming is human-caused. However, a close inspection of the survey results reveals that this is not true.

For instance, Doran and Zimmerman (2009) [146] sent a survey to over 10,000 Earth scientists and received more than 3000 responses. Of the 3146 respondents, $90 \%$ answered "risen" to the question, "When compared with pre-1800s levels, do you think that mean global temperatures have generally risen, fallen, or remained relatively constant?", i.e., they agreed that there has been global warming since "pre-1800s". However, the question they were asked on the causes of this warming was remarkably ambiguous: "Do you think human activity is a significant contributing factor in changing mean global temperatures?". While $82 \%$ of the respondents answered, "yes", Doran and Zimmerman neglected to ask them what percentage they considered to be "a significant contributing factor". In our experience, among the general public, "significant" is synonymous with "large" or "substantial", but among the scientific community, it generally means, "not insignificant", i.e., more than, e.g., $5 \%$. In other words, many of the respondents may still have felt that the recent global warming was mostly natural (or perhaps a mixture of human and natural factors).

On the other hand, Cook et al. (2013) [147] purported to be a survey of the scientific literature rather than the scientific community. The authors examined more than 10,000 abstracts from papers that matched the search phrases of either "global climate change" or "global warming". In total, 2/3 of the papers apparently expressed no position on the causes of global warming. Of the remaining abstracts, only $2.1 \%$ of the abstracts explicitly disputed that global warming was mostly human-caused and only $0.9 \%$ explicitly stated uncertainty over the causes of global warming. Therefore, they concluded that $97 \%$ of published scientific articles agreed that global warming is human-caused. However, as one of us has pointed out in Legates et al. (2015) [154], Cook et al. had neglected to mention that only $8 \%$ of the 11,944 abstracts had actually made any explicit claim on the causes of global warming. It is true that, of this $8 \%$, very few abstracts explicitly disputed the claim that recent global warming was mostly human-caused (3\%). However, similarly, very few abstracts explicitly endorsed the claim $(6 \%)$. The vast majority (91\%) of the abstracts that made an explicit claim on the causes of global warming merely implied that human activity was a factor, i.e., they did not state whether global warming was mostly human-caused or mostly natural.

Verheggen et al. (2014)'s survey of nearly 2000 climate scientists [149] was a bit more nuanced. However, a close inspection of the survey results reveals that only $38 \%$ of the respondents believed that recent global warming was entirely human-caused, and only $27 \%$ believed that it was mostly human-caused. Meanwhile $12 \%$ of respondents believed that it was mostly or entirely natural, $12 \%$ believed it was a mixture of both and 10\% did not know. Meanwhile Stenhouse et al. (2013)'s survey of nearly 2000 meteorologists [148] revealed that $52 \%$ believed that it was mostly or entirely human-caused, but that $15 \%$ believed it was mostly natural or a mixture of both, and $21 \%$ were unsure. The rest were not convinced that global warming would increase in the future.

In other words, there are actually several different perspectives among the scientific community as to the causes of recent global warming: 
- Paradigm 1. Recent global warming was mostly or entirely human-caused, and future climate change is going to be increasingly dominated by human-caused global warming

- Paradigm 2. Recent global warming was a mixture of human and natural causes. This means that the current climate models are probably underestimating the role of natural factors in the recent warming and are therefore probably overestimating the magnitude of human-caused global warming that we should expect.

- Paradigm 3. Recent global warming was mostly or entirely natural, and not human-caused. This implies that there is something fundamentally wrong with the computer models, and their projections of future human-caused global warming should be treated with skepticism.

This has important implications for our assessment of how much human-caused global warming we should expect under BAU. So, it is important to understand why there could be such disagreement among the scientific community on this fundamental point. To get an idea of why, in Figure 11, we consider two competing perspectives. The left-hand side, i.e., Figure 11a-f, illustrates a common take on the "mostly human-caused" paradigm as argued by the IPCC 5th Assessment Report [33]. The right-hand side, i.e., Figure 11g-l, summarizes the counter-arguments made by some of us in Soon et al. (2015) [152] and presents a perspective from the "mostly natural" paradigm. For a detailed discussion of each perspective, we refer readers to Chapter 10 of the IPCC 5th Assessment Report [33] and Soon et al. (2015) [152], respectively. However, in brief, the key differences are as follows:

- The IPCC argued that automated statistical homogenization techniques, such as Menne and Williams (2009) [155], are able to remove any non-climatic biases, such as the growth of urban heat islands, and therefore use as many stations as possible to estimate global temperature trends-regardless of whether they have been affected by urbanization bias or not. Soon et al. argued that those automated homogenization techniques are inadequate for that purpose, and therefore estimated global temperature trends using only rural (or mostly rural) stations.

- The IPCC argued that solar variability has been very low since the 19th century, and that solar activity has been, if anything, declining since the mid-20th century. Therefore, they only considered solar variability estimates that fit that narrative, e.g., Wang et al. (2005) [156] or Krivova et al. (2010) [157]. Soon et al. argued that all of the plausible estimates of solar variability in the literature should be considered, and they identified one which implied quite a substantial role for the Sun in global temperature changes since at least 1881, i.e., Scafetta and Willson (2014)'s updated version [158] of Hoyt and Schatten (1993) [159]—see also Scafetta et al. (2019) [160].

- The IPCC were therefore unable to explain any of the post-1950s global temperature trends in terms of natural factors and concluded that human-caused factors (chiefly increasing greenhouse gas concentrations) were needed to explain the warming since then. They therefore concluded that recent global warming was mostly (or entirely) human caused. On the other hand, Soon et al. were able to explain almost all of the temperature trends since 1881 in terms of changes in solar output. They therefore concluded that recent global warming was probably mostly (or entirely) natural.

\subsection{When Exactly Was "Pre-industrial"?}

The UNFCCC-organized 2015 Paris Agreement declared an international agreement to, "(hold) the increase in the global average temperature to well below $2{ }^{\circ} \mathrm{C}$ above pre-industrial levels and (pursue) efforts to limit the temperature increase to $1.5^{\circ} \mathrm{C}$ above pre-industrial levels" [19]. However, while this initially sounds like a very specific and definite agreement, a careful parsing of the wording reveals a remarkable degree of ambiguity about what exactly the agreement is agreeing to.

Implicit in the above agreement is the "recent global warming is mostly human-caused" paradigm described in Section 4.1. Pielke Jr. (2005) [161] has noted that the UNFCCC explicitly defines "climate change" as being entirely human-caused, and so it is therefore not surprising that their agreement does not consider the possibility that much (or even all) of this warming is natural. However, even if we ignore the ongoing debate over how much of the warming since the late-19th century is human-caused 
vs. natural, and assume for the sake of argument that the "mostly human-caused" argument is correct, what exactly is meant by "pre-industrial levels" [22,162,163]?

"Mostly human-caused" Paradigm (adapted from IPCC Working Group 1, 2013)
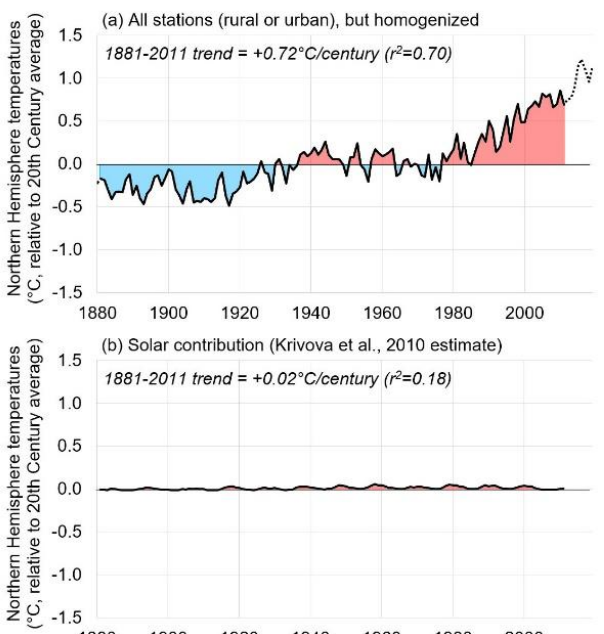

$\begin{array}{rllllll}1880 & 1900 & 1920 & 1940 & 1960 & 1980 & 2000\end{array}$
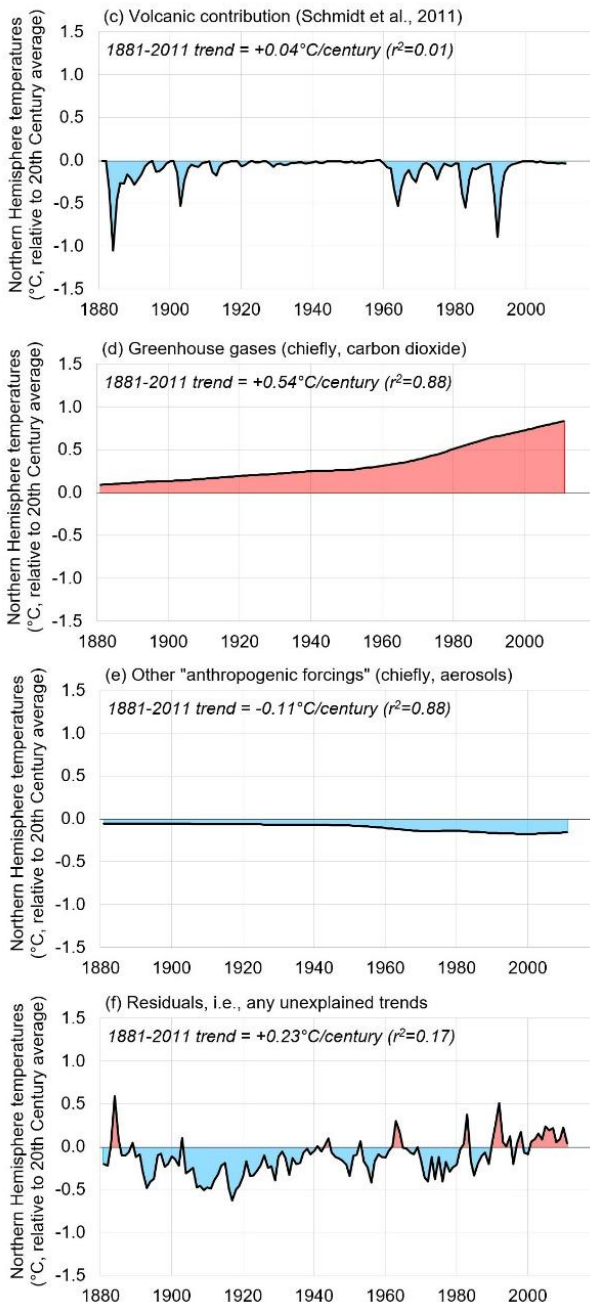

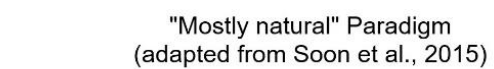

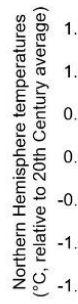

(g) Using rural stations only

$1881-2011$ trend $=+0.46^{\circ} \mathrm{C} /$ century $\left(r^{2}=0.31\right)$

疍 0.5

0.0

(1)

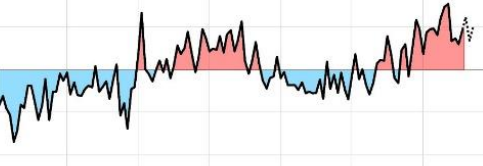

$\begin{array}{lllllll}880 & 1900 & 1920 & 1940 & 1960 & 1980 & 2000\end{array}$

फ. ब. 1.5 (h) Solar contribution (updated Hoyt \& Schatten, 1993 estimate)

$1881-2011$ trend $=+0.44^{\circ} \mathrm{C} /$ century $\left(r^{2}=0.58\right)$

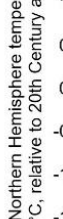

0.5

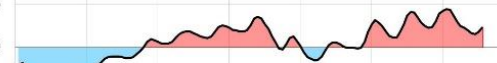

0.5

.

$\begin{array}{lllllll}1880 & 1900 & 1920 & 1940 & 1960 & 1980 & 2000\end{array}$
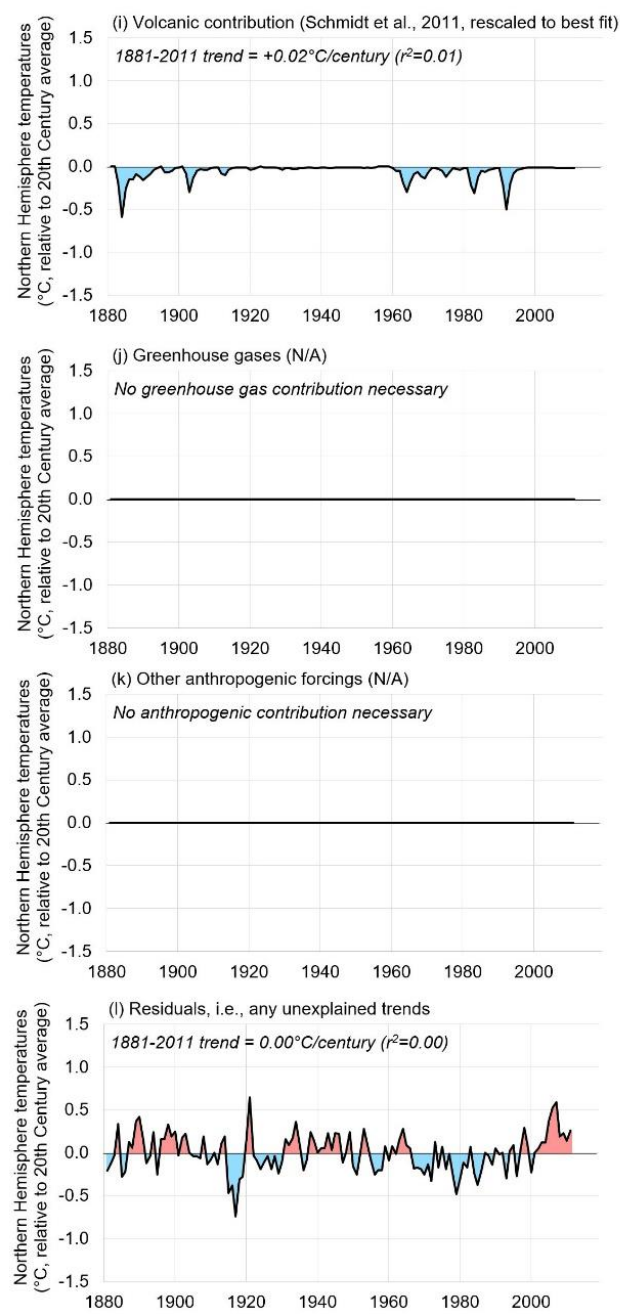

Figure 11. Example of two narratives from the competing $(\mathbf{a}-\mathbf{f})$ "recent global warming is mostly human-caused" and ( $\mathrm{g}-\mathbf{l})$ "recent global warming is mostly natural" paradigms. See text for a detailed discussion. The horizontal axes correspond to years. 
As noted by Hawkins et al. (2017) [162], "in the absence of a formal definition for preindustrial, the IPCC AR5 made a pragmatic choice to reference global temperatures to the mean of 1850-1900 when assessing the time at which particular temperature levels would be crossed". This decision seems to have been because several of the standard instrumentally based global temperature time series used by the IPCC began in 1850 or 1880. In the penultimate draft of the report, this period was apparently explicitly referred to as "preindustrial", but during the ensuing governmental approval session, this reference was removed.

Therefore, although the IPCC AR5 reports seem to have been considered during the drafting of the Paris Agreement, it is unclear which baseline was meant. Hawkins et al. (2017) argue that 1720-1800 would make a more suitable baseline for "pre-industrial" global average temperatures than 1850-1900, while Lüning and Vahrenholt (2017) [163] argue that 1940-1970 is the most suitable baseline. The choice of baseline is quite significant since paleoclimate reconstructions suggest that global average temperatures have varied substantially over the last millennium and earlier, e.g., refs. [164-170]. In particular, it seems that coincidentally the 18th and 19th centuries corresponded to a relatively cool period known as the "Little Ice Age". On this basis, Akasofu (2010) argued that much of the warming since the 19th century corresponded to a natural "recovery from the Little Ice Age" [171]. This would imply that using an 18th or 19th century baseline for "pre-industrial" would be too cold. By comparing the instrumental time series to various paleoclimate reconstructions, Lüning and Vahrenholt (2017) [163] argue that the 1940-1970 period was closer to the long-term global temperature average of the last few millennia. However, clearly, 1940-1970 is long after the start of the actual Industrial Revolution. Hawkins et al. (2017) argue that "pre-industrial" should be defined much earlier, e.g., 1720-1800 [162]. On the other hand, if the context of the baseline is to indicate a period before human activity had a significant influence on the climate, then some researchers have argued that humans were already significantly influencing the climate before the Industrial Revolution. E.g., Koch et al., 2019 [172] argue that depopulation from the disease epidemics in the Americas initiated by the arrival of Europeans in 1492 indirectly led to a substantial reforestation of the Americas, and that this might have caused a significant global cooling. On this basis, they argue that "the Great Dying of the Indigenous Peoples of the Americas resulted in a human-driven global impact on the Earth Systems in the two centuries prior to the Industrial Revolution" [172]. Ruddiman et al., 2016, argue that human influence on global average temperatures began even earlier-with the development of agriculture thousands of years ago [173].

At any rate, the question of which temperature baseline defines "pre-industrial levels" depends on how the global average temperature has varied over the last millennium or so. This turns out to be yet another topic of ongoing debate in the scientific literature. Up until the mid-1990s, it was generally accepted that before the Little Ice Age, sometime around 1000-1200, there was a Medieval Warm Period when global average temperatures were at least as warm as present, if not warmer. However, in the late-1990s, a series of paleoclimate reconstructions were published which implied that global average temperatures had been fairly constant for at least the last thousand years up until the end of the 19th century before rising sharply, e.g., [164]. In particular, the main figure of a highly cited paper, Mann et al., (1999) [164] was dubbed "the hockey stick graph" because its estimate of Northern Hemisphere temperatures since 1000 AD apparently looked similar to an ice hockey stick lying on the ground with the "blade" sticking up in the air. This graph featured prominently in the IPCC's 3rd Assessment Report (2001) [55], and appeared to confirm the claim of that report that global average temperature changes are currently dominated by human activities, and that the 20th century global warming was unprecedented in at least 1000 years. However, the striking claims of Mann et al. (1999) have been very controversial and contentious both in the scientific literature and in the wider public sphere. One important unanswered puzzle is the blending of proxy temperatures with instrumental thermometer data in the 20th century, which seems to have been a major component of the apparent "blade", as cautioned by Soon et al. (2004) [174]. Readers interested in a detailed discussion of the debate might find the books by Montford (2010) [175] and Mann (2013) [176] useful 
for seeing two opposing perspectives. Each of us has also written extensively on this debate elsewhere, e.g., $[113,150,151,177-179]$.

At any rate, within the scientific literature, the debate over both the Mann et al. (1999) "hockey stick" study (e.g., [150,151,177,180-189]) and the broader question of how the Medieval Warm Period and the Little Ice Age compare to the Current Warm Period (e.g., [165-168,170,190-196]) has been quite lively and contentious. This has been accentuated by the implications for the wider public debate over climate policy.

As an example of the contentious nature of this topic, in 2003, one of us (WS) co-authored two studies which disputed the claims of Mann et al. (1999), i.e., Soon and Baliunas (2003) [150] and Soon et al. (2003a) [151]. In response, Mann et al. (2003a) [181] criticized both of these studies. Although Soon et al. (2003b) [177] countered the criticism of Mann et al. (2003a) (see also Mann et al. (2003b)'s reply [182]), this coincided with considerable political pressure being placed on von Storch, the editor-in-chief of the journal that Soon and Baliunas (2003) had been published in. Although the founding editor of the journal defended the publication of the article [197], von Storch still chose to resign as editor-in-chief. However, ironically, the following year, von Storch also co-authored an article criticizing the Mann et al. (1999) study, i.e., von Storch et al. (2004) [186], which itself led to more debate with a group including one of the authors (Amman) of Mann et al. (2003a; 2003b), i.e., Wahl et al. (2006) [187] and von Storch et al. (2006) [189].

For readers who are interested in learning more about these debates and various other similar controversies that have arisen from the debate over this controversial topic, we recommend reading Connolly and Connolly (2014) [178]. However, it should already be apparent that this is another topic that includes several competing scientific paradigms. We can get an idea of these paradigms by considering Figure 12. Essentially, there appear to be four main paradigms when it comes to current views on how the Current Warm Period compares to the Little Ice Age and Medieval Warm Period:

- Paradigm 1. Until the end of the 19th century, global average temperatures were fairly constant, with if anything a gradual long-term cooling. This is consistent with the post-19th century warming being entirely human caused. An example of a reconstruction that fits this paradigm is the Mann et al. (1999) [164] reconstruction in Figure 12a.

- Paradigm 2. There was a Medieval Warm Period around 11th/12th centuries (or possibly a bit earlier), and the 18th/19th centuries were relatively cold (the Little Ice Age), but the Current Warm Period is warmer than the Medieval Warm Period was. This is consistent with much of the post-19th century warming being human caused, but also allows the possibility that some of it could be natural in origin (similar to the Medieval Warm Period). An example of a reconstruction that fits this paradigm is the D'Arrigo et al. (2006) [166] reconstruction in Figure 12b.

- Paradigm 3. There was a Medieval Warm Period around 11th/12th centuries (or possibly a bit earlier) and the 18th/19th centuries were relatively cold (the Little Ice Age), and the Medieval Warm Period was at least as warm as the Current Warm Period was. This is consistent with much of the post-19th century warming being natural in origin (similar to the Medieval Warm Period). An example of a reconstruction that fits this paradigm is the Moberg et al. (2005) [165] reconstruction in Figure 12c.

- Paradigm 4. There are still too many inconsistencies between the various reconstructions and uncertainties and poorly justified assumptions associated with many of the underlying proxy series for us to establish how the globally representative averaged temperature changes during the current period compared to those over the last millennium or longer. Some of these problems and uncertainties have been described by, e.g., [178,183-185,190-192,198,199].

The debate over the relative warmth of the Medieval Warm Period, Little Ice Age and Current Warm Period has continued, and appears to be ongoing. For instance, while the PAGES-2K (2019) reconstruction [170] appears to support Paradigm 1 or 2, the Ljungqvist (2010) [168] reconstruction appears to support Paradigm 3. Meanwhile Shi et al. (2013) [193] provide three different reconstructions 
all using the same data but different methods for processing the data. Each of the three Shi et al. (2013) reconstructions appears to support a different one of the first three paradigms. Some might argue that this in itself supports Paradigm 4.
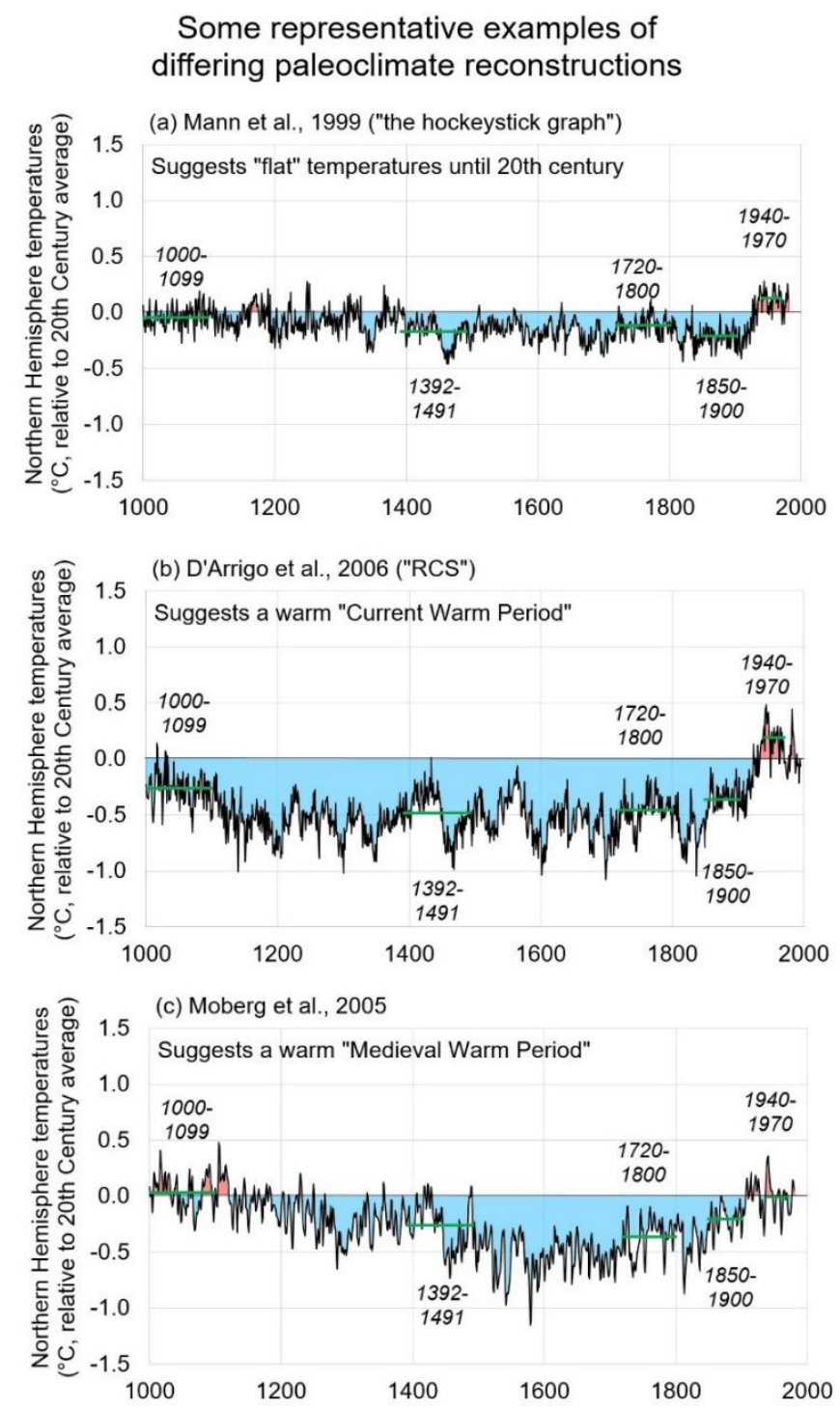

Figure 12. Examples of some of the different paleoclimate reconstructions for Northern Hemisphere temperature trends since 1000. (a) Mann et al. (1999) [164]; (b) D'Arrigo et al. (2006) [166]; (c) Moberg et al. (2005) [165]. The time series were downloaded from NOAA NCEI's Paleoclimatology public data repository, https://www.ncdc.noaa.gov/data-access/paleoclimatology-data (Accessed: January 2020). Highlighted dates correspond to different proposed baseline periods for the "pre-industrial" era, as discussed in the text. The horizontal axes correspond to years.

Another issue that should be noted is that we did not include any thermometer-based time series in Figure 12. Many groups have chosen to superimpose the instrumental record on top of the proxy-based series, e.g., refs. [164-170]. As noted by e.g., Soon et al. (2004) [174] and Ljungqvist (2010) [168], because the proxy-based series tend to show less variability than the direct instrumental record, this has the visual effect of artificially making the Current Warm Period seem warmer than it would otherwise.

At any rate, it should be apparent that there are many plausible baseline periods for defining "pre-industrial temperatures", but because climate change was also occurring during the pre-industrial era, you could end up with different answers depending on whether you chose a relatively cool 
period or a relatively warm period. However, we suggest that the underlying motivation behind the Paris Agreement was not to define any particular pre-industrial period as having a supposedly ideal global temperature. Rather, to us, the motivation seems to have been to attempt to minimize the magnitude of future human-caused global warming that was specifically due to increasing greenhouse gas concentrations.

With this in mind, we argue that a better metric to use for defining "pre-industrial levels" is to assume the Paris Agreement is only referring to changes in global temperature that are due to human-caused global warming from increasing greenhouse gases above pre-industrial levels. Therefore, for our analysis, we will calculate the estimated human-caused global warming up to 2100 under BAU in terms of the increases in greenhouse gases relative to "pre-industrial levels". We will define "pre-industrial levels" as that implied by the Antarctic ice cores, although we remind the reader of the controversies over the reliability of these estimates, which we discussed in Section 3.

\section{How "Sensitive" Is the Global Average Temperature to Changes in Greenhouse Gas Concentrations?}

If we assume that the changes in atmospheric greenhouse gas concentrations up to 2100 under Business-As-Usual conditions are indeed as proposed in Section 3.5, that still does not tell us how much Anthropogenic Global Warming this would cause. In order to establish this, we need to know what the "climate sensitivity" is, i.e., how much human-caused global warming is generated by an increase in greenhouse gases (typically defined in terms of a doubling of $\mathrm{CO}_{2}$ ). Unfortunately, there is as of yet still no consensus on what the actual "climate sensitivity" is, e.g., see Knutti et al. (2017) for a list of several hundred estimates [200].

\subsection{Climate Sensitivity Paradigms}

Part of the reason for the ongoing debate over the "climate sensitivity" is that nobody has been able to directly measure it. Although it has been well established experimentally that: (i) each of the greenhouse gases is infrared-active, e.g., Tyndall (1861) [31]; (ii) the presence of greenhouse gases in the Earth's atmosphere alters the shape of the outgoing infrared spectrum of the Earth, e.g., Harries et al. (2001) [201]; and (iii) globally-averaged surface temperatures have on average increased since the late-19th century, e.g., see the discussion in Section 4, there have (as yet!) been no experimental measurements that have directly demonstrated and quantified the proposed increase in atmospheric temperatures specifically from increasing greenhouse gases. We urge readers to note the nuance in this statement-as we will discuss in this section, there have indeed been many computer model-based, theoretical, or semi-empirical studies that have attempted to quantify the influence of increasing greenhouse gases on atmospheric temperature (and particularly surface temperatures). However, none of these studies have been able to directly demonstrate and quantify experimentally the proposed increase in atmospheric temperatures from an increase in atmospheric greenhouse gas concentrations.

In other words, it has not been directly established experimentally how "sensitive" the global average temperature is to changes in greenhouse gas concentrations. Instead, attempts have either been indirect by fitting the changes in greenhouse gas concentrations to global temperature trends (e.g., refs. [37,152,202-205]), computer model-based (e.g., refs. [2,8,10,206]), or relying on theoretical and/or semi-empirical models or assumptions (e.g., refs. [207-209]). We stress that this does not invalidate the attempts, but it means that the estimates that are obtained often depend heavily on the theoretical assumptions explicit (or implicit) in the approach taken. As in previous sections, we have identified several distinct paradigms within the literature on this topic, and each of them appear to involve different assumptions (implicit or explicit):

- Paradigm 1: "Global warming is mostly or entirely human-caused". Changes in greenhouse gas concentrations are the primary driver of global temperature change, especially in recent decades, and the long-term warming since the late-19th century is mostly (if not entirely) due to human-caused greenhouse gas emissions. Within this paradigm, there is generally less interest 
in trying to understand the causes of recent climate change, and instead the focus is largely on quantifying future climate change from increasing greenhouse gas concentrations, e.g., Andronova and Schlesinger (2001) [202]; Hegerl et al. (2006) [210]; Chylek et al. (2007) [211]; Aldrin et al. (2012) [212]; Ring et al. (2012) [203]; Lewis (2013) [213]; Shindell (2014) [214]; Skeie et al. (2014) [215]; Lovejoy (2014) [205]; Monckton et al. (2015a) [216]; Bates (2016) [209]; Marvel et al. (2016) [206]; Lewis and Curry (2018) [208]; Shurer et al. (2018) [217].

- Paradigm 2: "Global warming is a mixture of human-caused and natural factors". It is assumed that human-caused greenhouse gas emissions are a significant driver of recent global temperature change (as in Paradigm 1), but that natural climate change has probably also been a significant driver. Within this paradigm, satisfactorily establishing the relative roles of natural and human-caused factors in recent climate change is a primary focus since this strongly influences both our understanding of recent climate change and our expectations for future climate change. For instance, if $50 \%$ of the warming since the late-19th century was due to natural climate change, then this suggests that the future warming from increasing greenhouse gases would probably only be at most half of what might be expected if $100 \%$ of the warming was due to greenhouse gases, e.g., Idso (1998) [218]; Loehle and Scafetta (2011) [219]; Ziskin and Shaviv (2012) [220]; Loehle (2014) [221]; Spencer and Braswell (2014) [222]; van der Werf and Dolman (2014) [223]; Wyatt and Curry (2014) [224]; Lim et al. (2014) [225]; Harde (2017) [226]; Christy and McNider (2017) [227]; McKitrick and Christy (2018) [228].

- Paradigm 3: "Global warming is mostly or entirely natural". Greenhouse gases are not necessarily a major driver of global temperature change, and most (or all) of the warming since the late-19th century is due to the same natural climatic changes that have occurring since long before the Industrial Revolution. Within this paradigm, there is generally less interest in describing future climate change (which is typically assumed to be comparable to the climate changes experienced over the last few millennia). Instead, the primary focus tends to be on better quantifying the magnitudes and causes of past climate changes, e.g., Carter and Gammon (2004) [153]; Svensmark (2007) [229]; Eschenbach (2010); Loehle and Singer (2010) [230]; Carter (2010) [113]; Shaviv et al. (2014) [231]; Lüning and Vahrenholt (2015) [232]; Soon et al. (2015); Svensmark et al. (2016) [233]; Lüning and Vahrenholt (2016) [234]; Kravtsov et al. (2018) [235].

Within Paradigm 1, there are actually several competing philosophies and approaches that largely boil down to the fundamental question of whether or not the results from computer model simulations of potential future climate change are more relevant than observations of recent climate change. Within Paradigms 2 and 3, the fact that this question is debated can seem largely incomprehensible as it is usually assumed that empirical observations automatically take precedence over computer model results (the four of us can vouch for this since most of our climate change research has been based on either Paradigm 2 or 3 and it has been difficult for us to appreciate the unquestioned credibility afforded to computer model results by many in the scientific community). This is even the case for some working within Paradigm 1, e.g., Schwartz (2008) [236]. However, within Paradigm 1, the debate is considered non-trivial, e.g., see the debate over the Schwartz (2007) [237] study between Knutti et al. (2008) [238] and Schwartz (2008) [236], or that over Monckton et al. (2015a) [216] between Richardson et al. (2015) [239] and Monckton et al. (2015b) [240].

Given that Paradigm 1 assumes that greenhouse gas concentrations are the primary driver of climate change and is largely concerned with estimating future climate change if carbon dioxide doubles or trebles (along with other increasing greenhouse gases), the recent climate changes that have been experienced up to present are considered to be just the beginning of increasingly substantial human-caused global warming. As a result, many researchers within this paradigm, argue that the computer model projections of future global warming under substantially increased greenhouse gas concentrations provide more insight into future global warming than the experimental observations up to present, e.g., refs. $[8,206,238,239]$. That is, in terms of understanding the climate changes to be expected from increasing $\mathrm{CO}_{2}$, the computer model projections are considering concentrations twice, 
four times, or more that of pre-industrial $\mathrm{CO}_{2}$, while the historical observations still only cover a period where $\mathrm{CO}_{2}$ has still only increased by less than $45 \%$ relative to the pre-industrial concentrations implied by the Antarctic ice cores. Moreover, because the computer model simulations can provide continuous and complete values for every aspect of the model's climate system, the time series and results that can be extracted from the model simulations are very tidy, comprehensive, and precise, while experimental measurements of the real climate system are often based on an incomplete sampling network, and may be affected by various non-climatic biases and instrument errors [238].

On the other hand, other researchers argue that the computer model projections are only describing climate change in a computer model world. They argue that if you want to understand how the climate changes in the real world, you will get more realistic answers if you base them on actual experimental observations [236].

Meanwhile, many researchers argue that running a typical Global Climate Model simulation with the latest code requires a large computational expense (a typical run can take a few weeks or even months to complete for a climate modelling group even using high-end supercomputers). Furthermore, the simulations arguably report far more information than is necessary for most studies. As a result, a lot of climate sensitivity studies are based on relatively simple analytical models or theoretical frameworks that do not require the computational expense of a full Global Climate Model simulation. With this in mind, it can be helpful to divide Paradigm 1 into three sub-paradigms:

- Paradigm 1a: For estimating the future climate change that would occur if $\mathrm{CO}_{2}$ doubles or quadruples, the latest simulations from the most up-to-date Global Climate Models are probably more reliable than extrapolating from historical observations, e.g., Knutti et al. (2008) [238]; Shindell (2014) [214]; Marvel et al. (2016) [206]; Gregory and Andrews (2016) [241]; Rohrschneider et al. (2019) [242]; Forster et al. (2020) [243].

- Paradigm 1b: The use of relatively simple analytical models or theoretical frameworks (preferably coupled to historical observations) offers a quicker and more flexible method for estimating future climate changes, e.g., Aldrin et al. (2012) [212]; Lewis (2013) [213]; Geoffroy et al. (2013) [244]; Skeie et al. (2014) [215]; Monckton et al. (2015a) [216]; Bates (2016) [209]; Lewis and Curry (2018) [208].

- Paradigm 1c: The most realistic (or, at least, the most compelling) estimates of climate sensitivity are probably ones that are derived from historical observations, although the calculations often require making theoretical assumptions that can be subjective, e.g., Andronova and Schlesinger (2001) [202]; Edwards et al. (2007) [245]; Chylek et al. (2007) [211]; Schwartz (2007) [237]; (2008) [236]; Ring et al. (2012) [203]; Lovejoy (2014) [205].

\subsection{Different Climate Sensitivity Definitions and Estimates}

The computational power of the first climate model simulations in the 1960s, 1970s, and 1980s was very limited compared to today. As a result, most of the early attempts to model the effects that increasing $\mathrm{CO}_{2}$ would have on the climate tended to focus on idealized hypothetical scenarios where the atmospheric $\mathrm{CO}_{2}$ concentration was doubled relative to the concentration of the time. Modelers would run these " $2 \times \mathrm{CO}_{2}$ " simulations until the climate system in the model world had equilibrated. This climate system was then compared with the results from a similar model world where the atmospheric $\mathrm{CO}_{2}$ was the same as present (i.e., " $1 \times \mathrm{CO}_{2}$ "), e.g., Manabe and Wetherald (1975) [2]. The difference between the globally averaged temperatures of the two simulations came to be known as the "Equilibrium Climate Sensitivity" (ECS).

In a well-cited National Research Council report in 1979 [246], led by Jule Charney (and hence commonly referred to as "the Charney report"), the results of such ECS simulations from several computer modelling groups were used to conclude that a doubling of atmospheric $\mathrm{CO}_{2}$ would probably lead to $1.5-4.5^{\circ} \mathrm{C}$ of human-caused global warming. Schlesinger (1986) noted that although the simulations from these "general circulation models" did indeed imply a similar range of climate sensitivity estimates $\left(1.3-4.2{ }^{\circ} \mathrm{C}\right.$, taken from seven separate studies), alternative approaches led to 
different ranges [8]. He found three different studies that used "surface energy balance models", but implied the climate sensitivity was anywhere in the range $0.24-9.6^{\circ} \mathrm{C}$. He also found estimates from 17 studies using "radiative-convective models", and these implied that the range was $0.48-4.20^{\circ} \mathrm{C}$.

Nonetheless, van der Sluijs et al. (1998) noted that, "in international assessments of the climate issue, the consensus-estimate of 1.5 to $4.5^{\circ} \mathrm{C}$ for climate sensitivity has remained unchanged for two decades" [247]. More recently, Knutti et al. (2017) confirmed that, still, "the consensus on the 'likely' range for climate sensitivity of 1.5 to $4.5^{\circ} \mathrm{C}$ today is the same as given by Jule Charney in 1979" [200]. We will return to this question later, but for now we note that the most recent IPCC 5th Assessment Report (2013) also argued that the "likely" value for the Equilibrium Climate Sensitivity was probably in the range $1.5-4.5^{\circ} \mathrm{C}$ [15].

At any rate, by the mid-1980s, it was already apparent that the long-term global warming since 1880 was at least half of what would have been expected from the ECS values, given the increase in atmospheric $\mathrm{CO}_{2}$ that had already occurred. However, Schlesinger (1986) argued that this did not mean the climate models were wrong. Instead, he argued that the problem was that the ECS values were for equilibrium conditions and that, "the actual response of the climate system lags the equilibrium response because of the thermal inertia of the ocean" [8]. Bryan et al. (1982) had referred to this apparent lag as being the "Transient Climate Response to increasing atmospheric carbon dioxide" [248], and the term Transient Climate Response (TCR) is now generally used to refer to the climate sensitivity that would be observed as carbon dioxide gradually doubles over a multidecadal period (typically defined as a $1 \% /$ annum increase over 70 years).

Computational power has improved dramatically over the decades, and since the 2000s, it has become increasingly standard for climate modelling groups to carry out Transient Climate Response simulations where $\mathrm{CO}_{2}$ gradually increases over time as well as the original " $2 \times \mathrm{CO}_{2}$ " Equilibrium Climate Sensitivity simulations (and more recently, " $4 \times \mathrm{CO}_{2}$ " simulations [249]), e.g., refs. $[217,244,250-256]$. The climate sensitivity estimates implied by the Transient Climate Response simulations are typically a good bit lower than those from the Equilibrium Climate Sensitivity simulations. That is, the expected human-caused global warming for a doubling of $\mathrm{CO}_{2}$ is typically a good bit lower for the TCR estimates than the ECS estimates, e.g., Forster et al. (2013) estimate the ECS to be in the range $1.90-4.54^{\circ} \mathrm{C}$ with a most-likely value of $3.22^{\circ} \mathrm{C}$, while they estimate the TCR to be in the range $1.19-2.45{ }^{\circ} \mathrm{C}$ with a most-likely value of $1.82{ }^{\circ} \mathrm{C}$ [254].

Within Paradigm 1, it is now generally accepted that the reason why the climate sensitivities implied by the TCR simulations is lower than that from the ECS simulations is that proposed by Bryan et al. (1982) [248] and Schlesinger (1986) [8]. That is, in the computer model world, some of the extra "greenhouse heating" from increasing greenhouse gas concentrations is temporarily absorbed by the oceans, but because the model oceans have a large heat capacity and relatively slow circulation rates, this can take decades or even centuries of time (in model "years") before the climate system has fully equilibrated, see, e.g., Gregory and Mitchell (1997) [250]; Raper et al. (2002) [255]; Gregory et al. (2004) [251]; Hansen et al. (2005) [257]; Dufresne and Bony (2008) [258]; Winton et al. (2009) [256]; Held et al. (2010) [253]; Geoffroy et al. (2013) [244]; Gregory et al. (2015) [252]. According to this theory, even if $\mathrm{CO}_{2}$ concentrations stop increasing once they have doubled, the human-caused global warming will continue to rise over time until the oceans have equilibrated. At that point, the expected warming will be that of the ECS rather than the initial TCR. However, the models also predict that this could potentially take centuries, meaning that the lower TCR estimates are the ones that are most relevant for the coming century. Hope (2015) has even argued that finding out a more accurate value for the TCR has a "\$10 trillion value" [259]. Hansen et al. (2005) argue that the exact length of this proposed "lag" should increase with ECS, e.g., they argue that for an ECS of $\sim 1^{\circ} \mathrm{C}$, the lag could be as short as a decade, but for an ECS of $\sim 4{ }^{\circ} \mathrm{C}$ or greater, the lag could be a century or longer [257].

On the other hand, while these arguments carry a lot of weight within Paradigm 1a, many researchers from outside that paradigm are unimpressed by claims that we should base our policies solely on computer model predictions of how the climate would hypothetically change over multiple 
centuries into the future. Partly for that reason, a lot of researchers have tried to estimate the true climate sensitivity to greenhouse gases guided by observations of how the climate has changed already. As discussed in the previous section, different researchers have attempted this from within different paradigms.

Some of those working from within Paradigm $1 \mathrm{~b}$ or $1 \mathrm{c}$ have obtained similar estimates to those of the climate models, e.g., Otto et al. (2013) estimated the ECS is in the range $1.2-3.9{ }^{\circ} \mathrm{C}$ and that the TCR is in the range $0.9-2.0^{\circ} \mathrm{C}$ [207]. However, others find that the climate sensitivity is significantly smaller for both TCR and ECS, e.g., Lewis and Curry (2018) estimate the ECS is $1.05-2.45^{\circ} \mathrm{C}$ and the TCR is $0.9-1.7^{\circ} \mathrm{C}$ [208]; while Bates (2016) [209] estimates the ECS at $0.85-1.30^{\circ} \mathrm{C}$ and Lindzen and Choi (2011) [260] estimate it at $0.5-1.3^{\circ} \mathrm{C}$.

Many of the estimates based on Paradigm 2, i.e., assuming that some of the warming since the 19th century may have been natural, suggest climate sensitivities that are even lower still, e.g., Idso (1998) calculated a maximum climate sensitivity (equivalent to either ECS or TCR) of $0.4{ }^{\circ} \mathrm{C}$, while Zisking and Shaviv (2012) calculated a climate sensitivity range that is equivalent to an ECS of $0.69-1.26^{\circ} \mathrm{C}$.

We have found very few studies working from within Paradigm 3 that provide a climate sensitivity value. This seems to be because if you are finding (or assuming) that the global warming since the late 19th century is mostly or entirely natural (and therefore not a result of increasing $\mathrm{CO}_{2}$ ), then there is less motivation for estimating these values. However, as part of our analysis in Soon et al. (2015) [152] (which we summarized in Section 4.1), we argued that-after accounting for urbanization bias, and using the updated Hoyt and Schatten (1993) [231,232] estimate for solar variability-the residuals left implied a maximum climate sensitivity of $0.44{ }^{\circ} \mathrm{C}$ for a doubling of $\mathrm{CO}_{2}$. Although we did not define it there in terms of ECS or TCR, in this case, this would probably be most equivalent to an upper bound for TCR. However, as discussed in Section 4.1, even adding this small role for $\mathrm{CO}_{2}$ did not substantially improve the fit to the observed temperature trends from 1881-2014, i.e., it suggested that the climate sensitivity to greenhouse gases was very small or even zero [152].

At any rate, for the purposes of the final stage of our analysis, regardless of whether we use the TCR or ECS estimates, what value should we assume for the climate sensitivity? The IPCC 5th Assessment Report (2013)'s "likely" estimate for the TCR climate sensitivity is in the range $1.0^{\circ} \mathrm{C}-2.5^{\circ} \mathrm{C}$. They consider it "extremely unlikely" to be higher than $3.0^{\circ} \mathrm{C}$. They argue that the ECS, "is likely in the range $1.5^{\circ} \mathrm{C}$ to $4.5^{\circ} \mathrm{C}$ (high confidence), extremely unlikely less than $1^{\circ} \mathrm{C}$ (high confidence), and very unlikely greater than $6^{\circ} \mathrm{C}$ (medium confidence)" [33]. However, as can be seen from the list of estimates in Table 5, there is a wide range of estimates for both the ECS and TCR, and several of these estimates include values that are outside the IPCC's range. This is actually only a partial sample of the various estimates available in the literature. For a more complete list, Knutti et al. (2017) [200] provide a summary of hundreds of estimates for both TCR and ECS.

Given that the 2015 Paris Agreement has set an international, but voluntary, target of keeping human-caused global warming below $2{ }^{\circ} \mathrm{C}$, it should be apparent that establishing whether the actual values are at the high end or at the low end of the IPCC's ranges (or outside their ranges) has huge implications for what exactly the Paris Agreement has agreed to. More specifically for this study, in order to estimate how much human-caused global warming we should expect for our projected BAU increases in atmospheric greenhouse gas concentrations, we need to establish what the actual climate sensitivity is. However, as can be seen from Table 4, there are many different estimates of both the TCR and ECS published in the literature. 
Table 5. Various different estimates of the climate sensitivity, i.e., expected human-caused global warming from a doubling of atmospheric $\mathrm{CO}_{2}$, in terms of either Equilibrium Climate Sensitivity (ECS) or Transient Climate Response (TCR). The estimates are in no way meant as comprehensive (see Knutti et al. 2018 [200] for a summary of several hundred estimates in the literature), but are rather an illustrative sample of typical values in the literature, with examples taken from each of the paradigms described in the text. The values accompanied by a t correspond to the most-likely, mean, or median value if provided by the study.

\begin{tabular}{|c|c|c|c|}
\hline Study & Paradigm & ECS (or Equivalent) & TCR (or Equivalent) \\
\hline "Charney Report" (1979) [246] & 1 & $1.5-4.5^{\circ} \mathrm{C}$ & - \\
\hline Schlesinger (1986) [8] & 1 & $0.24-9.6^{\circ} \mathrm{C}$ & - \\
\hline IPCC AR1 (1990) [53] & 1 & $1.5-4.5^{\circ} \mathrm{C}$ & - \\
\hline IPCC AR2 (1995) [54] & 1 & $1.5-4.5^{\circ} \mathrm{C}$ & - \\
\hline IPCC AR3 (2001) [55] & 1 & $1.5-4.5^{\circ} \mathrm{C}$ & $1.1-3.1^{\circ} \mathrm{C}$ \\
\hline IPCC AR4 (2007) [56] & 1 & $2.0-4.5^{\circ} \mathrm{C}$ & $1.0-3.0^{\circ} \mathrm{C}$ \\
\hline IPCC AR5 (2013) [33] & 1 & $1.5-4.5^{\circ} \mathrm{C}$ & $1.0-2.5^{\circ} \mathrm{C}$ \\
\hline Gregory and Andrews (2008) [261] & $1 \mathrm{a}$ & - & $1.3-2.3^{\circ} \mathrm{C}$ \\
\hline Vial et al. (2013) [249] & $1 \mathrm{a}$ & $1.9-4.4^{\circ} \mathrm{C}$ & - \\
\hline Forster et al. (2013) [254] & $1 \mathrm{a}$ & $1.90-4.54{ }^{\circ} \mathrm{C}\left(+3.22^{\circ} \mathrm{C}\right)$ & $1.19-2.45^{\circ} \mathrm{C}\left(+1.82^{\circ} \mathrm{C}\right)$ \\
\hline Shindell (2014) [214] & $1 \mathrm{a}$ & - & $>1.3^{\circ} \mathrm{C}$ \\
\hline Marvel et al. (2016) [206] & $1 \mathrm{a}$ & $\sim 3.0^{\circ} \mathrm{C}$ & $\sim 1.8^{\circ} \mathrm{C}$ \\
\hline Zelinka et al. (2020) [262] & $1 \mathrm{a}$ & $1.8-5.6^{\circ} \mathrm{C}$ & - \\
\hline Lindzen \& Choi (2011) [260] & $1 b$ & $0.5-1.3^{\circ} \mathrm{C}\left(+0.7^{\circ} \mathrm{C}\right)$ & - \\
\hline Aldrin et al. (2012) [212] & $1 b$ & $0.7-4.3^{\circ} \mathrm{C}\left(+2{ }^{\circ} \mathrm{C}\right)$ & - \\
\hline Otto et al. (2013) [207] & $1 b$ & $1.2-3.9^{\circ} \mathrm{C}\left(+2.0^{\circ} \mathrm{C}\right)$ & $0.9-2.0^{\circ} \mathrm{C}\left(+1.3^{\circ} \mathrm{C}\right)$ \\
\hline Skeie et al. (2014) [215] & $1 b$ & $0.9-3.2^{\circ} \mathrm{C}\left(+1.8^{\circ} \mathrm{C}\right)$ & $0.79-2.2^{\circ} \mathrm{C}\left(+1.4^{\circ} \mathrm{C}\right)$ \\
\hline Monckton et al. (2015a) [216] & $1 b$ & $0.8-1.3^{\circ} \mathrm{C}\left(+1.05^{\circ} \mathrm{C}\right)$ & $0.8-1.3^{\circ} \mathrm{C}\left(+1.05^{\circ} \mathrm{C}\right)$ \\
\hline Bates (2016) [209] & $1 b$ & $0.85-1.30^{\circ} \mathrm{C}\left(+1.05^{\circ} \mathrm{C}\right)$ & - \\
\hline Lewis and Grünwald (2018) [263] & $1 b$ & $1.1-4.05^{\circ} \mathrm{C}\left(+1.87^{\circ} \mathrm{C}\right)$ & - \\
\hline Lewis and Curry (2018) [208] & $1 b$ & $1.05-2.45^{\circ} \mathrm{C}\left(+1.50^{\circ} \mathrm{C}\right)$ & $0.9-1.7^{\circ} \mathrm{C}\left(+1.20^{\circ} \mathrm{C}\right)$ \\
\hline Schurer et al. (2018) [217] & $1 b$ & - & $1.2-2.4^{\circ} \mathrm{C}\left(+1.7^{\circ} \mathrm{C}\right)$ \\
\hline Andronova and Schlesinger (2001) [202] & $1 c$ & $1.0-9.3^{\circ} \mathrm{C}$ & - \\
\hline Lea (2004) [264] & $1 c$ & $4.4-5.6^{\circ} \mathrm{C}$ & - \\
\hline Hegerl et al. (2006) [210] & $1 c$ & $1.6-6.2^{\circ} \mathrm{C}\left(+2.5^{\circ} \mathrm{C}\right)$ & - \\
\hline Chylek et al. (2007) [211] & $1 \mathrm{c}$ & $1.1-1.8^{\circ} \mathrm{C}$ & - \\
\hline Schwartz (2007) [237] & 1c & $0.6-1.6^{\circ} \mathrm{C}\left(+1.1^{\circ} \mathrm{C}\right)$ & - \\
\hline Schwartz (2008) [236] & $1 \mathrm{c}$ & $0.9-2.9^{\circ} \mathrm{C}\left(+1.9^{\circ} \mathrm{C}\right)$ & - \\
\hline Ring et al. (2012) [203] & $1 \mathrm{c}$ & $1.45-2.01^{\circ} \mathrm{C}\left(+1.6^{\circ} \mathrm{C}\right)$ & - \\
\hline Masters (2014) [265] & $1 \mathrm{c}$ & $1.2-5.1^{\circ} \mathrm{C}\left(+2.0^{\circ} \mathrm{C}\right)$ & - \\
\hline Lovejoy (2014) [205] & $1 \mathrm{c}$ & $2.5-3.66^{\circ} \mathrm{C}\left(+3.08^{\circ} \mathrm{C}\right)$ & - \\
\hline Idso (1998) [218] & 2 & $<0.4{ }^{\circ} \mathrm{C}$ & $<0.4^{\circ} \mathrm{C}$ \\
\hline Loehle and Scafetta (2011) [219] & 2 & $<1-1.5^{\circ} \mathrm{C}$ & $<1-1.5^{\circ} \mathrm{C}$ \\
\hline Ziskin and Shaviv (2012) [220] & 2 & $0.69-1.26^{\circ} \mathrm{C}\left(+0.93^{\circ} \mathrm{C}\right)$ & - \\
\hline van der Werf and Dolman (2014) [223] & 2 & - & $1.0-3.3^{\circ} \mathrm{C}\left(+1.6^{\circ} \mathrm{C}\right)$ \\
\hline Spencer and Braswell (2014) [222] & 2 & $1.3-2.2^{\circ} \mathrm{C}$ & - \\
\hline Loehle (2014) [221] & 2 & $1.75-2.23^{\circ} \mathrm{C}\left(+1.99^{\circ} \mathrm{C}\right)$ & $0.96-1.23^{\circ} \mathrm{C}\left(+1.09^{\circ} \mathrm{C}\right)$ \\
\hline Specht et al. (2016) [266] & 2 & $0.4^{\circ} \mathrm{C}$ & - \\
\hline Harde (2017) [226] & 2 & $0.7^{\circ} \mathrm{C}$ & - \\
\hline Christy and McNider (2017) [227] & 2 & - & $0.84-1.36^{\circ} \mathrm{C}\left(+1.10^{\circ} \mathrm{C}\right)$ \\
\hline Soon et al. (2015) [152] & 3 & - & $<0.44^{\circ} \mathrm{C}$ \\
\hline
\end{tabular}

Therefore, rather than considering just one value for the climate sensitivity, for the rest of our analysis, we will consider a range of six different values for TCR: $0.5,1.0,1.5,2.0,2.5$, and $3.0^{\circ} \mathrm{C}$ This covers the IPCC's current "likely" range of $1.0-2.5^{\circ} \mathrm{C}$, but also considers a lower value of $0.5^{\circ} \mathrm{C}$, recognizing that several recent studies have argued that the TCR could be less than $1.0{ }^{\circ} \mathrm{C}$, e.g., refs. $[152,207,208,215,216,219,221,227]$ as well as a higher value of $3.0^{\circ} \mathrm{C}$. Similarly, we consider a range of six different values for ECS $\left(1,2,3,4,5\right.$, and $\left.6^{\circ} \mathrm{C}\right)$, which encompasses the IPCC's current "likely" range of $1.5-4.5{ }^{\circ} \mathrm{C}$, but also considers the possibility that the ECS might be lower than $1.5{ }^{\circ} \mathrm{C}$, e.g., refs. [202,207-209,211,212,215,216,218-220,222,226,236,237,260,263,265,266] or that it might be higher than $4.5^{\circ}$ C, e.g., refs. [202,210,262,264,265]. We also stress that if Soon et al. (2015) are correct, then the TCR is less than $0.44{ }^{\circ} \mathrm{C}$ [152], i.e., less than the lowest value of $0.5^{\circ} \mathrm{C}$ that we will consider in this analysis. In that case, the expected human-caused global warming under BAU will be even smaller. 
5.3. Converting Projected Greenhouse Gas Concentrations into Projected Human-Caused Global Warming for Different Transient Climate Response and Equilibrium Climate Sensitivity Estimates

Both the TCR and ECS metrics are typically defined in terms of a doubling of atmospheric $\mathrm{CO}_{2}$ concentrations. However, our BAU projections of future greenhouse gas concentrations from Section 3.5 describe annual changes. Therefore, we need to come up with a suitable approach to translating a metric in terms of a doubling to the expected annual changes. Moreover, as discussed in the previous section, according to Paradigm 1, the equilibration time required for the ECS values to be reached is in the order of centuries, e.g., refs. [244,250-253,255-258]. Hence, since our projections only cover the $\sim 80$-year period up to the end of the 21st century, we will need to convert the ECS values into estimates of the shorter term warming that would have occurred up to 2100. Finally, since we are also considering the potential contributions of $\mathrm{CH}_{4}$ and $\mathrm{N}_{2} \mathrm{O}$, we will need to translate these $\mathrm{CO}_{2}$-defined metrics into metrics that are also relevant for $\mathrm{CH}_{4}$ and $\mathrm{N}_{2} \mathrm{O}$.

Let us consider the final problem first. Myhre et al. (1998) [267] and others (e.g., refs. [10,268-271]) argue that the expected relationship between increasing concentrations and global temperatures should be different for $\mathrm{CO}_{2}, \mathrm{CH}_{4}$, and $\mathrm{N}_{2} \mathrm{O}$, since they each have different infrared activities as well as different calculated atmospheric lifespans. Therefore, in order to convert an increase in concentration of a non- $\mathrm{CO}_{2}$ greenhouse gas into a $\mathrm{CO}_{2}$-equivalent concentration change, it has become standard practice to multiply the concentration change by a metric called the "Global Warming Potential" (GWP). The value of this calculated metric depends on the timescale being considered, and the IPCC reports offer different estimates for timescales of 20 years and 100 years. Since the timescale we are considering (up to 2100) is $\sim 80$ years, we use the 100-year GWP figures from Table 8.7 of the IPCC Working Group 1's 5th Assessment Report [33], as described in Section 3.5. We then sum the combined greenhouse gas concentrations for each year in $\mathrm{CO}_{2}$-equivalent concentrations, i.e., we sum the time series plotted in Figure $10 \mathrm{a}-\mathrm{c}$ into one time series.

In order to describe the modelled global temperature response to an increase in greenhouse gas concentrations predicted by climate models, it has become standard practice to describe the modelled relationships in terms of a metric called the "Radiative Forcing" (RF). This is a calculated metric with units of $\mathrm{W} \mathrm{m}^{-2}$, and so can be easily compared with measured changes in incoming solar irradiance, for instance. Calculated values of the RF associated with a change in atmospheric $\mathrm{CO}_{2}$ are so prevalent within the literature that some readers might initially have assumed that these values are somehow experimentally derived. Therefore, we stress that the $\mathrm{RF}$ of $\mathrm{CO}_{2}$ is a calculated metric. Some widely cited values are calculated from radiative transfer models, e.g., Shi (1992) [269]; Myhre et al. (1998) [267]; Byrne and Goldblatt (2014) [270]; Etminan et al. (2016) [271]. However, the RF for a given Global Climate Model can be also be inferred from the computer model output, e.g., Forster et al. (2013) [254].

At any rate, the $\mathrm{RF}$ of $\mathrm{CO}_{2}$ is typically assumed to increase logarithmically with concentration according to the following equation taken from Myhre et al. (1998) [267]:

$$
\Delta F=\alpha \ln \left(\frac{C}{C_{0}}\right)
$$

where $\Delta F$ is the change in $\mathrm{RF}$ (in $\mathrm{W} \mathrm{m} \mathrm{m}^{-2}$ ), $C$ is the new concentration, $C_{0}$ is the reference concentration (in our case, the pre-industrial concentrations implied by the Antarctic ice core estimates), and $\alpha$ is a constant. The value of $\alpha$ varies from study to study, e.g., in the IPCC's 1st Assessment Report (1990) [53], it was assumed that $\alpha=6.3$, but following Myhre et al. (1998) [267], more recent reports have assumed that $\alpha=5.35$. This implies an RF of $\Delta F=3.71 \mathrm{~W} \mathrm{~m}^{-2}$ for a doubling of atmospheric $\mathrm{CO}_{2}$. However, the exact value varies from study to study, e.g., Forster et al. (2013) [254] found that the RF for a doubling of $\mathrm{CO}_{2}$ for each of the CMIP5 Global Climate Models covered the range 2.59-4.31 W m $\mathrm{W}^{-2}$. For this paper, we will assume that the value of $\Delta F=3.71 \mathrm{~W} \mathrm{~m}^{-2}$ used in the IPCC's 5th Assessment Report [33] applies. However, for comparison, in the Supplementary Materials, we will include the equivalent results using the upper and lower values from Forster et al. (2013) [254]. 
Gregory and Mitchell (1997) [250] argued that this increase in radiative forcing can be related to the temperature response, $\Delta T$, for a well-equilibrated system via the following equation:

$$
\Delta T=\frac{\Delta F}{\lambda}
$$

where $\lambda$ is a constant "climate response factor", sometimes called the "feedback" factor, meaning that for a doubling of $\mathrm{CO}_{2}, \Delta T$ in Equation (2) would correspond to the ECS. Meanwhile, for the Transient Climate Response, the transient temperature response is reduced by a term to account for the proposed lag due to ocean heat uptake, which is expressed as follows:

$$
\Delta T=\frac{\Delta F}{\lambda-\kappa}
$$

where $\kappa$ is also treated as a constant which is known as the "ocean heat uptake efficiency". (Note: Gregory and Mitchell (1997) actually used a different label of $Q$ for $\Delta F$ ).

This relatively simple framework for relating the Transient Climate Response and Equilibrium Climate System has become quite popular, and many studies have included estimates of $\kappa$, e.g., refs. $[252,255,258,261]$. For example, Dufresne and Bony (2008) calculated that $\mathcal{\kappa}$ varied from a 0.53 to $0.92 \mathrm{~W} \mathrm{~m}^{-2} \mathrm{~K}^{-1}$ with a mean of $0.69 \mathrm{~W} \mathrm{~m}^{-2} \mathrm{~K}^{-1}$ across 12 of the CMIP3 Global Climate Models [258].

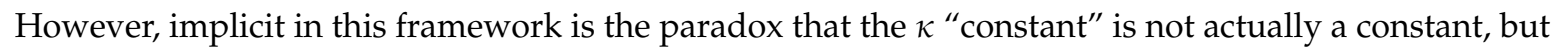
that it must tend towards zero as the oceans equilibrate, i.e., Equations (2) and (3) must equal each other under equilibrium conditions.

As a result, several researchers have attempted to develop more sophisticated analytical approaches to overcome the eventual breakdown of this simple approximation, e.g., the Held et al. (2010) [253] and Geoffroy et al. (2012) [244] "two-layer models". Geoffroy et al. (2012) found that their two-layer model is able to replicate the transient and equilibrium temperature responses of the CMIP5 Global Climate Models with a fairly high accuracy [244].

Rohrschneider et al. (2019) compared the results from this two-layer model-and also "two-region models" similar to those used by Bates (2016) [209] — to those of the complete Global Climate Models. They found that the two-layer models did indeed provide a good approximation of the Global Climate Models (and that in terms of globally averaged results they were equivalent to the two-region models), but they recommended that the Global Climate Models were more reliable for detailed studies [242].

Gregory et al. (2015) [252] also carried out a detailed comparison of the two-layer model approach to the equivalent results from CMIP5 Global Climate Models. They also compared the results of the Gregory and Mitchell (1997) [250] framework of Equations (2) and (3) described above, which they call the "zero-layer model". They found that the two-layer model was a much better approximation of the CMIP5 model results than the zero-layer model when considering long timescales of several centuries at high $\mathrm{CO}_{2}$ concentrations. Specifically, they found that in the CMIP5 models, the implied value of $\kappa$ gradually decreased from a range of $0.73 \pm 0.11 \mathrm{~W} \mathrm{~m}^{-2} \mathrm{~K}^{-1}$ to $0.54 \pm 0.11 \mathrm{~W} \mathrm{~m}^{-2} \mathrm{~K}^{-1}$ after 120-140 years, during which $\mathrm{CO}_{2}$ quadrupled.

Therefore, if we were to extend our BAU projections to, e.g., the middle of the 22nd century, then we would probably need to use a more sophisticated approach than the zero-layer model. However, since we are only extending our projections $\sim 80$ years, i.e., to 2100 , and greenhouse gas concentrations are only projected to have slightly more than doubled by then (see Figure 10), we argue that the zero-layer model is a reasonable approximation for estimating the transient temperature response to increasing greenhouse gas concentrations over the next $\sim 80$ years for a given climate sensitivity.

With this in mind, we will take the following approach to converting the projected BAU greenhouse gas increases into the expected human-caused global warming for a given climate sensitivity:

For the TCR values, we will assume that $\lambda$ and $\kappa$ are both constant, and that the increase in temperature, $\Delta T$, for a given year is therefore proportional to the increase in $\Delta F$ (Equation (3)). The TCR 
value corresponds to the $\Delta T$ when $C=2 \times C_{0}$ in Equation (1). Therefore, the expected $\Delta T$ for a given year is related to the concentration of greenhouse gases in that year (in $\mathrm{CO}_{2}$-equivalent), $\mathrm{C}$, by:

$$
\Delta T=\mathrm{TCR} \times \ln \left(\frac{C}{C_{0}}\right) \div \ln (2),
$$

The calculations are a little more complex for a given ECS value. If we want to calculate the transient temperature response for a given year, we need to use Equation (3). However, the ECS only tells us what the expected temperature response would be for Equation (2), i.e., when $\kappa=0$.

Our first step is to decide on a suitable value of $\kappa$. As mentioned above, Gregory et al. (2015) [252] calculated the mean value of $\kappa$ for the CMIP5 models after a doubling of $\mathrm{CO}_{2}$ was $0.73 \mathrm{~W} \mathrm{~m}^{-2} \mathrm{~K}^{-1}$. Therefore, for our analysis in this paper, we will assume that $\kappa=0.73 \mathrm{~W} \mathrm{~m}^{-2} \mathrm{~K}^{-1}$. However, in the Supplementary Materials, we also provide equivalent analyses using either the highest or lowest values for a doubling of $\mathrm{CO}_{2}$ of the CMIP5 models from Gregory et al. (2015)'s Table 1.

We then need to decide on a value for $\lambda$. We do this by assuming $\Delta F=3.71 \mathrm{~W} \mathrm{~m}^{-2}$ for a doubling of $\mathrm{CO}_{2}$, i.e., the value used by Myhre et al. (1998) [267] and also the IPCC 5th Assessment Report [33]. However, in the Supplementary Materials, we also provide equivalent analyses using the highest and lowest estimates of $\Delta F$ calculated by Forster et al. (2013) [254] for the CMIP5 models, i.e., 2.59 and $4.31 \mathrm{~W} \mathrm{~m}^{-2}$. We can then calculate the corresponding value of $\lambda$ for each of our ECS values by rearranging Equation (2):

$$
\lambda=\frac{\Delta F\left(\times 2 \mathrm{CO}_{2}\right)}{\Delta T\left(\times 2 \mathrm{CO}_{2}\right)}
$$

where $\Delta T\left(\times 2 \mathrm{CO}_{2}\right)$ is the ECS value. We then use Equation (3) to calculate $\Delta T$ for each year by calculating $\Delta F$ for that year by plugging the corresponding concentration, $C$ into Equation (1).

\section{How Much Human-Caused Global Warming Should We Expect with Business-As-Usual (BAU) Climate Policies?}

Figure 13a shows the results of our analysis for a TCR of $0.5,1.0,1.5,2.0,2.5$, and $3.0^{\circ} \mathrm{C}$, while Figure $13 \mathrm{~b}$ shows the results for an ECS of $1,2,3,4,5$, and $6{ }^{\circ} \mathrm{C}$. One point which might initially seem surprising is that the results are already different for the historic period, 1980-2019. That is, the magnitude of "human-caused global warming", which is presumed to have already occurred over the historic period, increases with the value of the higher climate sensitivity which is assumed. Some readers may wonder at why there should be uncertainty over this given that we have reasonable estimates of the global warming which occurred over this period. However, as discussed in Section 4.1, the magnitude of "global warming" over a given period does not automatically tell us the magnitude of "human-caused global warming" from increasing greenhouse gases. Some (or even all) of the observed global warming may have been due to natural factors and/or other non-greenhouse gas-related factors. On the other hand, there may have been additional "global cooling" factors-either natural (e.g., decreases in solar activity) or human-caused (e.g., increases in aerosols)—-that led to a reduction in human-caused global warming. That is, the amount of human-caused global warming that should have already occurred might be less than or greater than the amount of observed global warming. Indeed, this is a major part of the reason why there is still such uncertainty over the actual climate sensitivity to greenhouse gases.

At any rate, for us, probably the most striking result is the sheer range of possible values by the end of our BAU projections in 2100. This is quite problematic given that recently international climate policies have been framed within the context of limiting the magnitude of future human-caused global warming to within a specific value. In particular, the 2015 Paris Agreement involved a voluntary international agreement for, "holding the increase in the global average temperature to well below $2{ }^{\circ} \mathrm{C}$ above pre-industrial levels and pursuing efforts to limit the temperature increase to $1.5^{\circ} \mathrm{C}$ above pre-industrial levels" [19]. More recently, in 2018, the IPCC issued an intermediate Special Report entitled, "Global Warming of $1.5^{\circ} \mathrm{C}$. An IPCC Special Report on the impacts of global warming of $1.5^{\circ} \mathrm{C}$ above 
pre-industrial levels and related global greenhouse gas emission pathways, in the context of strengthening the global response to the threat of climate change, sustainable development, and efforts to eradicate poverty." [272]. For readers who are more interested in future human-caused global warming relative to present, in the Supplementary Materials we provide an equivalent figure using 2018 greenhouse gas concentrations as the starting baseline.

\section{Projected Human-caused Global Warming under Business-As-Usual conditions}
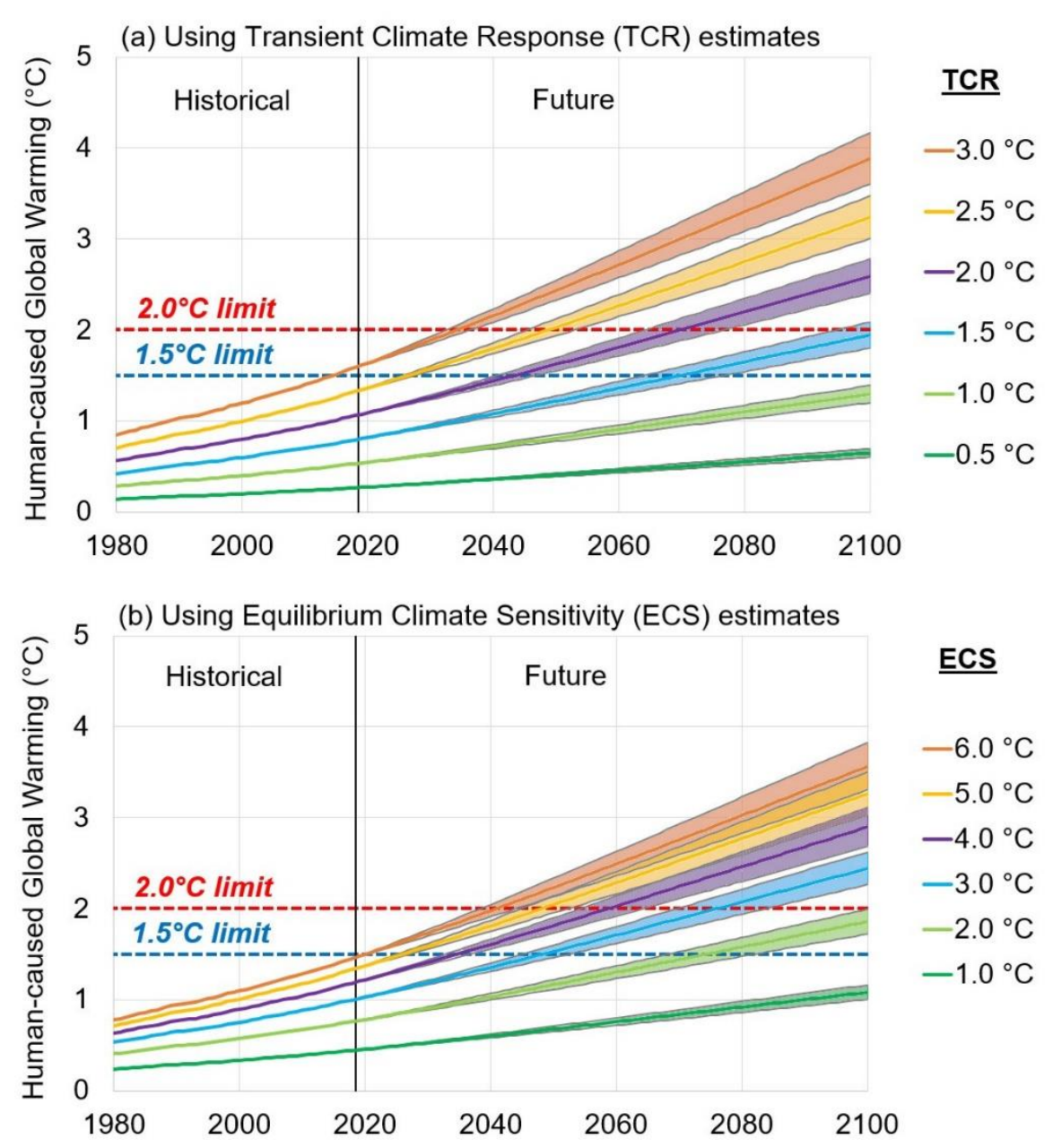

Figure 13. Projected human-caused global warming (from $\mathrm{CO}_{2}, \mathrm{CH}_{4}$, and $\mathrm{N}_{2} \mathrm{O}$ greenhouse gases) up to 2100 under Business-As-Usual conditions for various estimates of (a) the Transient Climate Response and (b) Equilibrium Climate Sensitivity. For comparison, the 2.0 and $1.5^{\circ} \mathrm{C}$ targets described under the Paris Agreement (2015) [19] are shown. The horizontal axes correspond to years.

We will not get into the debate here which we referred to in the introduction, e.g., refs. [21-26], over whether those specific targets of 1.5 and $2.0^{\circ} \mathrm{C}$ are useful. Although, we do note that Lang and Gregory (2019) [273] have calculated that, "3.0 ${ }^{\circ} \mathrm{C}$ of global warming from 2000 would increase global economic growth", and Dayaratna et al. (2020) [274] have recently argued that some recent research suggests that increasing $\mathrm{CO}_{2}$ could be a net positive, "at least through the mid-twenty-first century". See also NIPCC (2019) [17]. Rather, we will explicitly assume here that these targets of keeping human-caused global warming well below $2.0^{\circ} \mathrm{C}$ and ideally below $1.5^{\circ} \mathrm{C}$ are indeed worthy. With than in mind, what implications do the results in Figure 13 have for these targets?

If the ECS is $5{ }^{\circ} \mathrm{C}$ or higher, or the TCR is $2.5^{\circ} \mathrm{C}$ or higher, then under Business-As-Usual, we are projected to have broken the $1.5^{\circ} \mathrm{C}$ target by $2026-2028$, and the $2{ }^{\circ} \mathrm{C}$ target by $2045-2053$. On the other 
hand, if the ECS is $2{ }^{\circ} \mathrm{C}$, we are not projected to break the $1.5^{\circ} \mathrm{C}$ target until 2069-2082, and we are not projected to break the $2{ }^{\circ} \mathrm{C}$ target until the 22nd century. Similarly, if the TCR is $1.5^{\circ} \mathrm{C}$, then we are not projected to break the $1.5^{\circ} \mathrm{C}$ target until 2065-2077, and we would probably not break the $2{ }^{\circ} \mathrm{C}$ target until the 22nd century (or 2095 at the earliest). Meanwhile, if the ECS or TCR is $1{ }^{\circ} \mathrm{C}$ or less, then we are not projected to break either of the two targets in the 21st century under BAU.

In other words, the urgency (or otherwise) of the Paris Agreement depends critically on what the actual value of the climate sensitivity is. According to the IPCC's 5th Assessment Report, the ECS is "likely" to be any value in the range $1.5-4.5^{\circ} \mathrm{C}$ and the TCR is "likely" to be any value in the range 1.0-2.5 ${ }^{\circ} \mathrm{C}$ [33]. That is, the results of the latest IPCC Assessment Report still do not tell us whether the Paris Agreement is trying to solve a problem for the next few decades or the 22nd century.

Moreover, as can be seen from Table 4, several studies have suggested that the climate sensitivity may be either higher or lower than the IPCC's "likely" ranges. For instance, Zelinka et al. (2020) have noted that several of the latest CMIP6 Global Climate Models imply an ECS that is greater than $4.5^{\circ} \mathrm{C}$. On the other hand, Lindzen and Choi (2011) argue that the ECS is in the range $0.5-1.3^{\circ} \mathrm{C}$, with a most likely value of $0.7^{\circ} \mathrm{C}$ [260], and both Monckton et al. (2015a) [216] and Bates (2016) [209] argue that the ECS is in the range $0.8-1.3^{\circ} \mathrm{C}$, with a most likely value of $1.05^{\circ} \mathrm{C}$. All of these estimates are below the IPCC's "likely" range. Meanwhile, some of us have argued in Soon et al. (2015) that the TCR is less than $0.44^{\circ} \mathrm{C}$, and that it is possible to explain all of the observed warming since at least 1881 in terms of natural climate change [152].

Supplementary Materials: The following are available online at http://www.mdpi.com/1996-1073/13/6/1365/s1, Figure S1: Effects on projected future greenhouse gas concentrations (from $\mathrm{CO}_{2}, \mathrm{CH}_{4}$ and $\mathrm{N}_{2} \mathrm{O}$ greenhouse gases) up to 2100 of using the implied projected airborne fractions of the IPCC RCP scenarios (as used for IPCC AR5) compared to using the fixed, empirically-derived estimates as in the paper, Figure S2: Effects of changing the ocean heat uptake efficiency constant, $\mathrm{k}$, on projected human-caused global warming (from $\mathrm{CO}_{2}, \mathrm{CH}_{4}$ and $\mathrm{N}_{2} \mathrm{O}$ greenhouse gases) up to 2100 under Business-As-Usual conditions for various estimates of Equilibrium Climate Sensitivity. For comparison the $2.0^{\circ} \mathrm{C}$ and $1.5^{\circ} \mathrm{C}$ targets described under the Paris Agreement (2015) are shown; Figure S3: Effects of changing the estimated Radiative Forcing for a doubling of $\mathrm{CO}_{2}, \mathrm{~F}\left(\times 2 \mathrm{CO}_{2}\right)$, on projected human-caused global warming (from $\mathrm{CO}_{2}, \mathrm{CH}_{4}$ and $\mathrm{N}_{2} \mathrm{O}$ greenhouse gases) up to 2100 under Business-As-Usual conditions for various estimates of Equilibrium Climate Sensitivity. For comparison the $2.0^{\circ} \mathrm{C}$ and $1.5^{\circ} \mathrm{C}$ targets described under the Paris Agreement (2015) are shown. Figure S4: As for Figure 13 in the main article, except only projecting future warming (relative to 2018 values). Projected human-caused global warming (from $\mathrm{CO}_{2}, \mathrm{CH}_{4}$ and $\mathrm{N}_{2} \mathrm{O}$ greenhouse gases) up to 2100 under Business-As-Usual conditions for various estimates of (a) Transient Climate Response and (b) Equilibrium Climate Sensitivity. The horizontal axes correspond to years.

Author Contributions: Sadly, R.M.C. died unexpectedly during the preparation of an earlier 2016 version of this article, however his family encouraged us to continue the article without him. Although W.S. was not involved with the 2016 version, he has contributed substantially to the current version. Conceptualization, R.M.C., R.C. and M.C.; methodology, R.M.C. (for the 2016 version), R.C., M.C. and W.S.; writing-original draft preparation, R.M.C. (for the 2016 version), R.C., M.C. and W.S.; writing-review and editing, R.C., M.C. and W.S. All authors have read and agreed to the published version of the manuscript.

Funding: Two of us (RC and WS) received financial support from the Center for Environmental Research and Earth Sciences (CERES), http://ceres-science.com/, while carrying out the research for this paper. The aim of CERES is to promote open-minded and independent scientific inquiry. For this reason, donors to CERES are strictly required not to attempt to influence either the research directions or the findings of CERES.

Acknowledgments: As mentioned above, our co-author, Robert "Bob" M. Carter, passed away during the preparation of an earlier version of this article. His calm, measured, yet passionate love of science and his good sense of humour were inspiring, and he is deeply missed by his friends and colleagues. We would like to thank Bob's family for encouraging us to finish the article without him. After the 2016 version was submitted for peer review, two reviewers provided several critical comments which prompted us to take a much more comprehensive approach than in the original version as well as to substantially rewrite and revise much of the paper. We would like to thank the two reviewers of that early manuscript for these comments, as well as the editor and four reviewers of this revised manuscript whose collective feedback substantially improved our analysis and manuscript.

Conflicts of Interest: The authors declare no conflict of interest. 


\section{References}

1. Manabe, S.; Wetherald, R.T. Thermal Equilibrium of the Atmosphere with a Given Distribution of Relative Humidity. J. Atmos. Sci. 1967, 24, 241-259. [CrossRef]

2. Manabe, S.; Wetherald, R.T. The Effects of Doubling the $\mathrm{CO}_{2}$ Concentration on the climate of a General Circulation Model. J. Atmos. Sci. 1975, 32, 3-15. [CrossRef]

3. Budyko, M.I. The effect of solar radiation variations on the climate of the Earth. Tellus 1969, 21, 611-619. [CrossRef]

4. Kukla, G.J.; Angell, J.K.; Korshover, J.; Dronia, H.; Hoshiai, M.; Namias, J.; Rodewald, M.; Yamamoto, R.; Iwashima, T. New data on climatic trends. Nature 1977, 270, 573-580. [CrossRef]

5. Jones, P.D.; Wigley, T.M.L.; Wright, P.B. Global temperature variations between 1861 and 1984. Nature 1986, 322, 430-434. [CrossRef]

6. Hansen, J.; Lebedeff, S. Global trends of measured surface air temperature. J. Geophys. Res. Atmos. 1987, 92, 13345-13372. [CrossRef]

7. Hansen, J.; Lebedeff, S. Global surface air temperatures: Update through 1987. Geophys. Res. Lett. 1988, 15, 323-326. [CrossRef]

8. Schlesinger, M.E. Equilibrium and transient climatic warming induced by increased atmospheric $\mathrm{CO}_{2}$. Clim. Dyn. 1986, 1, 35-51. [CrossRef]

9. Tricot, C.; Berger, A. Modelling the equilibrium and transient responses of global temperature to past and future trace gas concentrations. Clim. Dyn. 1987, 2, 39-61. [CrossRef]

10. Hansen, J.; Fung, I.; Lacis, A.; Rind, D.; Lebedeff, S.; Ruedy, R.; Russell, G.; Stone, P. Global climate changes as forecast by Goddard Institute for Space Studies three-dimensional model. J. Geophys. Res. Atmos. 1988, 93, 9341-9364. [CrossRef]

11. Shabecoff, P.; Times, S.T. The N.Y. Global Warming Has Begun, Expert Tells Senate. The New York Times. 1988. Available online: https://www.nytimes.com/1988/06/24/us/global-warming-has-begun-expert-tells-senate. html (accessed on 15 January 2020).

12. United Nations. United Nations Framework Convention on Climate Change. Available online: http://unfccc. int/files/essential_background/background_publications_htmlpdf/application/pdf/conveng.pdf (accessed on 15 January 2020).

13. UN General Assembly Protection of Global Climate for Present and Future Generations of Mankind: Resolution/Adopted by the General Assembly, 22 December 1989, A/RES/44/207. Available online: https://unfccc.int/documents/4587 (accessed on 15 January 2020).

14. Lacis, A.A.; Schmidt, G.A.; Rind, D.; Ruedy, R.A. Atmospheric $\mathrm{CO}_{2}$ : Principal Control Knob Governing Earth's Temperature. Science 2010, 330, 356-359. [CrossRef] [PubMed]

15. IPCC Summary for Policymakers. Climate Change 2013: The Physical Science Basis. Contribution of Working Group I to the Fifth Assessment Report of the Intergovernmental Panel on Climate Change; Cambridge University Press: Cambridge, UK; New York, NY, USA, 2013.

16. Idso, C.D.; Carter, R.M.; Singer, S.F. Climate Change Reconsidered II: Physical Science; Karnick, S.T., Bast, D.C., Eds.; The Heartland Institute: Chicago, IL, USA, 2013; ISBN 978-1-934791-40-0.

17. Bezdek, R.; Idso, C.D.; Legates, D.R.; Singer, S.F. Climate Change Reconsidered II: Fossil Fuels; Bast, J.L., Bast, D.C., Eds.; The Heartland Institute: Arlington Heights, IL, USA, 2019; ISBN 978-1-934791-45-5.

18. Kyoto Protocol to the United Nations Framework Convention on Climate Change-UNFCCC. Available online: https://unfccc.int/documents/2409 (accessed on 15 January 2020).

19. UNFCCC. Report of the Conference of the Parties on its Twenty-First Session, Held in Paris from 30 November to 13 December 2015. Addendum. Part Two: Action Taken by the Conference of the Parties at Its TwentyFirst Session-UNFCCC; United Nations: San Francisco, CA, USA, 2016.

20. Friedman, L. Trump Serves Notice to Quit Paris Climate Agreement. The New York Times. 2019. Available online: https://www.nytimes.com/2019/11/04/climate/trump-paris-agreement-climate.html (accessed on 15 January 2020).

21. Mahony, M. Climate change and the geographies of objectivity: The case of the IPCC's burning embers diagram. Trans. Inst. Br. Geogr. 2015, 40, 153-167. [CrossRef]

22. Knutti, R.; Rogelj, J.; Sedláček, J.; Fischer, E.M. A scientific critique of the two-degree climate change target. Nat. Geosci. 2016, 9, 13-18. [CrossRef] 
23. Tschakert, P. $1.5^{\circ} \mathrm{C}$ or $2{ }^{\circ} \mathrm{C}$ : A conduit's view from the science-policy interface at COP20 in Lima, Peru. Clim. Chang. Responses 2015, 2, 3. [CrossRef]

24. Rogelj, J.; Luderer, G.; Pietzcker, R.C.; Kriegler, E.; Schaeffer, M.; Krey, V.; Riahi, K. Energy system transformations for limiting end-of-century warming to below $1.5^{\circ} \mathrm{C}$. Nat. Clim. Chang. 2015, 5, 519-527. [CrossRef]

25. Gao, Y.; Gao, X.; Zhang, X. The $2{ }^{\circ} \mathrm{C}$ Global Temperature Target and the Evolution of the Long-Term Goal of Addressing Climate Change-From the United Nations Framework Convention on Climate Change to the Paris Agreement. Engineering 2017, 3, 272-278. [CrossRef]

26. Hansen, J.; Sato, M.; Kharecha, P.; Beerling, D.; Berner, R.; Masson-Delmotte, V.; Pagani, M.; Raymo, M.; Royer, D.L.; Zachos, J.C. Target Atmospheric CO: Where Should Humanity Aim? Open Atmos. Sci. J. 2008, 2, 217-231. [CrossRef]

27. Randalls, S. History of the $2{ }^{\circ} \mathrm{C}$ climate target. WIREs Clim. Chang. 2010, 1, 598-605. [CrossRef]

28. Victor, D.G.; Kennel, C.F. Climate policy: Ditch the $2{ }^{\circ} \mathrm{C}$ warming goal. Nat. News 2014, 514, 30. [CrossRef]

29. Geden, O.; Beck, S. Renegotiating the global climate stabilization target. Nat. Clim. Chang. 2014, 4, 747-748. [CrossRef]

30. Hulme, M. $1.5^{\circ} \mathrm{C}$ and climate research after the Paris Agreement. Nat. Clim. Chang. 2016, 6, $222-224$. [CrossRef]

31. Tyndall, J.I. The Bakerian Lecture-On the absorption and radiation of heat by gases and vapours, and on the physical connexion of radiation, absorption, and conduction. Philos. Trans. R. Soc. Lond. 1861, 151, 1-36.

32. Hartmann, D.L. Global Physical Climatology, 2nd ed.; Elsevier Science: Amsterdam, The Netherlands; Boston, MA, USA, 2006; ISBN 978-0-12-328531-7.

33. IPCC. Climate Change 2013: The Physical Science Basis. Contribution of Working Group I to the Fifth Assessment Report of the Intergovernmental Panel on Climate Change; Cambridge University Press: Cambridge, UK; New York, NY, USA, 2013.

34. Arrhenius, P.S. XXXI. On the influence of carbonic acid in the air upon the temperature of the ground. Lond. Edinb. Dublin Philos. Mag. J. Sci. 1896, 41, 237-276. [CrossRef]

35. Ångström, K. Knut Ångström on atmospheric absorption. Mon. Wea. Rev. 1901, 29, 268.

36. Simpson, G.C. Past Climates. Nature 1929, 124, 988-991. [CrossRef]

37. Callendar, G.S. The artificial production of carbon dioxide and its influence on temperature. Q. J. R. Meteorol. Soc. 1938, 64, 223-240. [CrossRef]

38. Rubino, M.; Etheridge, D.M.; Thornton, D.P.; Howden, R.; Allison, C.E.; Francey, R.J.; Langenfelds, R.L.; Steele, L.P.; Trudinger, C.M.; Spencer, D.A.; et al. Revised records of atmospheric trace gases $\mathrm{CO}_{2}, \mathrm{CH}_{4}, \mathrm{~N}_{2} \mathrm{O}$, and $\delta^{13} \mathrm{C}-\mathrm{CO}_{2}$ over the last 2000 years from Law Dome, Antarctica. Earth Syst. Sci. Data 2019, 11, 473-492. [CrossRef]

39. Friedlingstein, P.; Jones, M.W.; O'Sullivan, M.; Andrew, R.M.; Hauck, J.; Peters, G.P.; Peters, W.; Pongratz, J.; Sitch, S.; Quéré, C.L.; et al. Global Carbon Budget 2019. Earth Syst. Sci. Data 2019, 11, 1783-1838. [CrossRef]

40. Boden, T.A.; Marland, G.; Andres, R.J. Global, Regional, and National Fossil-Fuel $\mathrm{CO}_{2}$ Emissions; Emissions. Carbon Dioxide Information Analysis Center, Oak Ridge National Laboratory, U.S. Department of Energy: Oak Ridge, TN, USA; Available online: https://doi.org/10.3334/CDIAC/00001_V2017 (accessed on 26 January 2020).

41. Smith, S.J.; Rothwell, A. Carbon density and anthropogenic land-use influences on net land-use change emissions. Biogeosciences 2013, 10, 6323-6337. [CrossRef]

42. Gütschow, J.; Jeffery, M.L.; Gieseke, R.; Gebel, R.; Stevens, D.; Krapp, M.; Rocha, M. The PRIMAP-hist national historical emissions time series. Earth Syst. Sci. Data 2016, 8, 571-603. [CrossRef]

43. Gütschow, J.; Jeffery, L.; Gieseke, R. The PRIMAP-hist national historical emissions time series (1850-2016). Earth Syst. Sci. Data 2016, 8, 571-603. Available online: http://dataservices.gfz-potsdam.de/pik/showshort. php?id=escidoc:3842934 (accessed on 15 January 2020). [CrossRef]

44. Tirpak, D.; Vellinga, P. Emissions Scenarios. In AR1, Working Group 3: The IPCC Response Strategies-IPCC; Island Press: Washington, DC, USA, 1990.

45. Palisades, NY: NASA Socioeconomic Data and Applications Center (SEDAC) Intergovernmental Panel on Climate Change-IPCC. IPCC IS92 Emissions Scenarios (A, B, C, D, E, F) Dataset Version 1.1. 2000. Available online: https://doi.org/10.7927/H41C1TT4 (accessed on 26 January 2020). 
46. Nakicenovic, N.; Swart, R. Special Report on Emissions Scenarios: A Special Report of Working Group III of the Intergovernmental Panel on Climate Change; Cambridge University Press: Cambridge, UK, 2000.

47. van Vuuren, D.P.; Edmonds, J.; Kainuma, M.; Riahi, K.; Thomson, A.; Hibbard, K.; Hurtt, G.C.; Kram, T.; Krey, V.; Lamarque, J.-F.; et al. The representative concentration pathways: An overview. Clim. Chang. 2011, 109, 5. [CrossRef]

48. Riahi, K.; van Vuuren, D.P.; Kriegler, E.; Edmonds, J.; O’Neill, B.C.; Fujimori, S.; Bauer, N.; Calvin, K.; Dellink, R.; Fricko, O.; et al. The Shared Socioeconomic Pathways and their energy, land use, and greenhouse gas emissions implications: An overview. Glob. Environ. Chang. 2017, 42, 153-168. [CrossRef]

49. Houghton, R.A.; House, J.I.; Pongratz, J.; van der Werf, G.R.; DeFries, R.S.; Hansen, M.C.; Quéré, C.L.; Ramankutty, N. Carbon emissions from land use and land-cover change. Biogeosciences 2012, 9, 5125-5142. [CrossRef]

50. Hansis, E.; Davis, S.J.; Pongratz, J. Relevance of methodological choices for accounting of land use change carbon fluxes. Glob. Biogeochem. Cycles 2015, 29, 1230-1246. [CrossRef]

51. Arneth, A.; Sitch, S.; Pongratz, J.; Stocker, B.D.; Ciais, P.; Poulter, B.; Bayer, A.D.; Bondeau, A.; Calle, L.; Chini, L.P.; et al. Historical carbon dioxide emissions caused by land-use changes are possibly larger than assumed. Nat. Geosci. 2017, 10, 79-84. [CrossRef]

52. Houghton, R.A.; Nassikas, A.A. Global and regional fluxes of carbon from land use and land cover change 1850-2015. Glob. Biogeochem. Cycles 2017, 31, 456-472. [CrossRef]

53. IPCC-Intergovernmental Panel on Climate Change Climate Change: The IPCC Scientific Assessment; Cambridge University Press: Cambridge, UK; New York, NY, USA, 1990; ISBN 0-521-40360-X.

54. Intergovernmental Panel on Climate Change. Climate Change 1995: The Science of Climate Change: Contribution of Working Group I to the Second Assessment Report of the Intergovernmental Panel on Climate Change, 1st ed.; Houghton, J.T., Filho, L.G.M., Callander, B.A., Harris, N., Kattenburg, A., Maskell, K., Eds.; Cambridge University Press: Cambridge, UK; New York, NY, USA, 1996; ISBN 978-0-521-56433-5.

55. Intergovernmental Panel on Climate Change. Climate Change 2001: The Scientific Basis: Contribution of Working Group I to the Third Assessment Report of the Intergovernmental Panel on Climate Change; Houghton, J.T., Ding, Y., Griggs, D.J., Noguer, M., van der Linden, P.J., Dai, X., Maskell, K., Johnson, C.A., Eds.; Cambridge University Press: Cambridge, UK; New York, NY, USA, 2001; ISBN 978-0-521-80767-8.

56. Intergovernmental Panel on Climate Change. Climate Change 2007-The Physical Science Basis: Working Group I Contribution to the Fourth Assessment Report of the IPCC; Cambridge University Press: Cambridge, UK; New York, NY, USA, 2007; ISBN 978-0-521-88009-1.

57. Mckitrick, R.; Strazicich, M.C.; Lee, J. Long-Term Forecasting of Global Carbon Dioxide Emissions: Reducing Uncertainties Using a Per Capita Approach. J. Forecast. 2013, 32, 435-451. [CrossRef]

58. Castles, I.; Henderson, D. The IPCC Emission Scenarios: An Economic-Statistical Critique. Energy Environ. 2003, 14, 159-185. [CrossRef]

59. Nakicenovic, N.; Grübler, A.; Gaffin, S.; Jung, T.T.; Kram, T.; Morita, T.; Pitcher, H.; Riahi, K.; Schlesinger, M.; Shukla, P.R.; et al. IPCC Sres Revisited: A Response. Energy Environ. 2003, 14, 187-214. [CrossRef]

60. Castles, I.; Henderson, D. Economics, Emissions Scenarios and the Work of the IPCC. Energy Environ. 2003, 14, 415-435. [CrossRef]

61. Grübler, A.; Nakicenovic, N.; Alcamo, J.; Davis, G.; Fenhann, J.; Hare, B.; Mori, S.; Pepper, B.; Pitcher, H.; Riahi, K.; et al. Emissions Scenarios: A Final Response. Energy Environ. 2004, 15, 11-24. [CrossRef]

62. Henderson, D. SRES, IPCC and the Treatment of Economic Issues: What Has Emerged? Energy Environ. 2005, 16, 549-578. [CrossRef]

63. Ritchie, J.; Dowlatabadi, H. Why do climate change scenarios return to coal? Energy 2017, 140, $1276-1291$. [CrossRef]

64. Ritchie, J.; Dowlatabadi, H. The $1000 \mathrm{GtC}$ coal question: Are cases of vastly expanded future coal combustion still plausible? Energy Econ. 2017, 65, 16-31. [CrossRef]

65. Ritchie, J.; Dowlatabadi, H. Defining climate change scenario characteristics with a phase space of cumulative primary energy and carbon intensity. Environ. Res. Lett. 2018, 13, 024012. [CrossRef]

66. Hausfather, Z.; Peters, G.P. Emissions-The 'business as usual' story is misleading. Nature 2020, 577, 618-620. [CrossRef] 
67. O’Neill, B.C.; Kriegler, E.; Riahi, K.; Ebi, K.L.; Hallegatte, S.; Carter, T.R.; Mathur, R.; van Vuuren, D.P. A new scenario framework for climate change research: The concept of shared socioeconomic pathways. Clim. Chang. 2014, 122, 387-400. [CrossRef]

68. O’Neill, B.C.; Kriegler, E.; Ebi, K.L.; Kemp-Benedict, E.; Riahi, K.; Rothman, D.S.; van Ruijven, B.J.; van Vuuren, D.P.; Birkmann, J.; Kok, K.; et al. The roads ahead: Narratives for shared socioeconomic pathways describing world futures in the 21st century. Glob. Environ. Chang. 2017, 42, 169-180. [CrossRef]

69. US Department of Commerce. NOAA/ESRL Global Monitoring Division-The Noaa Annual Greenhouse Gas Index (AGGI). Available online: https://www.esrl.noaa.gov/gmd/aggi/aggi.html (accessed on 26 January 2020).

70. US Department of Commerce. ESRL Global Monitoring Division-Halocarbons and other Atmospheric Trace Species. Available online: https://www.esrl.noaa.gov/gmd/hats/ (accessed on 28 January 2020).

71. Rubino, M.; Etheridge, D.M.; Thornton, D.P.; Howden, R.; Allison, C.E.; Francey, R.J.; Langenfelds, R.L.; Steele, L.P.; Trudinger, C.; Spencer, D.A.; et al. Law Dome, Antarctica 2000 Year Ice Core $\mathrm{CO}_{2}, \mathrm{CH} 4, \mathrm{~N} 2 \mathrm{O}$ and d13C- $\mathrm{CO}_{2}$ Data. Available online: https://www.ncdc.noaa.gov/paleo-search/study/25830 (accessed on 26 January 2020).

72. Monnin, E.; Indermühle, A.; Dällenbach, A.; Flückiger, J.; Stauffer, B.; Stocker, T.F.; Raynaud, D.; Barnola, J.-M. Atmospheric $\mathrm{CO}_{2}$ Concentrations over the Last Glacial Termination. Science 2001, 291, 112-114. [CrossRef]

73. Ciais, P.; Sabine, C.L.; Bala, G.; Bopp, L.; Brovkin, V.; Canadell, J.; Chhabra, A.; DeFries, R.S.; Galloway, J.N.; Heimann, M.; et al. Carbon and Other Biogeochemical Cycles. In Climate Change 2013: The Physical Science Basis. Contribution of Working Group I to the Fifth Assessment Report of the Intergovernmental Panel on Climate Change; Cambridge University Press: Cambridge, UK; New York, NY, USA, 2013.

74. Rörsch, A.; Courtney, R.S.; Thoenes, D. Global Warming and the Accumulation of Carbon Dioxide in the Atmosphere: A Critical Consideration of the Evidence. Energy Environ. 2005, 16, 101-125. [CrossRef]

75. Rörsch, A.; Courtney, R.S.; Thoenes, D. The Interaction of Climate Change and the Carbon Dioxide Cycle. Energy Environ. 2005, 16, 217-238.

76. Quirk, T. Sources and Sinks of Carbon Dioxide. Energy Environ. 2009, 20, 105-121. [CrossRef]

77. Ahlbeck, D.J.R. On the Increased Rate of Atmospheric Carbon Dioxide Accumulation 1980-2008. Energy Environ. 2009, 20, 1149-1154. [CrossRef]

78. Salby, M.L. Global emission of carbon dioxide: The contribution from natural sources. In Proceedings of the Sydney Institute, Sydney, NSW, Australia, 2 August 2011; Available online: https://thesydneyinstitute. com.au/blog/global-emission-of-carbon-dioxide-the-contribution-from-natural-sources/ (accessed on 15 January 2020).

79. Humlum, O.; Stordahl, K.; Solheim, J.-E. The phase relation between atmospheric carbon dioxide and global temperature. Glob. Planet. Chang. 2013, 100, 51-69. [CrossRef]

80. Harde, H. Scrutinizing the carbon cycle and $\mathrm{CO}_{2}$ residence time in the atmosphere. Glob. Planet. Chang. 2017, 152, 19-26. [CrossRef]

81. Harde, $\mathrm{H}$. What Humans Contribute to Atmospheric $\mathrm{CO}_{2}$ : Comparison of Carbon Cycle Models with Observations. Earth Sci. 2019, 8, 139.

82. Berry, E.X. Human $\mathrm{CO}_{2}$ Emissions Have Little Effect on Atmospheric $\mathrm{CO}_{2}$. Int. J. Atmos. Ocean. Sci. 2019, $3,13$.

83. Jaworowski, Z.; Segalstad, T.V.; Ono, N. Do glaciers tell a true atmospheric $\mathrm{CO}_{2}$ story? Sci. Total Environ. 1992, 114, 227-284. [CrossRef]

84. Jaworowski, Z. Ancient atmosphere- Validity of ice records. Environ. Sci. Pollut. Res. 1994, 1, $161-171$. [CrossRef]

85. Starr, C. Atmospheric $\mathrm{CO}_{2}$ residence time and the carbon cycle. Energy 1993, 18, 1297-1310. [CrossRef]

86. Linden, H.R. Are the IPCC Carbon Emission and Carbon Dioxide Stabilization Scenarios Realistic? Energy Environ. 1998, 9, 647-657. [CrossRef]

87. Beck, E.-G. 180 Years of Atmospheric $\mathrm{CO}_{2}$ Gas Analysis by Chemical Methods. Energy Environ. 2007, 18, 259-282. [CrossRef]

88. Beck, E.-G. Comments on "180 Years of Atmospheric $\mathrm{CO}_{2}$ Gas Analysis by Chemical Methods". Energy Environ. 2007, 18, 641-646. [CrossRef]

89. Beck, E.-G. 50 Years of Continuous Measurement of $\mathrm{CO}_{2}$ on Mauna Loa. Energy Environ. 2008, 19, 1017-1028. [CrossRef] 
90. O'Neill, B.C.; Gaffin, S.R.; Oppenheimer, M. Reply to “Reservoir timescales for anthropogenic $\mathrm{CO}_{2}$ in the atmosphere: Commentary". Tellus B Chem. Phys. Meteorol. 1996, 48, 707-709.

91. O'Neill, B.C.; Oppenheimer, M.; Gaffin, S.R. Measuring Time in the Greenhouse; an Editorial Essay. Clim. Chang. 1997, 37, 491-505. [CrossRef]

92. Tans, P.P. The $\mathrm{CO}_{2}$ Lifetime Concept Should Be Banished; an Editorial Comment. Clim. Chang. 1997, 37, 487-490. [CrossRef]

93. Kern, Z.; Leuenberger, M. Comment on "The phase relation between atmospheric carbon dioxide and global temperature" Humlum et al. [Glob. Planet. Change 100: 51-69.]: Isotopes ignored. Glob. Planet. Chang. 2013, 109, 1-2. [CrossRef]

94. Masters, T.; Benestad, R. Comment on "The phase relation between atmospheric carbon dioxide and global temperature". Glob. Planet. Chang. 2013, 106, 141-142. [CrossRef]

95. Richardson, M. Comment on "The phase relation between atmospheric carbon dioxide and global temperature" by Humlum, Stordahl and Solheim. Glob. Planet. Chang. 2013, 107, 226-228. [CrossRef]

96. Grosjean, M.; Guiot, J.; Yu, Z. Commentary: H. Harde: "Scrutinizing the carbon cycle and $\mathrm{CO}_{2}$ residence time in the atmosphere". Global and Planetary Change 152 (2017), 19-26. Glob. Planet. Chang. 2018, 164, 65-66. [CrossRef]

97. Köhler, P.; Hauck, J.; Völker, C.; Wolf-Gladrow, D.A.; Butzin, M.; Halpern, J.B.; Rice, K.; Zeebe, R.E. Comment on "Scrutinizing the carbon cycle and $\mathrm{CO}_{2}$ residence time in the atmosphere" by H. Harde. Glob. Planet. Chang. 2018, 164, 67-71. [CrossRef]

98. Meijer, H.A.J.; Keeling, R.F. Comment on "180 Years of Atmospheric $\mathrm{CO}_{2}$ Gas Analysis by Chemical Methods" by Ernst-Georg Beck: Energy \& Environment, Vol. 18(2), 2007. Energy Environ. 2007, 18, 635-640.

99. Oeschger, H.Z. Jaworowski: Ancient atmosphere-Validity of ice records ESPR 1 (3) 161-171 (1994). Environ. Sci. Pollut. Res. 1995, 2, 60-61. [CrossRef]

100. Kuhn, T.S.; Hacking, I. The Structure of Scientific Revolutions: 50th Anniversary Edition; University of Chicago Press: Chicago, IL, USA; London, UK, 2012; ISBN 978-0-226-45812-0.

101. Callendar, G.S. On the Amount of Carbon Dioxide in the Atmosphere. Tellus 1958, 10, 243-248. [CrossRef]

102. Plass, G.N. The Carbon Dioxide Theory of Climatic Change. Tellus 1956, 8, 140-154. [CrossRef]

103. Bolin, B. The Atmosphere and the Sea in Motion: Scientific Contributions to the Rossby Memorial Volume; Rockefeller Institute Press: New York, NY, USA, 1959.

104. US EPA. Endangerment and Cause or Contribute Findings for Greenhouse Gases under the Section 202(a) of the Clean Air Act. Available online: https://www.epa.gov/ghgemissions/endangerment-and-cause-or-contributefindings-greenhouse-gases-under-section-202a-clean (accessed on 15 January 2020).

105. Ballantyne, A.P.; Alden, C.B.; Miller, J.B.; Tans, P.P.; White, J.W.C. Increase in observed net carbon dioxide uptake by land and oceans during the past 50 years. Nature 2012, 488, 70-72. [CrossRef]

106. Raupach, M.R. The exponential eigenmodes of the carbon-climate system, and their implications for ratios of responses to forcings. Earth Syst. Dyn. 2013, 4, 31-49. [CrossRef]

107. Bennedsen, M.; Hillebrand, E.; Koopman, S.J. Trend analysis of the airborne fraction and sink rate of anthropogenically released $\mathrm{CO}_{2}$. Biogeosciences 2019, 16, 3651-3663. [CrossRef]

108. Le Quéré, C.; Raupach, M.R.; Canadell, J.G.; Marland, G.; Bopp, L.; Ciais, P.; Conway, T.J.; Doney, S.C.; Feely, R.A.; Foster, P.; et al. Trends in the sources and sinks of carbon dioxide. Nat. Geosci. 2009, 2, 831-836. [CrossRef]

109. Betts, R.A.; Collins, M.; Hemming, D.L.; Jones, C.D.; Lowe, J.A.; Sanderson, M.G. When could global warming reach $4{ }^{\circ}$ C? Philos. Trans. R. Soc. A Math. Phys. Eng. Sci. 2011, 369, 67-84. [CrossRef] [PubMed]

110. Raich, J.W.; Schlesinger, W.H. The global carbon dioxide flux in soil respiration and its relationship to vegetation and climate. Tellus B Chem. Phys. Meteorol. 1992, 44, 81-99. [CrossRef]

111. Bond-Lamberty, B.; Bailey, V.L.; Chen, M.; Gough, C.M.; Vargas, R. Globally rising soil heterotrophic respiration over recent decades. Nature 2018, 560, 80-83. [CrossRef]

112. Takahashi, T.; Sutherland, S.C.; Sweeney, C.; Poisson, A.; Metzl, N.; Tilbrook, B.; Bates, N.; Wanninkhof, R.; Feely, R.A.; Sabine, C.; et al. Global sea-air $\mathrm{CO}_{2}$ flux based on climatological surface ocean $\mathrm{pCO}_{2}$, and seasonal biological and temperature effects. Deep Sea Res. Part II Top. Stud. Oceanogr. 2002, 49, 1601-1622. [CrossRef]

113. Carter, P.R. Climate: The Counter-Consensus; Stacey International: London, UK, 2010; ISBN 978-1-906768-29-4.

114. Calder, N. The Carbon Dioxide Thermometer and the Cause of Global Warming. Energy Environ. 1999, 10, 1-18. [CrossRef] 
115. Kanwisher, J. $\mathrm{pCO}_{2}$ in Sea Water and its Effect on the Movement of $\mathrm{CO}_{2}$ in Nature. Tellus 1960, 12, $209-215$. [CrossRef]

116. Revelle, R.; Suess, H.E. Carbon Dioxide Exchange Between Atmosphere and Ocean and the Question of an Increase of Atmospheric $\mathrm{CO}_{2}$ during the Past Decades. Tellus 1957, 9, 18-27. [CrossRef]

117. Wagner, F.; Bohncke, S.J.P.; Dilcher, D.L.; Kürschner, W.M.; van Geel, B.; Visscher, H. Century-Scale Shifts in Early Holocene Atmospheric $\mathrm{CO}_{2}$ Concentration. Science 1999, 284, 1971-1973. [CrossRef]

118. Mcelwain, J.C.; Mayle, F.E.; Beerling, D.J. Stomatal evidence for a decline in atmospheric $\mathrm{CO}_{2}$ concentration during the Younger Dryas stadial: A comparison with Antarctic ice core records. J. Quat. Sci. 2002, 17, 21-29. [CrossRef]

119. Wagner, F.; Aaby, B.; Visscher, H. Rapid atmospheric $\mathrm{CO}_{2}$ changes associated with the 8200-years-B.P. cooling event. Proc. Natl. Acad. Sci. USA 2002, 99, 12011-12014. [CrossRef] [PubMed]

120. Rundgren, M.; Björck, S. Late-glacial and early Holocene variations in atmospheric $\mathrm{CO}_{2}$ concentration indicated by high-resolution stomatal index data. Earth Planet. Sci. Lett. 2003, 213, 191-204. [CrossRef]

121. Wagner, F.; Kouwenberg, L.L.R.; van Hoof, T.B.; Visscher, H. Reproducibility of Holocene atmospheric $\mathrm{CO}_{2}$ records based on stomatal frequency. Quat. Sci. Rev. 2004, 23, 1947-1954. [CrossRef]

122. Hoof, T.B.V.; Kaspers, K.A.; Wagner, F.; Wal, R.S.W.V.D.; Kürschner, W.M.; Visscher, H. Atmospheric $\mathrm{CO}_{2}$ during the 13th century AD: Reconciliation of data from ice core measurements and stomatal frequency analysis. Tellus B 2005, 57, 351-355. [CrossRef]

123. Kouwenberg, L.; Wagner, R.; Kürschner, W.; Visscher, H. Atmospheric $\mathrm{CO}_{2}$ fluctuations during the last millennium reconstructed by stomatal frequency analysis of Tsuga heterophylla needles. Geology 2005, 33, 33-36. [CrossRef]

124. Van Hoof, T.B.; Wagner-Cremer, F.; Kürschner, W.M.; Visscher, H. A role for atmospheric $\mathrm{CO}_{2}$ in preindustrial climate forcing. Proc. Natl. Acad. Sci. USA 2008, 105, 15815-15818. [CrossRef] [PubMed]

125. Finsinger, W.; Wagner-Cremer, F. Stomatal-based inference models for reconstruction of atmospheric $\mathrm{CO}_{2}$ concentration: A method assessment using a calibration and validation approach. Holocene 2009, 19, 757-764. [CrossRef]

126. Steinthorsdottir, M.; Wohlfarth, B.; Kylander, M.E.; Blaauw, M.; Reimer, P.J. Stomatal proxy record of $\mathrm{CO}_{2}$ concentrations from the last termination suggests an important role for $\mathrm{CO}_{2}$ at climate change transitions. Quat. Sci. Rev. 2013, 68, 43-58. [CrossRef]

127. Steinthorsdottir, M.; de Boer, A.M.; Oliver, K.I.C.; Muschitiello, F.; Blaauw, M.; Reimer, P.J.; Wohlfarth, B. Synchronous records of $\mathrm{pCO}_{2}$ and $\triangle 14 \mathrm{C}$ suggest rapid, ocean-derived $\mathrm{pCO}_{2}$ fluctuations at the onset of Younger Dryas. Quat. Sci. Rev. 2014, 99, 84-96. [CrossRef]

128. Barnola, J.M.; Anklin, M.; Porcheron, J.; Raynaud, D.; Schwander, J.; Stauffer, B. $\mathrm{CO}_{2}$ evolution during the last millennium as recorded by Antarctic and Greenland ice. Tellus B 1995, 47, 264-272. [CrossRef]

129. Indermühle, A.; Stauffer, B.; Stocker, T.F.; Raynaud, D.; Barnola, J.-M.; Birks, H.H.; Eide, W.; Birks, H.J.B.; Wagner, F.; Kurschner, W.M.; et al. Early Holocene Atmospheric $\mathrm{CO}_{2}$ Concentrations. Science 1999, 286, 1815. [CrossRef]

130. Tschumi, J.; Stauffer, B. Reconstructing past atmospheric $\mathrm{CO}_{2}$ concentration based on ice-core analyses: Open questions due to in situ production of $\mathrm{CO}_{2}$ in the ice. J. Glaciol. 2000, 46, 45-53. [CrossRef]

131. Köhler, P.; Fischer, H.; Schmitt, J.; Brook, E.J.; Marcott, S.A. Comment on "Synchronous records of $\mathrm{pCO}_{2}$ and $\triangle 14 \mathrm{C}$ suggest rapid, ocean-derived $\mathrm{pCO}_{2}$ fluctuations at the onset of Younger Dryas" by Steinthorsdottir et al. Quat. Sci. Rev. 2015, 107, 267-270. [CrossRef]

132. Butler, J.H.; Montzka, S.A. NOAA/ESRL Global Monitoring Division-The Noaa Annual Greenhouse Gas Index (AGGI). Available online: https://www.esrl.noaa.gov/gmd/aggi/aggi.html (accessed on 26 January 2020).

133. Kirschke, S.; Bousquet, P.; Ciais, P.; Saunois, M.; Canadell, J.G.; Dlugokencky, E.J.; Bergamaschi, P.; Bergmann, D.; Blake, D.R.; Bruhwiler, L.; et al. Three decades of global methane sources and sinks. Nat. Geosci. 2013, 6, 813-823. [CrossRef]

134. Ganesan, A.L.; Schwietzke, S.; Poulter, B.; Arnold, T.; Lan, X.; Rigby, M.; Vogel, F.R.; van der Werf, G.R.; Janssens-Maenhout, G.; Boesch, H.; et al. Advancing Scientific Understanding of the Global Methane Budget in Support of the Paris Agreement. Glob. Biogeochem. Cycles 2019, 33, 1475-1512. [CrossRef] 
135. Nisbet, E.G.; Manning, M.R.; Dlugokencky, E.J.; Fisher, R.E.; Lowry, D.; Michel, S.E.; Myhre, C.L.; Platt, S.M.; Allen, G.; Bousquet, P.; et al. Very Strong Atmospheric Methane Growth in the 4 Years 2014-2017: Implications for the Paris Agreement. Glob. Biogeochem. Cycles 2019, 33, 318-342. [CrossRef]

136. Saunois, M.; Bousquet, P.; Poulter, B.; Peregon, A.; Ciais, P.; Canadell, J.G.; Dlugokencky, E.J.; Etiope, G.; Bastviken, D.; Houweling, S.; et al. The global methane budget 2000-2012. Earth Syst. Sci. Data 2016, 8, 697-751. [CrossRef]

137. PBL. Trends in Global CO2 and Total Greenhouse Gas Emissions: 2018 Report. Available online: https://www. pbl.nl/en/publications/trends-in-global-CO2-and-total-greenhouse-gas-emissions-2018-report (accessed on 14 January 2020).

138. Gupta, J. The History of Global Climate Governance, 1st ed.; Cambridge University Press: Cambridge, UK; New York, NY, USA, 2014; ISBN 978-1-107-04051-9.

139. Tian, H.; Chen, G.; Lu, C.; Xu, X.; Ren, W.; Zhang, B.; Banger, K.; Tao, B.; Pan, S.; Liu, M.; et al. Global methane and nitrous oxide emissions from terrestrial ecosystems due to multiple environmental changes. Ecosyst. Health Sustain. 2015, 1, 1-20. [CrossRef]

140. Zhang, G.; Xiao, X.; Dong, J.; Xin, F.; Zhang, Y.; Qin, Y.; Doughty, R.B.; Moore, B. Fingerprint of rice paddies in spatial-temporal dynamics of atmospheric methane concentration in monsoon Asia. Nat. Commun. 2020, 11, 1-11. [CrossRef]

141. Bastviken, D.; Tranvik, L.J.; Downing, J.A.; Crill, P.M.; Enrich-Prast, A. Freshwater Methane Emissions Offset the Continental Carbon Sink. Science 2011, 331, 50. [CrossRef]

142. Davidson, E.A.; Kanter, D. Inventories and scenarios of nitrous oxide emissions. Environ. Res. Lett. 2014, 9 , 105012. [CrossRef]

143. Soper, F.M.; Sullivan, B.W.; Osborne, B.B.; Shaw, A.N.; Philippot, L.; Cleveland, C.C. Leaf-cutter ants engineer large nitrous oxide hot spots in tropical forests. Proc. R. Soc. B Biol. Sci. 2019, 286, 20182504. [CrossRef]

144. Machacova, K.; Vainio, E.; Urban, O.; Pihlatie, M. Seasonal dynamics of stem N 2 O exchange follow the physiological activity of boreal trees. Nat. Commun. 2019, 10, 1-13. [CrossRef]

145. Fuss, S.; Lamb, W.F.; Callaghan, M.W.; Hilaire, J.; Creutzig, F.; Amann, T.; Beringer, T.; de Garcia, W.O.; Hartmann, J.; Khanna, T.; et al. Negative emissions-Part 2: Costs, potentials and side effects. Environ. Res. Lett. 2018, 13, 063002. [CrossRef]

146. Doran, P.T.; Zimmerman, M.K. Examining the Scientific Consensus on Climate Change. Eos Trans. Am. Geophys. Union 2009, 90, 22-23. [CrossRef]

147. Cook, J.; Nuccitelli, D.; Green, S.A.; Richardson, M.; Winkler, B.; Painting, R.; Way, R.; Jacobs, P.; Skuce, A. Quantifying the consensus on anthropogenic global warming in the scientific literature. Environ. Res. Lett. 2013, 8, 024024. [CrossRef]

148. Stenhouse, N.; Maibach, E.; Cobb, S.; Ban, R.; Bleistein, A.; Croft, P.; Bierly, E.; Seitter, K.; Rasmussen, G.; Leiserowitz, A. Meteorologists' Views About Global Warming: A Survey of American Meteorological Society Professional Members. Bull. Am. Meteorol. Soc. 2013, 95, 1029-1040. [CrossRef]

149. Verheggen, B.; Strengers, B.; Cook, J.; van Dorland, R.; Vringer, K.; Peters, J.; Visser, H.; Meyer, L. Scientists' Views about Attribution of Global Warming. Environ. Sci. Technol. 2014, 48, 8963-8971. [CrossRef]

150. Soon, W.; Baliunas, S. Proxy climatic and environmental changes of the past 1000 years. Clim. Res. 2003, 23, 89-110. [CrossRef]

151. Soon, W.; Baliunas, S.; Idso, C.; Idso, S.; Legates, D.R. Reconstructing Climatic and Environmental Changes of the Past 1000 Years: A Reappraisal. Energy Environ. 2003, 14, 233-296. [CrossRef]

152. Soon, W.; Connolly, R.; Connolly, M. Re-evaluating the role of solar variability on Northern Hemisphere temperature trends since the 19th century. Earth-Sci. Rev. 2015, 150, 409-452. [CrossRef]

153. Carter, R.M.; Gammon, P. New Zealand Maritime Glaciation: Millennial-Scale Southern Climate Change Since 3.9 Ma. Science 2004, 304, 1659-1662. [CrossRef]

154. LeGates, D.R.; Soon, W.; Briggs, W.M.; Brenchley, C.M.O. Climate Consensus and 'Misinformation': A Rejoinder to Agnotology, Scientific Consensus, and the Teaching and Learning of Climate Change. Sci. Educ. 2015, 24, 299-318. [CrossRef]

155. Menne, M.J.; Williams, C.N. Homogenization of Temperature Series via Pairwise Comparisons. J. Clim. 2009, 22, 1700-1717. [CrossRef]

156. Wang, Y.-M.; Lean, J.L.; Sheeley, J.N.R. Modeling the Sun's Magnetic Field and Irradiance since 1713. Astrophys. J. 2005, 625, 522. [CrossRef] 
157. Krivova, N.A.; Vieira, L.E.A.; Solanki, S.K. Reconstruction of solar spectral irradiance since the Maunder minimum. J. Geophys. Res. Space Phys. 2010, 115, A12. [CrossRef]

158. Scafetta, N.; Willson, R.C. ACRIM total solar irradiance satellite composite validation versus TSI proxy models. Astrophys. Space Sci. 2014, 350, 421-442. [CrossRef]

159. Hoyt, D.V.; Schatten, K.H. A discussion of plausible solar irradiance variations, 1700-1992. J. Geophys. Res. Space Phys. 1993, 98, 18895-18906. [CrossRef]

160. Scafetta, N.; Willson, R.C.; Lee, J.N.; Wu, D.L. Modeling Quiet Solar Luminosity Variability from TSI Satellite Measurements and Proxy Models during 1980-2018. Remote Sens. 2019, 11, 2569. [CrossRef]

161. Pielke, R.A. Misdefining "climate change": Consequences for science and action. Environ. Sci. Policy 2005, 8, 548-561. [CrossRef]

162. Hawkins, E.; Ortega, P.; Suckling, E.; Schurer, A.; Hegerl, G.; Jones, P.; Joshi, M.; Osborn, T.J.; Masson-Delmotte, V.; Mignot, J.; et al. Estimating Changes in Global Temperature since the Preindustrial Period. Bull. Am. Meteorol. Soc. 2017, 98, 1841-1856. [CrossRef]

163. Lüning, S.; Vahrenholt, F. Paleoclimatological Context and Reference Level of the $2{ }^{\circ} \mathrm{C}$ and $1.5{ }^{\circ} \mathrm{C}$ Paris Agreement Long-Term Temperature Limits. Front. Earth Sci. 2017, 5, 104. [CrossRef]

164. Mann, M.E.; Bradley, R.S.; Hughes, M.K. Northern hemisphere temperatures during the past millennium: Inferences, uncertainties, and limitations. Geophys. Res. Lett. 1999, 26, 759-762. [CrossRef]

165. Moberg, A.; Sonechkin, D.M.; Holmgren, K.; Datsenko, N.M.; Karlén, W. Highly variable Northern Hemisphere temperatures reconstructed from low- and high-resolution proxy data. Nature 2005, 433, 613-617. [CrossRef]

166. D'Arrigo, R.; Wilson, R.; Jacoby, G. On the long-term context for late twentieth century warming. J. Geophys. Res. Atmos. 2006, 111, D03103. [CrossRef]

167. Loehle, C.; McCulloch, J.H. Correction to: A 2000-Year Global Temperature Reconstruction Based on Non-Tree Ring Proxies. Energy Environ. 2008, 19, 93-100. [CrossRef]

168. Ljungqvist, F.C. A new reconstruction of temperature variability in the extra-tropical northern hemisphere during the last two millennia. Geogr. Ann. Ser. A Phys. Geogr. 2010, 92, 339-351. [CrossRef]

169. Ljungqvist, F.C.; Zhang, Q.; Brattström, G.; Krusic, P.J.; Seim, A.; Li, Q.; Zhang, Q.; Moberg, A. Centennial-Scale Temperature Change in Last Millennium Simulations and Proxy-Based Reconstructions. J. Clim. 2019, 32, 2441-2482. [CrossRef]

170. Neukom, R.; Barboza, L.A.; Erb, M.P.; Shi, F.; Emile-Geay, J.; Evans, M.N.; Franke, J.; Kaufman, D.S.; Lücke, L.; Rehfeld, K.; et al. Consistent multidecadal variability in global temperature reconstructions and simulations over the Common Era. Nat. Geosci. 2019, 12, 643-649.

171. Akasofu, S.-I. On the recovery from the Little Ice Age. Nat. Sci. 2010, 2, 1211-1224. [CrossRef]

172. Koch, A.; Brierley, C.; Maslin, M.M.; Lewis, S.L. Earth system impacts of the European arrival and Great Dying in the Americas after 1492. Quat. Sci. Rev. 2019, 207, 13-36. [CrossRef]

173. Ruddiman, W.F.; Fuller, D.Q.; Kutzbach, J.E.; Tzedakis, P.C.; Kaplan, J.O.; Ellis, E.C.; Vavrus, S.J.; Roberts, C.N.; Fyfe, R.; He, F.; et al. Late Holocene climate: Natural or anthropogenic? Rev. Geophys. 2016, 54, 93-118. [CrossRef]

174. Soon, W.W.-H.; Legates, D.R.; Baliunas, S.L. Estimation and representation of long-term ( $>40$ year) trends of Northern-Hemisphere-gridded surface temperature: A note of caution. Geophys. Res. Lett. 2004, 31. [CrossRef]

175. Montford, A.W. The Hockey Stick Illusion; Climategate and the Corruption of Science, Later Printing edition; Stacey International: London, UK, 2010; ISBN 978-1-906768-35-5.

176. Mann, M. The Hockey Stick and the Climate Wars: Dispatches from the Front Lines, Reprint ed.; Columbia University Press: New York, NY, USA, 2013; ISBN 978-0-231-15255-6.

177. Soon, W.; Baliunas, S.; Legates, D. Comment on “On past temperatures and anomalous late-20th century warmth". Eos Trans. Am. Geophys. Union 2003, 84, 473-476. [CrossRef]

178. Connolly, R.; Connolly, M. Global temperature changes of the last millennium. Open Peer Rev. J. $2014,16,1$.

179. Byatt, S.I.; Carter, B.; Castles, I.; de Freitas, C.; Goklany, I.M.; Henderson, D.; Holland, D.; Blaby, L.L.; Lindzen, R.S.; McKitrick, R.; et al. The Stern Review: A Dual Critique. World Econ. 2006, 7, 165-232.

180. Broecker, W.S. Was the Medieval Warm Period Global? Science 2001, 291, 1497-1499. [CrossRef] 
181. Mann, M.; Amman, C.; Bradley, R.; Briffa, K.; Jones, P.; Osborn, T.; Crowley, T.; Hughes, M.; Oppenheimer, M.; Overpeck, J.; et al. On past temperatures and anomalous late-20th-century warmth. Eos Trans. Am. Geophys. Union 2003, 84, 256. [CrossRef]

182. Mann, M.; Ammann, C.; Bradley, R.; Briffa, K.; Jones, P.; Osborn, T.; Crowley, T.; Hughes, M.; Oppenheimer, M.; Overpeck, J.; et al. Response "[to Comment on 'On past temperatures and anomalous late-20th-century warmth"']. Eos. Trans. Am. Geophys. Union 2003, 84, 473. [CrossRef]

183. McIntyre, S.; McKitrick, R. Corrections to the Mann et al. (1998) Proxy Data Base and Northern Hemispheric Average Temperature Series. Energy Environ. 2003, 14, 751-771. [CrossRef]

184. McIntyre, S.; McKitrick, R. Hockey sticks, principal components, and spurious significance. Geophys. Res. Lett. 2005, 32, L03710. [CrossRef]

185. McIntyre, S.; McKitrick, R. The M\&M Critique of the MBH98 Northern Hemisphere Climate Index: Update and Implications. Energy Environ. 2005, 16, 69-100.

186. Von Storch, H.; Zorita, E.; Jones, J.M.; Dimitriev, Y.; González-Rouco, F.; Tett, S.F.B. Reconstructing Past Climate from Noisy Data. Science 2004, 306, 679-682. [CrossRef] [PubMed]

187. Wahl, E.R.; Ritson, D.M.; Ammann, C.M. Comment on "Reconstructing Past Climate from Noisy Data". Science 2006, 312, 529. [CrossRef]

188. Mann, M.E.; Rutherford, S.; Wahl, E.; Ammann, C. Testing the Fidelity of Methods Used in Proxy-Based Reconstructions of Past Climate. J. Clim. 2005, 18, 4097-4107. [CrossRef]

189. Von Storch, H.; Zorita, E.; Jones, J.M.; Gonzalez-Rouco, F.; Tett, S.F.B. Response to Comment on “Reconstructing Past Climate from Noisy Data". Science 2006, 312, 529. [CrossRef]

190. Bürger, G.; Cubasch, U. Are multiproxy climate reconstructions robust? Geophys. Res. Lett. 2005, 32, $227-235$. [CrossRef]

191. Bürger, G.; Fast, I.; Cubasch, U. Climate reconstruction by regression-32 variations on a theme. Tellus $A$ Dyn. Meteorol. Oceanogr. 2006, 58, 227-235. [CrossRef]

192. McShane, B.B.; Wyner, A.J. A statistical analysis of multiple temperature proxies: Are reconstructions of surface temperatures over the last 1000 years reliable? Ann. Appl. Stat. 2011, 5, 5-44. [CrossRef]

193. Shi, F.; Yang, B.; Mairesse, A.; von Gunten, L.; Li, J.; Bräuning, A.; Yang, F.; Xiao, X. Northern Hemisphere temperature reconstruction during the last millennium using multiple annual proxies. Clim. Res. 2013, 56, 231-244. [CrossRef]

194. Xing, P.; Chen, X.; Luo, Y.; Nie, S.; Zhao, Z.; Huang, J.; Wang, S. The Extratropical Northern Hemisphere Temperature Reconstruction during the Last Millennium Based on a Novel Method. PLoS ONE 2016, 11, e0146776. [CrossRef] [PubMed]

195. Christiansen, B.; Ljungqvist, F.C. Challenges and perspectives for large-scale temperature reconstructions of the past two millennia. Rev. Geophys. 2017, 55, 40-96. [CrossRef]

196. Esper, J.; George, S.S.; Anchukaitis, K.; D'Arrigo, R.; Ljungqvist, F.C.; Luterbacher, J.; Schneider, L.; Stoffel, M.; Wilson, R.; Büntgen, U. Large-scale, millennial-length temperature reconstructions from tree-rings. Dendrochronologia 2018, 50, 81-90. [CrossRef]

197. Kinne, O. Climate Research: An article unleashed worldwide storms. Clim. Res. 2003, 24, 197-198. [CrossRef]

198. Bürger, G. On the verification of climate reconstructions. Clim. Past 2007, 3, 397-409. [CrossRef]

199. Loehle, C. A mathematical analysis of the divergence problem in dendroclimatology. Clim. Chang. 2009, 94, 233-245. [CrossRef]

200. Knutti, R.; Rugenstein, M.A.A.; Hegerl, G.C. Beyond equilibrium climate sensitivity. Nat. Geosci. 2017, 10, 727-736. [CrossRef]

201. Harries, J.E.; Brindley, H.E.; Sagoo, P.J.; Bantges, R.J. Increases in greenhouse forcing inferred from the outgoing longwave radiation spectra of the Earth in 1970 and 1997. Nature 2001, 410, 355-357. [CrossRef]

202. Andronova, N.G.; Schlesinger, M.E. Objective estimation of the probability density function for climate sensitivity. J. Geophys. Res. Atmos. 2001, 106, 22605-22611. [CrossRef]

203. Ring, M.J.; Lindner, D.; Cross, E.F.; Schlesinger, M.E. Causes of the Global Warming Observed since the 19th Century. Atmos. Clim. Sci. 2012, 2, 401. [CrossRef]

204. Muller, R.A.; Rohde, R.; Jacobsen, R.; Muller, E.; Perlmutter, S.; Rosenfeld, A.; Wurtele, J.; Groom, D.; Wickham, C. A New Estimate of the Average Earth Surface Land Temperature Spanning 1753 to 2011. Geoinform. Geostat. Overv. 2013, 2013. [CrossRef] 
205. Lovejoy, S. Scaling fluctuation analysis and statistical hypothesis testing of anthropogenic warming. Clim. Dyn. 2014, 42, 2339-2351. [CrossRef]

206. Marvel, K.; Schmidt, G.A.; Miller, R.L.; Nazarenko, L.S. Implications for climate sensitivity from the response to individual forcings. Nat. Clim. Chang. 2016, 6, 386-389. [CrossRef]

207. Otto, A.; Otto, F.E.L.; Boucher, O.; Church, J.; Hegerl, G.; Forster, P.M.; Gillett, N.P.; Gregory, J.; Johnson, G.C.; Knutti, R.; et al. Energy budget constraints on climate response. Nat. Geosci. 2013, 6, 415-416. [CrossRef]

208. Lewis, N.; Curry, J. The Impact of Recent Forcing and Ocean Heat Uptake Data on Estimates of Climate Sensitivity. J. Clim. 2018, 31, 6051-6071. [CrossRef]

209. Bates, J.R. Estimating climate sensitivity using two-zone energy balance models. Earth Space Sci. 2016, 3 , 207-225. [CrossRef]

210. Hegerl, G.C.; Crowley, T.J.; Hyde, W.T.; Frame, D.J. Climate sensitivity constrained by temperature reconstructions over the past seven centuries. Nature 2006, 440, 1029-1032. [CrossRef]

211. Chylek, P.; Lohmann, U.; Dubey, M.; Mishchenko, M.; Kahn, R.; Ohmura, A. Limits on climate sensitivity derived from recent satellite and surface observations. J. Geophys. Res. Atmos. 2007, 112, D24. [CrossRef]

212. Aldrin, M.; Holden, M.; Guttorp, P.; Skeie, R.B.; Myhre, G.; Berntsen, T.K. Bayesian estimation of climate sensitivity based on a simple climate model fitted to observations of hemispheric temperatures and global ocean heat content. Environmetrics 2012, 23, 253-271. [CrossRef]

213. Lewis, N. An Objective Bayesian Improved Approach for Applying Optimal Fingerprint Techniques to Estimate Climate Sensitivity. J. Clim. 2013, 26, 7414-7429. [CrossRef]

214. Shindell, D.T. Inhomogeneous forcing and transient climate sensitivity. Nat. Clim. Chang. 2014, 4, $274-277$. [CrossRef]

215. Skeie, R.B.; Berntsen, T.; Aldrin, M.; Holden, M.; Myhre, G. A lower and more constrained estimate of climate sensitivity using updated observations and detailed radiative forcing time series. Earth Syst. Dyn. 2014, 5, 139-175. [CrossRef]

216. Monckton, C.; Soon, W.W.-H.; Legates, D.R.; Briggs, W.M. Why models run hot: Results from an irreducibly simple climate model. Sci. Bull. 2015, 60, 122-135. [CrossRef]

217. Schurer, A.; Hegerl, G.; Ribes, A.; Polson, D.; Morice, C.; Tett, S. Estimating the Transient Climate Response from Observed Warming. J. Clim. 2018, 31, 8645-8663. [CrossRef]

218. Idso, S.B. $\mathrm{CO}_{2}$-induced global warming: A skeptic's view of potential climate change. Clim. Res. 1998, 10, 69-82. [CrossRef]

219. Loehle, C.; Scafetta, N. Climate Change Attribution Using Empirical Decomposition of Climatic Data. Open Atmos. Sci. J. 2011, 5. Available online: https://benthamopen.com/ABSTRACT/TOASCJ-5-74 (accessed on 31 January 2020). [CrossRef]

220. Ziskin, S.; Shaviv, N.J. Quantifying the role of solar radiative forcing over the 20th century. Adv. Space Res. 2012, 50, 762-776. [CrossRef]

221. Loehle, C. A minimal model for estimating climate sensitivity. Ecol. Model. 2014, 276, 80-84. [CrossRef]

222. Spencer, R.W.; Braswell, W.D. The role of ENSO in global ocean temperature changes during 1955-2011 simulated with a 1D climate model. Asia-Pac. J. Atmos. Sci. 2014, 50, 229-237. [CrossRef]

223. Van der Werf, G.R.; Dolman, A.J. Impact of the Atlantic Multidecadal Oscillation (AMO) on deriving anthropogenic warming rates from the instrumental temperature record. Earth Syst. Dyn. 2014, 5, 375-382. [CrossRef]

224. Wyatt, M.G.; Curry, J.A. Role for Eurasian Arctic shelf sea ice in a secularly varying hemispheric climate signal during the 20th century. Clim. Dyn. 2014, 42, 2763-2782. [CrossRef]

225. Lim, H.-G.; Yeh, S.-W.; Kim, J.-W.; Park, R.; Song, C.-K. Contributions of solar and greenhouse gases forcing during the present warm period. Meteorol. Atmos. Phys. 2014, 126, 71-79. [CrossRef]

226. Harde, H. Radiation Transfer Calculations and Assessment of Global Warming by $\mathrm{CO}_{2}$. Int. J. Atmos. Sci. 2017, 2017. [CrossRef]

227. Christy, J.R.; McNider, R.T. Satellite bulk tropospheric temperatures as a metric for climate sensitivity. Asia-Pac. J. Atmos. Sci. 2017, 53, 511-518. [CrossRef]

228. McKitrick, R.; Christy, J. A Test of the Tropical 200- to 300-hPa Warming Rate in Climate Models. Earth Space Sci. 2018, 5, 529-536. [CrossRef]

229. Svensmark, H. Cosmoclimatology: A new theory emerges. Astron. Geophys. 2007, 48, 1.18-1.24. [CrossRef] 
230. Loehle, C.; Singer, S.F. Holocene temperature records show millennial-scale periodicity. Can. J. Earth Sci. 2010, 47, 1327-1336. [CrossRef]

231. Shaviv, N.J.; Prokoph, A.; Veizer, J. Is the Solar System's Galactic Motion Imprinted in the Phanerozoic Climate? Sci. Rep. 2014, 4, 1-6. [CrossRef]

232. Luning, S.; Vahrenholt, F. The Neglected Sun: Why the Sun Precludes Climate Catastrophe, 2nd English ed.; The Heartland Institute: Arlington Heights, IL, USA, 2015.

233. Svensmark, J.; Enghoff, M.B.; Shaviv, N.J.; Svensmark, H. The response of clouds and aerosols to cosmic ray decreases. J. Geophys. Res. Space Phys. 2016, 121, 8152-8181. [CrossRef]

234. Lüning, S.; Vahrenholt, F. Chapter 16-The Sun's Role in Climate. In Evidence-Based Climate Science, 2nd ed.; Easterbrook, D.J., Ed.; Elsevier: Amsterdam, The Netherlands, 2016; pp. 283-305. ISBN 978-0-12-804588-6.

235. Kravtsov, S.; Grimm, C.; Gu, S. Global-scale multidecadal variability missing in state-of-the-art climate models. NPJ Clim. Atmos. Sci. 2018, 1, 1-10. [CrossRef]

236. Schwartz, S.E. Reply to comments by G. Foster et al., R. Knutti et al., and N. Scafetta on "Heat capacity, time constant, and sensitivity of Earth's climate system". J. Geophys. Res. Atmos. 2008, 113, D15105. [CrossRef]

237. Schwartz, S.E. Heat capacity, time constant, and sensitivity of Earth's climate system. J. Geophys. Res. Atmos. 2007, 112, D24. [CrossRef]

238. Knutti, R.; Krähenmann, S.; Frame, D.J.; Allen, M.R. Comment on "Heat capacity, time constant, and sensitivity of Earth's climate system" by S. E. Schwartz. J. Geophys. Res. Atmos. 2008, 113, D15103. [CrossRef]

239. Richardson, M.; Hausfather, Z.; Nuccitelli, D.A.; Rice, K.; Abraham, J.P. Misdiagnosis of Earth climate sensitivity based on energy balance model results. Sci. Bull. 2015, 60, 1370-1377. [CrossRef]

240. Monckton of Brenchley, C.; Soon, W.W.-H.; Legates, D.R.; Briggs, W.M. Keeping it simple: The value of an irreducibly simple climate model. Sci. Bull. 2015, 60, 1378-1390. [CrossRef]

241. Gregory, J.M.; Andrews, T. Variation in climate sensitivity and feedback parameters during the historical period. Geophys. Res. Lett. 2016, 43, 3911-3920. [CrossRef]

242. Rohrschneider, T.; Stevens, B.; Mauritsen, T. On simple representations of the climate response to external radiative forcing. Clim. Dyn. 2019, 53, 3131-3145. [CrossRef]

243. Forster, P.M.; Maycock, A.C.; McKenna, C.M.; Smith, C.J. Latest climate models confirm need for urgent mitigation. Nat. Clim. Chang. 2020, 10, 7-10. [CrossRef]

244. Geoffroy, O.; Saint-Martin, D.; Olivié, D.J.L.; Voldoire, A.; Bellon, G.; Tytéca, S. Transient Climate Response in a Two-Layer Energy-Balance Model. Part I: Analytical Solution and Parameter Calibration Using CMIP5 AOGCM Experiments. J. Clim. 2012, 26, 1841-1857. [CrossRef]

245. Edwards, T.L.; Crucifix, M.; Harrison, S.P. Using the past to constrain the future: How the palaeorecord can improve estimates of global warming. Prog. Phys. Geogr. 2007, 31, 481-500. [CrossRef]

246. National Research Council; Assembly of Mathematical and Physical Sciences; Climate Research Board; Ad Hoc Study Group on Carbon Dioxide and Climate. Carbon Dioxide and Climate: A Scientific Assessment; National Academy of Science: Washington, DC, USA, 1979.

247. Van der Sluijs, J.; van Eijndhoven, J.; Shackley, S.; Wynne, B. Anchoring Devices in Science for Policy: The Case of Consensus around Climate Sensitivity. Soc. Stud. Sci. 1998, 28, 291-323. [CrossRef]

248. Bryan, K.; Komro, F.G.; Manabe, S.; Spelman, M.J. Transient Climate Response to Increasing Atmospheric Carbon Dioxide. Science 1982, 215, 56-58. [CrossRef] [PubMed]

249. Vial, J.; Dufresne, J.-L.; Bony, S. On the interpretation of inter-model spread in CMIP5 climate sensitivity estimates. Clim. Dyn. 2013, 41,3339-3362. [CrossRef]

250. Gregory, J.M.; Mitchell, J.F.B. The climate response to $\mathrm{CO}_{2}$ of the Hadley Centre coupled AOGCM with and without flux adjustment. Geophys. Res. Lett. 1997, 24, 1943-1946. [CrossRef]

251. Gregory, J.M.; Ingram, W.J.; Palmer, M.A.; Jones, G.S.; Stott, P.A.; Thorpe, R.B.; Lowe, J.A.; Johns, T.C.; Williams, K.D. A new method for diagnosing radiative forcing and climate sensitivity. Geophys. Res. Lett. 2004, 31. [CrossRef]

252. Gregory, J.M.; Andrews, T.; Good, P. The inconstancy of the transient climate response parameter under increasing $\mathrm{CO}_{2}$. Philos. Trans. R. Soc. A Math. Phys. Eng. Sci. 2015, 373. [CrossRef]

253. Held, I.M.; Winton, M.; Takahashi, K.; Delworth, T.; Zeng, F.; Vallis, G.K. Probing the Fast and Slow Components of Global Warming by Returning Abruptly to Preindustrial Forcing. J. Clim. 2010, 23, 2418-2427. [CrossRef] 
254. Forster, P.M.; Andrews, T.; Good, P.; Gregory, J.M.; Jackson, L.S.; Zelinka, M. Evaluating adjusted forcing and model spread for historical and future scenarios in the CMIP5 generation of climate models. J. Geophys. Res. Atmos. 2013, 118, 1139-1150. [CrossRef]

255. Raper, S.C.B.; Gregory, J.M.; Stouffer, R.J. The Role of Climate Sensitivity and Ocean Heat Uptake on AOGCM Transient Temperature Response. J. Clim. 2002, 15, 124-130. [CrossRef]

256. Winton, M.; Takahashi, K.; Held, I.M. Importance of Ocean Heat Uptake Efficacy to Transient Climate Change. J. Clim. 2009, 23, 2333-2344. [CrossRef]

257. Hansen, J.; Nazarenko, L.; Ruedy, R.; Sato, M.; Willis, J.; Genio, A.D.; Koch, D.; Lacis, A.; Lo, K.; Menon, S.; et al. Earth's Energy Imbalance: Confirmation and Implications. Science 2005, 308, 1431-1435. [CrossRef] [PubMed]

258. Dufresne, J.-L.; Bony, S. An Assessment of the Primary Sources of Spread of Global Warming Estimates from Coupled Atmosphere-Ocean Models. J. Clim. 2008, 21, 5135-5144. [CrossRef]

259. Hope, $\mathrm{C}$. The $\$ 10$ trillion value of better information about the transient climate response. Philos. Trans. $R$. Soc. A Math. Phys. Eng. Sci. 2015, 373. [CrossRef] [PubMed]

260. Lindzen, R.S.; Choi, Y.-S. On the observational determination of climate sensitivity and its implications. Asia-Pac. J. Atmos. Sci. 2011, 47, 377. [CrossRef]

261. Gregory, J.M.; Forster, P.M. Transient climate response estimated from radiative forcing and observed temperature change. J. Geophys. Res. Atmos. 2008, 113. [CrossRef]

262. Zelinka, M.D.; Myers, T.A.; McCoy, D.T.; Po-Chedley, S.; Caldwell, P.M.; Ceppi, P.; Klein, S.A.; Taylor, K.E. Causes of Higher Climate Sensitivity in CMIP6 Models. Geophys. Res. Lett. 2020, 47. [CrossRef]

263. Lewis, N.; Grünwald, P. Objectively combining AR5 instrumental period and paleoclimate climate sensitivity evidence. Clim. Dyn. 2018, 50, 2199-2216. [CrossRef]

264. Lea, D.W. The 100 000-Yr Cycle in Tropical SST, Greenhouse Forcing, and Climate Sensitivity. J. Clim. 2004, 17, 2170-2179. [CrossRef]

265. Masters, T. Observational estimate of climate sensitivity from changes in the rate of ocean heat uptake and comparison to CMIP5 models. Clim. Dyn. 2014, 42, 2173-2181. [CrossRef]

266. Specht, E.; Redemann, T.; Lorenz, N. Simplified mathematical model for calculating global warming through anthropogenic $\mathrm{CO}_{2}$. Int. J. Therm. Sci. 2016, 102, 1-8. [CrossRef]

267. Myhre, G.; Highwood, E.J.; Shine, K.P.; Stordal, F. New estimates of radiative forcing due to well mixed greenhouse gases. Geophys. Res. Lett. 1998, 25, 2715-2718. [CrossRef]

268. Wigley, T.M.L. The effect of model structure on projections of greenhouse-gas-induced climatic change. Geophys. Res. Lett. 1987, 14, 1135-1138. [CrossRef]

269. Shi, G.-Y. Radiative forcing and greenhouse effect due to the atmospheric trace gases. Sci. China Ser. B-Chem. Life Sci. Earth Sci. 1992, 35, 217-229.

270. Byrne, B.; Goldblatt, C. Radiative forcing at high concentrations of well-mixed greenhouse gases. Geophys. Res. Lett. 2014, 41, 152-160. [CrossRef]

271. Etminan, M.; Myhre, G.; Highwood, E.J.; Shine, K.P. Radiative forcing of carbon dioxide, methane, and nitrous oxide: A significant revision of the methane radiative forcing. Geophys. Res. Lett. 2016, 43, 12614-12623. [CrossRef]

272. IPCC Summary for Policymakers. Global Warming of $1.5^{\circ} \mathrm{C}$. An IPCC Special Report on the Impacts of Global Warming of $1.5^{\circ} \mathrm{C}$ above Pre-Industrial Levels and Related Global Greenhouse Gas Emission Pathways, in the Context of Strengthening the Global Response to the Threat of Climate Change, Sustainable Development, and Efforts to Eradicate Poverty; Masson-Delmotte, V., Zhai, P., Pörtner, H.-O., Roberts, D., Skea, J., Shukla, P.R., Pirani, A., Moufouma-Okia, W., Péan, C., Pidcock, R., et al., Eds.; Cambridge University Press: Cambridge, UK; New York, NY, USA, 2018.

273. Lang, P.A.; Gregory, K.B. Economic Impact of Energy Consumption Change Caused by Global Warming. Energies 2019, 12, 3575. [CrossRef]

274. Dayaratna, K.D.; McKitrick, R.; Michaels, P.J. Climate sensitivity, agricultural productivity and the social cost of carbon in FUND. Environ. Econ. Policy Stud. 2020, 1-16. [CrossRef]

(C) 2020 by the authors. Licensee MDPI, Basel, Switzerland. This article is an open access article distributed under the terms and conditions of the Creative Commons Attribution (CC BY) license (http://creativecommons.org/licenses/by/4.0/). 